University of New Hampshire

University of New Hampshire Scholars' Repository

Master's Theses and Capstones

Student Scholarship

Spring 2011

\title{
The frequency and cause of shallow winter mixed layers in the Gulf of Maine
}

Michael Christensen

University of New Hampshire, Durham

Follow this and additional works at: https://scholars.unh.edu/thesis

\section{Recommended Citation}

Christensen, Michael, "The frequency and cause of shallow winter mixed layers in the Gulf of Maine" (2011). Master's Theses and Capstones. 626.

https://scholars.unh.edu/thesis/626

This Thesis is brought to you for free and open access by the Student Scholarship at University of New Hampshire Scholars' Repository. It has been accepted for inclusion in Master's Theses and Capstones by an authorized administrator of University of New Hampshire Scholars' Repository. For more information, please contact Scholarly.Communication@unh.edu. 


\title{
THE FREQUENCY AND CAUSE OF SHALLOW WINTER MIXED LAYERS IN THE GULF OF MAINE
}

\author{
BY \\ Michael Christensen \\ Bachelor of Science, University of Massachusetts at Amherst, 2009
}

\section{THESIS}

Submitted to the University of New Hampshire in partial fulfillment of the requirements for the Degree of

\author{
Master of Science \\ in
}

Earth Sciences: Physical Oceanography

May 2011 
UMI Number: 1498948

All rights reserved

INFORMATION TO ALL USERS

The quality of this reproduction is dependent upon the quality of the copy submitted.

In the unlikely event that the author did not send a complete manuscript and there are missing pages, these will be noted. Also, if material had to be removed, a note will indicate the deletion.

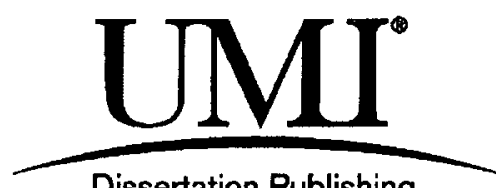

Dissertation Publishing

UMI 1498948

Copyright 2011 by ProQuest LLC.

All rights reserved. This edition of the work is protected against unauthorized copying under Title 17, United States Code.

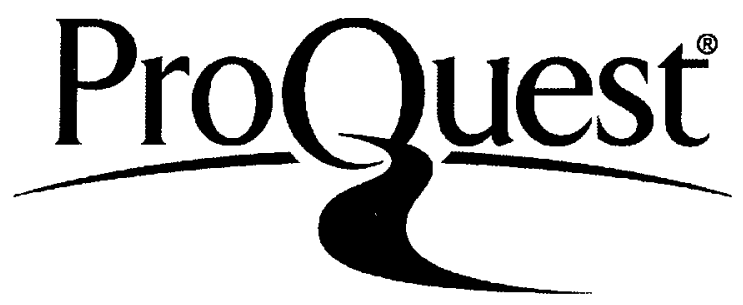

ProQuest LLC

789 East Eisenhower Parkway

P.O. Box 1346

Ann Arbor, MI 48106-1346 
This thesis has been examined and approved.

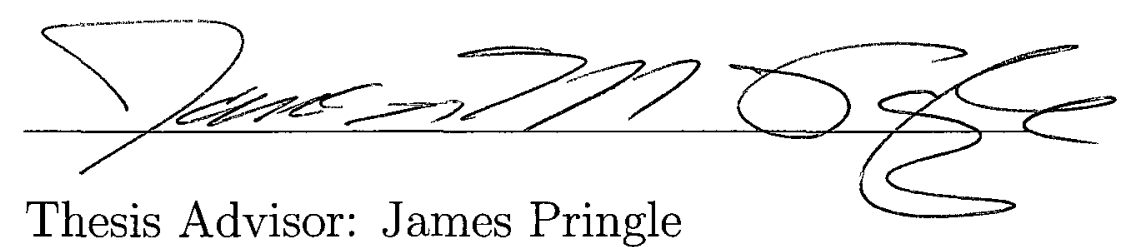

Associate Professor

Institute for the Study of Earth, Oceans, and

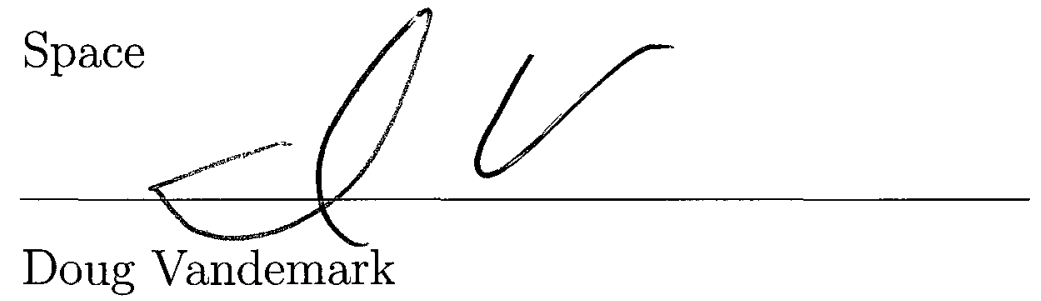

Research Associate Professor

Institute for the Study of Earth, Oceans, and Space

Tom Lippmann

Research Associate Professor

Institute for the Study of Earth, Oceans, and Space

$$
5-3-11
$$

Date 


\section{DEDICATION}

This work is dedicated to my family and friends. 


\section{ACKNOWLEDGMENTS}

I would like to thank my family, friends, and professors for their support and guidance through this journey. Thank you for believing in me, and always encouraging me to look at the big picture. Now, at the end of this project, I realize how much I have learned and grown as a student and person.

Special thanks to my thesis advisor, Jamie Pringle, for trusting my work ethic and taking me on as his student. Without his guidance and willingness to answer my questions, I would not be where I am today. Also, special thanks to my other committee members, Doug Vandemark and Tom Lippmann, for their insight and critique of my work. In the Ocean Processes Analysis Lab, thank you Mimi Szeto and Shivanesh Rao for teaching me MATLAB. Your kindness and helpfulness will not be forgotten. Also, thank you Olivia De Meo for helping me with LaTeX and the formatting of my thesis. Finally, thanks to all my other professors at UNH for their wisdom and support. 


\section{TABLE OF CONTENTS}

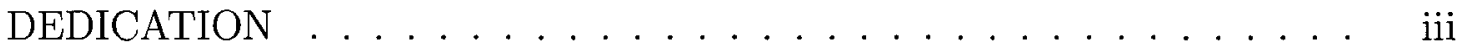

ACKNOWLEDGMENTS ................. iv

LIST OF TABLES ........................ v viii

LIST OF FIGURES . . . . . . . . . . . . . . . . . .

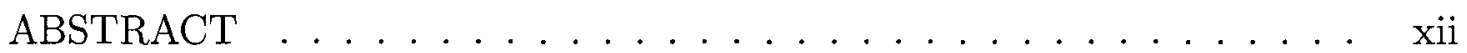

1 INTRODUCTION 1

1.1 Stabilization and Phytoplankton Blooms . . . . . . . . . . . . 1

1.2 The Critical Depth Model . . . . . . . . . . . . . . . . . 3

1.3 Study Objectives $\ldots \ldots \ldots \ldots \ldots \ldots$

1.4 Background . . . . . . . . . . . . . . . . . 8

1.4.1 Gulf of Maine Definition . . . . . . . . . . . . . . 8

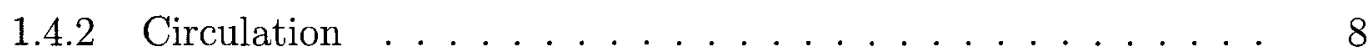

1.4.3 Historical Observations: Seasonal Patterns in Salinity, Temper-

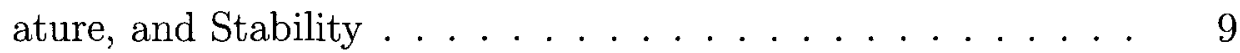

1.4.4 Recent Observations . . . . . . . . . . . . . . . . 11

1.5 Mixed Layer Depth Definition . . . . . . . . . . . . . . . . . . 12

1.5.1 A Numerical Approximation for Mixed Layer Depth . . . . . . 12

1.5.2 Drawbacks of the Threshold Method . . . . . . . . . . 14

2 REGIONAL PATTERNS IN WINTERTIME SALINITY, TEMPERATURE, AND STABILITY 22

2.1 Hydrographic/Atmospheric Data . . . . . . . . . . . . . . 22

2.1.1 Gulf of Maine Ocean Observing System Buoy Data . . . . . . 22 
2.1 .2 Cast Data . . . . . . . . . . . . . . . . . 23

2.1 .3 NCEP-DOE Reanalysis II . . . . . . . . . . . . . . 25

2.2 Methods . . . . . . . . . . . . . . . . . . . 25

2.2.1 Defining Zones within the Gulf of Maine . . . . . . . . 25

2.2.2 Winter Decorrelation Time-Scales at GOMOOS Buoys . . . 26

2.2.3 Calculating Average Salinity and Temperature . . . . . . . 27

2.2 .4 Calculating Average Stability . . . . . . . . . . . . . 29

2.2 .5 Comparison of Averages . . . . . . . . . . . . . 30

2.3 Results . . . . . . . . . . . . . . . . . . . . . . 32

2.3.1 Surface Salinity and Temperature f. . . . . . . . 32

2.3.2 Average Salinity/Temperature Difference with Depth . . . . . 34

$2.3 .3 \quad$ Average Stability . . . . . . . . . . . . . . . . . . . 36

3 PATTERNS IN WINTERTIME .STRATIFICATION 56

3.1 Methods . . . . . . . . . . . . . . . . . . 56

3.1.1 Calculating the Relative Contributions of Salinity and Temper-

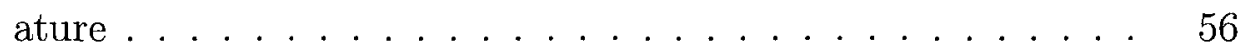

3.1.2 Calculating Duration and Frequency of Shallow Mixed Layer Events ........................ 60

3.1.3 Quantifying the Relationship Between Wind Stress and Strati-

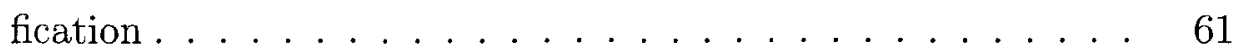

3.2 Spatial and Temporal Patterns in Mixed Layer Depth . . . . . . . . 62

3.3 Spatial Patterns in Salinity and Temperature Contribution . . . . . . 65

3.4 Winter Stratification and its Causes . . . . . . . . . . . . 68

3.4.1 Trends in Stratification and Interannual Variability in Salinity

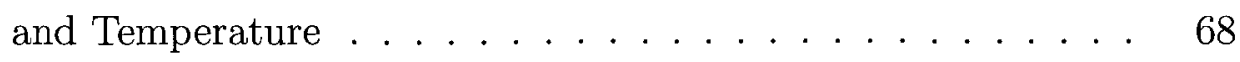

3.4.2 The Impacts of Salinity, Temperature, and Wind Stress on

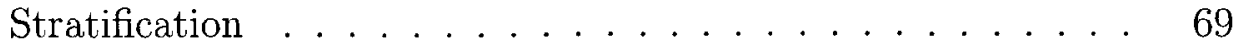


4.1 Major Findings . . . . . . . . . . . . . . . . . . . . . 94

4.1.1 Regional Differences in Stratification . . . . . . . . . . . 94

4.1.2 Patterns in the Coastal and Eastern Zones . . . . . . . . . 94

4.1.3 Patterns in the Western Zone . . . . . . . . . . . . 96

4.1.4 Patterns in the Northern Zone and over Georges Bank . . . . 97

4.1.5 Interannual Variability of Salinity and Temperature in the Upper $50 \mathrm{~m} \ldots \ldots \ldots \ldots \ldots \ldots \ldots \ldots$

4.1.6 Wind Stress and Stratification . . . . . . . . . . . . 99

4.2 Contributions of Cast Data to Understanding Region-Wide Patterns in Stratification . . . . . . . . . . . . . . . . . . . 101

4.3 Biological and Physical Implications . . . . . . . . . . . . . . 105

4.4 Final Thoughts and Future Research Needs . . . . . . . . . . . . 108

$\begin{array}{ll}\text { REFERENCES } & 117\end{array}$ 


\section{List of Tables}

2.1 Decorrelation Times for GOMOOS Buoys during the Winter . . . . 39

2.2 Wintertime Salinity and Temperature Differences with Depth at GO-

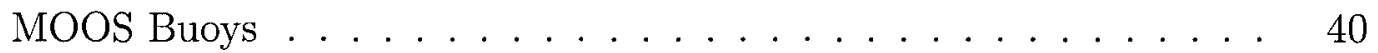

2.3 Salinity, Temperature, and Potential Density Differences with Depth for Casts during the Winter . . . . . . . . . . . . . 41

2.4 Comparison of Wintertime Salinity at $1 \mathrm{~m}$ between GOMOOS Buoys . 42

2.5 Comparison of Wintertime Salinity at $1 \mathrm{~m}$ between Zones . . . . . . 43

2.6 Comparison of Wintertime Temperature at $1 \mathrm{~m}$ between GOMOOS Buoys 44

2.7 Comparison of Wintertime Temperature at $1 \mathrm{~m}$ between Zones . . . . 45

2.8 Comparison of Wintertime Salinity Difference (20m-1m) between Zones 46

2.9 Comparison of Wintertime Salinity Difference (20m-1m) between GOMOOS Buoys $\ldots \ldots \ldots \ldots \ldots \ldots$

2.10 Comparison of Wintertime Temperature Difference (20m-1m) between

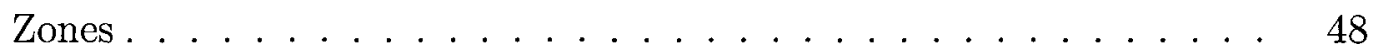

2.11 Comparison of Wintertime Temperature Difference (20m-1m) between GOMOOS Buoys $\ldots \ldots \ldots \ldots \ldots \ldots$

2.12 Density Differences with Depth at GOMOOS Buoys during the Winter 50

2.13 Regional Wintertime Stabilities . . . . . . . . . . . . . 51

2.14 Comparison of Wintertime Stability Values between Zones . . . . . . 52

2.15 Comparison of Wintertime Stability Values between GOMOOS Buoys 53

3.1 Relative Contributions by Zone during the Winter . . . . . . . . . 72

3.2 Comparison of Wintertime Mixed Layer Depth between Zones . . . . 73 
3.3 Sensitivity of Chosen Mixed Layer Depth Threshold Value . . . . . . 74

3.4 Number of Winter Days with a Shallow Mixed Layer at GOMOOS Buoys 75

3.5 Comparison of Wintertime Temperature Contribution between Zones 76

3.6 Comparison of Wintertime Salinity Contribution between Zones . . . 77

3.7 Relative Contributions of Salinity and Temperature during the Winter 78

3.8 Comparison of Wintertime Salinity Contributions at GOMOOS Buoys 79

3.9 Comparison of Wintertime Temperature Contributions at GOMOOS

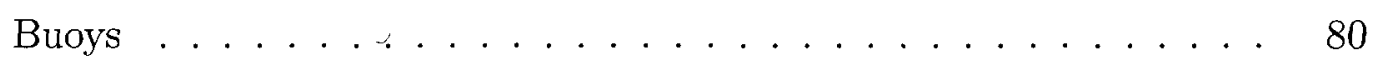

3.10 Depth-Averaged Wintertime Salinities and Temperatures at GOMOOS Buoys ................................ 81

3.11 Stratification and Wind Stress . . . . . . . . . . . . 82

4.1 Case Study: 2006 Stratification Event . . . . . . . . . . . . . . . 110 


\section{List of Figures}

1-1 A Comparison of Winter and Spring Mixed Layers . . . . . . . . . 15

1-2 Sources of Volume Flux into the Gulf of Maine . . . . . . . . . . 16

1-3 Map of Study Site . . . . . . . . . . . . . . . . . 17

1-4 Gulf of Maine Circulation . . . . . . . . . . . . . . 18

1-5 Interannual Salinity Variability at Select GOMOOS buoys . . . . . 19

1-6 Interannual Temperature Variability at Select GOMOOS buoys _. . 20

1-7 "Upper Water-Column Stratification . . . . . . . . . . . . . 21

2-1 GOMOOS Mooring Locations . . . . . . . . . . . . . . . . 54

2-2 Yearly Average Winter Stability Values for GOMOOS Buoys . . . . . 55

3-1 Spatial Patterns in Winter Mixed Layer Depth . . . . . . . . . . . . 83

3-2 Percentage of Mixed Layers in given Depth Ranges . . . . . . . . . 84

3-3 Spatial Pattern in the Relative Contributions of Salinity and Temperature ........................... 85

3-4 Percentage of Casts Dominated by Temperature/Salinity by Zone . . 86

$3-5$ Buoy A Winter Time-Series . . . . . . . . . . . . . . . . 87

3-6 Buoy B Winter Time-Series . . . . . . . . . . . . . . . . . . 88

3-7 Buoy E Winter Time-Series ． . . . . . . . . . . . . . . . . . . . 89

3-8 Buoy I Winter Time-Series . . . . . . . . . . . . . . . . . . . . 90

3-9 Buoy M Winter Time-Series . . . . . . . . . . . . . . . . . . . . . 91

3-10 Buoy N Winter Time-Series . . . . . . . . . . . . . . . . . . . 92

3-11 River Discharge in the Gulf of Maine (2001-2008) . . . . . . . . . 93

4-1 Relative Contribution Map for Casts with a Shallow Mixed Layer . . 111 
4-2 Wind Stress and and Direction during the 2006 Winter Stratification

Event on the Western Maine' Shelf . . . . . . . . . . . . . . . 112

4-3 Inter-Zonal Patterns in Stratification in the Winter of $1991 \ldots . . . .113$

4-4 Inter-Zonal Patterns in Stratification in the Winter of 1998 . . . . . 114

4-5 Inter-Zonal Patterns in Stratification in the Winter of $2006 \ldots \ldots 115$

4-6 March 2006: Mixed Layer Depths and Relative Contributions _. . . 116 


\section{ABSTRACT \\ THE FREQUENCY AND CAUSE OF SHALLOW WINTER MIXED LAYERS IN THE GULF OF MAINE \\ by \\ Michael Christensen \\ University of New Hampshire, May, 2011 \\ Advisor: Dr. James Pringle}

In the Gulf of Maine, regional differences in wintertime stratification have important biological and physical implications. Phytoplankton blooms linked with shallow stratification events during the winter are important because they can provide an additional food source for zooplankton and larval fish populations. Regional differences in stratification and mixed layer depth may also affect rates of air-sea gas exchange. On an annual basis, variability in wintertime air-sea $\mathrm{CO}_{2}$ exchange is significant since it can affect the entire region's role as a sink or source of atmospheric carbon. Before examining how patterns in stratification affect biological and physical systems in the Gulf of Maine, it is necessary to understand the spatial and temporal variability in wintertime mixed layer depths.

The cause and frequency of shallow winter mixed layers in the Gulf of Maine is investigated using salinity, temperature, and wind data. Salinity and temperature data comes from hydrographic profiles and moored, autonomous data collection buoys. Hydrographic profile data are available from the Bedford Institute of Oceanography (BIO) and Coastal Ocean Observing and Analysis (COOA) databanks. Time-series salinity and temperature data are taken from Gulf of Maine Ocean Observing System (GOMOOS) moorings. Wind data are available from the National Center for Envi- 
ronmental Prediction (NCEP) Reanalysis II model. The roles of salinity, temperature, and wind stress are quantified to identify the cause of temporal and spatial patterns in stratification. To examine spatial variability, the Gulf of Maine is divided into 5 zones; Coastal, Western, Eastern, Northern, and Georges Bank. Inter-zonal comparison of mixed layer depth reveals distinct regional differences. Cast data shows considerable changes in mixed layer depth can occur over short distances. GOMOOS mooring data show that shallow mixed layers often occur and persist through the entire winter in the coastal and eastern Gulf of Maine. In these areas upper water-column (0-20m) stratification is governed by salinity. Cast data indicate deeper mixing over Wilkinson Basin. In this area, stratification in the upper $20 \mathrm{~m}$ is weak and often governed by temperature decrease with depth. However, in all regions salinity increase with depth is responsible for the majority of shallow winter mixed layers. Comparison of wind stress and stratification at the GOMOOS moorings shows that winter wind events do not break down salinity driven stratification. 


\section{CHAPTER 1}

\section{INTRODUCTION}

\subsection{Stabilization and Phytoplankton Blooms}

The stabilization of the water column and the initiation of a phytoplankton bloom are often linked (Ji et al., 2008). Stabilization occurs under conditions of reduced turbulence, for example, during periods of low wind stress or water-column stratification (van Oostveen et al., 1999). Stratification and the subsequent suppression of vertical mixing occurs when less-dense water overlies deeper, more-dense water. Typically in the Gulf of Maine (GOM), stratification is at a minimum during the winter and at a maximum in the late summer (Mountain and Manning, 1994) (Fig. 1-1). The density of seawater is directly influenced by its salinity and temperature. Cold, salty water is more dense than warm, fresh water. In the GOM, wind, salinity and temperature control the depth of the upper, nearly homogeneous mixed layer. The mixed layer is defined by its uniform to near uniform density, active vertical mixing and homogeneous salinity and temperature (Thomson and Fine, 2003). Cold temperatures and high surface salinities promote vertical mixing and deepening of the mixed layer. On the other hand, warm surface temperatures and low surface salinity facilitate the shoaling of the mixed layer. The relative contributions of salinity and temperature to the density of the upper water column, and subsequently their effect on the mixed layer depth, is variable both temporally and spatially in the GOM.

Since total phytoplankton biomass ultimately impacts the biology at higher trophic levels, it is crucial to identify the frequency, duration, location, and cause of shallow mixed layer events. In this study, shallow mixed layer events during the winter are 
of particular interest because they may be very important for increasing phytoplankton stocks (Durbin et al., 2003). In turn, the presence of additional phytoplankton biomass may affect higher trophic levels by increasing survival rates of food limited larval fish populations (Platt et al., 2003).

Using GOM moored buoy data gathered during the last decade, Deese-Riordan (2009) identified "re-stabilization" events in the western GOM during the winter with stability values in the upper $20 \mathrm{~m}$ capable of supporting phytoplankton blooms. The stability values capable of supporting a bloom, however, are not well-constrained, and are likely variable for different phytoplankton species. For instance, different species will dominate depending on the time of year (Smetacek and Passow, 1990). According to Riley (1957), in the GOM a density difference of $0.1-0.2 \Delta \sigma_{t}$ in the top $30 \mathrm{~m}$ is required for the initiation of the spring bloom. Using a study from Pingree et al. (1976), however, Townsend et al. (1992) argued that even small degrees of stratification can "provide sufficient stabilization of the water column" to allow a bloom to commence.

Although the discovery that wintertime "re-stabilization" events occur in the western coastal GOM is significant biologically, it is necessary to look at patterns in stability and mixed layer depth beyond the relatively small coastal region. The coastal zone comprises only a fraction of the entire GOM, and the physical processes that govern stability and mixed layer depth outside the coastal zone need to be investigated to help in our understanding of wintertime phytoplankton blooms. In this this study I expand on the work of Deese-Riordan (2009) by analyzing a comprehensive set of salinity and temperature data from hydrographic profiles to investigate spatial trends and causes of winter stratification throughout the GOM. Hydrographic profile data, further referred to as cast data, are obtained from conductivity, temperature, and depth (CTD) measurements at different locations. I also go beyond the work of Deese-Riordan (2009) by using Gulf of Maine Ocean Observing System (GOMOOS) 
mooring data to consider all times when a shallow mixed layer is present. It is imperative to consider all times when a shallow mixed layer is present because even small stability values within the upper water-column may have important biological and physical implications. Stratification may slow down or shut off vertical nutrient exchange between deep and surface waters. Deep, nutrient-rich waters are critical for fueling the spring bloom ( $\mathrm{Ji}$ et al., 2008). Changes in stratification could also affect air-sea gas flux on seasonal or longer time scales (Takahashi et al., 2002). Over longer time scales, and over broad areas of the ocean, changes in air-sea gas exchange may affect global climate.

\subsection{The Critical Depth Model}

The relationship between the depth of the mixed layer and the development of phytoplankton blooms is a focal point of much past and ongoing research. The depth of vertical mixing, nutrient availability, phytoplankton biomass loss, and sunlight are all factors which impact the timing of a phytoplankton bloom (Smetacek and Passow, 1990; Platt et al., 1991). Phytoplankton biomass losses are connected to respiration, grazing, and sedimentation (Smetacek and Passow, 1990; Platt et al., 1991). In Sverdrup's model, he predicted that a bloom would occur when the mixed layer was less than some critical depth. The critical depth is the depth at which depth integrated photosynthesis equals respiration. Sverdrup (1953) based his critical depth on a variety of factors including the amount of incoming radiation, the transparency of the water, and solar energy at the compensation depth. According to Sverdrup the compensation depth is the depth at which the rate of production/photosynthesis is equal to the rate of destruction/respiration. Gran and Braarud (1935) concluded that the critical depth is 5 to 10 times the compensation depth. In modern literature, the critical depth is defined as the point where vertically integrated mean irradiance 
value is equal to $20.9 \mathrm{~W} / \mathrm{m}^{2}$ (Riley, 1957; Hitchcock and Smayda, 1977; Townsend and Spinrad, 1986; Townsend et al., 1992; Pingree et al., 1976).

Sverdrup's critical depth and mixed layer model for the phytoplankton spring bloom was a major stepping stone for research of this kind. Townsend and Spinrad (1986) suggested that slope water inflows may play a role in the timing and intensity of the spring bloom in Jordan Basin. Slope water flows into the eastern GOM through the Northeast Channel (Fig. 1-2). The source of the highly saline slope waters is believed to alternate between Labrador Current and Gulf Stream origins (Gatien, 1976). Slope water with Labrador Current origins is designated as Labrador Slope Water (LSW), where as slope water with Gulf Stream origins is designated as Warm Slope Water (WSW). WSW is warmer, more saline, and more nutrient rich than the LSW (Townsend and Spinrad, 1986). Townsend and Spinrad (1986) speculated that the spring phytoplankton bloom in the GOM occurs earlier and is more pronounced when WSW is the dominant deep inflow. This slope water hypothesis was used to explain a bloom that occurred in the Jordan Basin in February of 1984, as well an early bloom in 1999 (Thomas et al., 2003). The idea is that increased inflow of salty and dense WSW causes a "doming" (shallowing) of the pycnocline above some critical depth, thereby providing the physical conditions suitable for a bloom (Sverdrup, 1953). Smetacek and Passow (1990) did not agree with some parts of Sverdrup's critical depth model, but they agreed that the temporary stabilization of a shallow mixed layer is often accompanied by a build-up of biomass. Platt et al. (1991) concluded that Sverdrup's critical depth criterion was a "necessary but not sufficient condition for the initiation of phytoplankton blooms". A sufficient condition he believed was that phytoplankton growth be large enough when compared to the "loss terms" to build up biomass in the surface layer (Platt et al., 1991).

Ji et al. (2007) demonstrated with a dataset spanning from 1998-2006 that the inundation of fresh Scotian Shelf Water (SSW) from the West Greenland/Labrador 
Current may trigger the onset of the spring phytoplankton bloom. Ji et al. (2007) noticed a general western progression of the spring phytoplankton bloom from the Nova Scotian Shelf to the western GOM consistent with the counter-clockwise circulation pattern in the GOM (Miller et ál., 1998). The onset of the bloom on the Nova Scotian Shelf was correlated closely with negative sea surface salinity anomalies. The main idea was that lower salinity surface waters created a more stable water column which allowed a phytoplankton bloom to develop. Durbin et al. (2003) also concluded that a 1999 winter bloom in the central GOM was caused by the advection of less-dense, fresh SSW. The presence of SSW in turn led to stabilization of the upper water-column. Importantly, increased phytoplankton stocks in 1999 coincided with a 10 fold increase in zooplankton abundance when compared to 2000 (Durbin et al., 2003). According to Townsend and Spinrad (1986), it is likely that the influence of ocean freshening will not be as significant in the western GOM as in the eastern GOM since mixing of surface and deep saline waters breaks down vertical stratification over time. Vertical stratification, however, can be maintained in coastal areas by freshwater input from rivers draining into the GOM. For example, Deese-Riordan (2009) found that high river discharge in the fall of 2005 led to greater stratification during 2006 than other years.

Many have argued that phytoplankton blooms occur in the absence of vertical water column stratification (Heimdal, 1974; Schei, 1974; Townsend et al., 1992; Ellertsen, 1993; Backhaus et al., 2003; Dale et al., 1999; Körtzinger et al., 2008). Townsend et al. (1994) argued that a spring phytoplankton bloom can occur following the typical winter deep convective mixing in an un-stratified water column if wind speeds are below a certain value. Similarly, van Oostveen et al. (1999) argued that a bloom can occur if turbulent mixing rates are less than some critical turbulence value. In either case, phytoplankton growth rates can "overcome the vertical mixing rates imposed by turbulent diffusion" (van Oostveen et al., 1999). 
Behrenfeld's recently proposed explanation for phytoplankton blooms using satellite data dismisses Sverdrup's critical depth model entirely. In fact, Behrenfeld (2010) argued that blooms are not initiated by stratification of the water-column, but rather by the annual cycle of mixed layer deepening. Under Behrenfeld's "DilutionRecoupling Hypothesis," stratification of the water-column actually "accelerates the spring increase in grazing pressure within the mixed layer by concentrating mobile heterotrophs" (Evans and Parslow, 1985).

The purpose of this research is not to focus on the onset of the spring bloom or on the complicated biological aspects of the system. Instead, this study focuses on the physical conditions which should normally lead to wintertime phytoplankton blooms. That said, relatively little is known about winter phytoplankton blooms and their impact on the ecosystem as a whole. Investigations to this point have shown that on one hand, winter blooms can lead to increased stocks of zooplankton, which are the food source of many fish (Durbin et al., 2003), while alternatively winter phytoplankton blooms may have a negative impact on the ecosystem by depleting surface waters of nutrients. In the latter case, phytoplankton blooms may actually be responsible for "reducing the overall primary productivity throughout the region" (Ji et al., 2008). In order to determine which scenario is more likely, it is necessary to first investigate the physical conditions typically present during the winter in different regions of the GOM. Doing this will provide a foundation for future work studying the relationship between stratification and wintertime phytoplankton blooms. In this study, it is assumed that the fundamental oceanic processes that occur during the spring bloom are the same during ephemeral winter phytoplankton blooms. In other words, given sufficient light, it is assumed that the stabilization of the water column typically provides the right conditions for biomass to build up in the surface layer. 


\subsection{Study Objectives}

My research utilizes historical data from the Gulf of Maine Ocean Observing System (GOMOOS), the Bedford Institute of Oceanography (BIO) hydrographic database, the National Center for Environmental Prediction (NCEP Reanalysis II), and data from the Coastal Ocean Observing and Analysis (COOA) dataset compiled at the University of New Hampshire. The combined BIO and COOA cast data provide good spatial coverage of the GOM with 1420 wintertime data points spanning from 1970-2009 (Fig. 1-3). The GOMOOS data complements the BIO and COOA data by providing hourly or better time-series data from roughly 2001-2010 for moored buoys in the GOM. The NCEP Reanalysis II data provides daily averaged wind stress values for a large portion of the GOM. The purpose of this study is: 1.) To compare regional patterns in temperature, salinity, and stability in the upper water-column $(0-20 \mathrm{~m})$; 2.) To describe the frequency, duration, and spatial patterns in shallow winter mixed layers; 3.$)$ To determine quantitatively the regionally averaged relative contributions of salinity and temperature to the density gradient in the upper water-column. Regionally averaged wind stress values will serve as auxiliary material, and will aid in determining whether shallow mixed layer events are linked with decreased wind stress, salinity driven density stratification, increased surface layer temperatures, or some combination of these three.

I define shallow mixed layers as mixed layers less than $20 \mathrm{~m}$. Shallow mixed layers are defined in this way since the highest phytoplankton growth rates occur in the upper 20m (Smetacek and Passow, 1990). Furthermore, since data are only available at 1,20 , and $50 \mathrm{~m}$ for many coastal GOMOOS buoys, it is not possible to determine a more precise mixed layer depth. 


\subsection{Background}

\subsubsection{Gulf of Maine Definition}

The Gulf of Maine is the continental shelf sea on the east coast of North America, situated between Cape Cod, MA and Nova Scotia, Canada (Townsend et al., 1994). The ocean perimeter of the GOM is defined by the Nantucket Shoals and Georges Bank to the south, and Brown's Bank to the east. The GOM is important biologically as it serves as a source for seed populations of zooplankton which are advected onto Georges Bank (Durbin et al., 2003). Georges Bank is one of the richest fisheries in the North Atlantic and is characterized by high levels of primary production and fish production (Fogarty and Murawski, 1998). Some native fish to the GOM include cod, haddock, flounder, mackerel, menhaden, herring and squid.

\subsubsection{Circulation}

The GOM has a counter-clockwise circulation with deep inflow of nutrient-rich, warm, saline slope water through the Northeast Channel (Hopkins and III, 1979) as well as surface inflow of fresh, cold SSW near Cape Sable, Nova Scotia (Smith, 1983). Outflow from the GOM occurs through the Northeast Channel, the Great South Channel or north of Georges Bank. In the last case, near surface waters from the western GOM flow over the northern flank of Georges Bank before turning clockwise and flowing westward past the Nantucket Shoals into the Mid-Atlantic Bight (Brown and Beardsley, 1978) (Fig. 1-4). As mentioned earlier, the source of the highly saline slope water is believed to alternate between Labrador Current and Gulf Stream origins (Gatien, 1976). Townsend (1991) hypothesized that slope water likely enters through the Northeast Channel in "pulse-like events that may be correlated with winter winds." The main source of SSW, on the other hand, is the West Greenland/Labrador Current system with smaller inputs from the St. Lawrence 
River (Smith et al., 2001). SSW provides the majority of fresh water to the GOM (Brown and Irish, 1993). Rivers, however, are important in that they are another source of fresh, nutrient-rich water to the GOM contributing on average $3 \times 10^{3} \mathrm{~m}^{3}$ $\mathrm{s}^{-1}$ (Meade and Emery, 1971). The major rivers moving counter-clockwise around the GOM from north to south are: St. John, St. Croix, Penobscot, Kennebec, Androscoggin, Saco, and Merrimack Rivers (Fig. 1-4).

\subsubsection{Historical Observations: Seasonal Patterns in Salinity, Temperature, and Stability}

Water-column salinity, temperature, and stability vary spatially, temporally, and vertically with depth across the GOM. Large interannual variability in salinity, temperature, and stability is common since seasonal cycles in water temperature and salinity are strongly influenced by patterns of insolation, river discharge, evaporation, winds, and currents (Benway et al., 1993). External forcing factors such as the variability in SSW or slope water inflow also affect patterns in salinity and temperature throughout the GOM. Localized coastal freshening from high river discharge also impacts salinity and temperature patterns (Deese-Riordan, 2009). Fong et al. (1997) found that localized freshwater plumes can affect salinity and temperature patterns across a wide area. These fresh plumes are capable of thinning and spreading up to $50 \mathrm{~km}$ offshore during upwelling favorable winds (Fong et al., 1997).

Using hydrographic data from about 52 stations collected in the GOM from the Marine Resources Monitoring Assessment and Prediction (MARMAP) program from the period 1977-1987, Mountain and Manning (1994) found distinct spatial and temporal patterns in salinity, temperature, and stability. According to the MARMAP data the annual mean temperature and the range of the mean annual cycle of temperature in the upper $50 \mathrm{~m}$ varies very little across the GOM. For surface waters $(<5 \mathrm{~m})$, however, Mountain and Manning (1994) found that the range of the annual cycle of 
temperature is greater in the western area of the GOM due to higher summer-time temperatures from the nearby heating of the land. Annual cycles in temperature minimum and maximum are in sync throughout the GOM. Minimum surface temperatures occur in late winter (year days 70-80), and maximum surface temperatures occur in the summer (year days 250-260). Salinity does not follow the same pattern as temperature. The annual range in salinity values is greater in coastal regions than in the interior GOM. The large seasonal salinity range in the coastal area is the result of fresh river input during the spring snow melt. Advection of cold, fresh SSW also influences regional patterns in surface salinity, both coastally and in the interior GOM. The impacts of fresh SSW are seen from east to west consistent with the GOM's circulation. Freshening from SSW will be seen first in northern coastal areas before eventually affecting western coastal areas by spring and summer (Mountain and Manning, 1994; Deese-Riordan, 2009).

Mountain and Manning (1994) also found that the "contribution that temperature and salinity make to the annual cycle of surface layer density is additive in the western Gulf, but nearly canceling in the eastern Gulf." In other words, in the eastern GOM cold winter air temperatures decrease water temperatures and increase their density, while at the same time, advection of fresh SSW decrease their density. By contrast, in the western GOM the minimum salinity values during the summer months coincide with the maximum surface water temperatures. In this case, both warm and fresh conditions contribute to low surface densities. Overall, Mountain and Manning (1994) found that during the winter the eastern GOM remains fairly stratified because of the inflow of low salinity SSW, while the western GOM is less stratified because of high surface salinities in combination with cold air temperatures. 


\subsubsection{Recent Observations}

Observations in the GOM at buoys A, B, E, I, M, and N during the last decade agree closely with the findings of (Mountain and Manning, 1994) (Fig. 1-5 and Fig. 1-3). Details on hydrographic data and data processing can be found in Chapter

2. Yearly averaged salinity and temperature data given here are based on a 20 day rolling averages to smooth short-term variability.

Maximum and minimum salinity values occur at different times depending on location. For example, the maximum salinity occurs close to the first day of the year at Buoy M in Jordan Basin, while at Buoy B on the Western Maine Shelf, salinity continues to increase until roughly day 70 . At Buoy B, salinity at $1 \mathrm{~m}$ shows considerably more intra-annual variability than at other buoys north and east. The cause of intra-annual variability in surface salinity, and differences between buoys will be discussed later. Buoy I in the northern coastal GOM follows a seasonal salinity cycle similar to Buoy M in Jordan's Basin, with peak salinities at the start of the calendar year and a gradual decrease in salinity at all depths until about day 150 . Compared with Buoy I, however, Buoy M shows a slightly larger salinity gradient between 1 and $50 \mathrm{~m}$ beginning in the later spring and continuing into the summer. Both Buoys I and M show smaller intra-annual variability than buoys in the western coastal and eastern GOM. Salinity differences between 1, 20, and 50m at Buoy N are very pronounced throughout the year with the largest difference occurring in the summer, near day 200. The large salinity difference between 1 and 50m may be attributed to the maximum annual mean inflow of deep slope water through the Northeast Channel during late summer (Ramp et al., 1985).

Temperature observations gathered during the last decade also closely reflect historical measurements (Fig. 1-6). At all GOMOOS buoys temperature is at a minimum in late winter and at a maximum during the summer. Within year temperature variability is greatest at $1 \mathrm{~m}$ since this water is in direct contact with the atmosphere. In 
agreement with Mountain and Manning (1994), temperature variation at $1 \mathrm{~m}$ is greatest in coastal areas. However, significant $\left(>10^{\circ} \mathrm{C}\right)$ swings from winter to summer are also seen at buoys $M$ and $N$, in Jordan Basin and over the Northeast Channel, respectively. Comparatively smaller intra-annual variability in salinity and temperature at Buoy I, on the Eastern Maine Shelf, is noticeable from Figures 1-5 and 1-6. Patterns in salinity and temperature will be discussed in more detail in the following chapters. During the winter, an average temperature inversion is present at all GOMOOS buoys. A temperature inversion occurs when temperatures increase with depth. In the spring, temperature inversions break down at the GOMOOS moorings as surface waters are heated by the sun. The cause of wintertime temperature inversions and their magnitude will be discussed later.

\subsection{Mixed Layer Depth Definition}

\subsubsection{A Numerical Approximation for Mixed Layer Depth}

The mixed layer is defined by its uniform to near uniform density, active vertical mixing and homogeneous salinity and temperature (Thomson and Fine, 2003). Turbulence in the surface waters of the ocean created by wind, cooling, breaking waves, and current shear are the main factors which deepen the mixed layer. Heat flux into the surface, as well as freshwater runoff from the seasonal melting of continental ice and rain can also create stratification and shallow the mixed layer. Temperature and turbulence can also affect the mixed layer depth on short time scales. For example, field observations have shown that on days when the wind is calm and solar irradiance is high, warming of the surface layer can occur down to a few meters setting up a shallow, stable mixed layer (Smetacek and Passow, 1990).

The method used to define the mixed layer is not consistent between authors. One method of determining the mixed layer depth is to use the gradient method (Bathen, 
1972; Lukas and Lindstrom, 1991; Richards et al., 1995). This method defines the mixed layer depth as the depth at which the change in density with depth, or the change in temperature with depth, exceeds a certain value. The gradient method is problematic because it assumes that there is a definite interface between the mixed layer and underlying water mass. I do not use this method since it can only be used with high resolution salinity and temperature profiles.

In this study the mixed layer depth is defined using the threshold method. This method uses a finite difference criterion. In other words, the mixed layer is the depth at which water density exceeds a pre-determined value. This value is discussed in the following paragraph. Older datasets often relied simply on temperature profiles if salinity data were not available to calculate density. Some common sea surface temperature (SST) based examples are as follows: Thompson (1976) defined a SST$0.2^{\circ} \mathrm{C}$ as his isothermal layer depth (equivalent to mixed layer depth in absence of other data), whereas Price et al. (1986) defined his mixed layer depth as SST- $0.5^{\circ} \mathrm{C}$. Many similar values are used when dealing with temperature based criterion (Kara et al., 2000).

Here, since both temperature and salinity data are available, potential densities are calculated and used to determine the mixed layer depth. It is preferable to use potential density rather than temperature profiles because the structure of the watercolumn is dependant on both temperature and salinity. Potential density accounts for changes in salinity, temperature, and pressure with depth and is given by $\sigma_{\theta}=$ $(\rho(\mathrm{S}, \mathrm{T})-1000) \mathrm{kg} / \mathrm{m}^{3}$, where $\mathrm{S}$ is salinity, $\mathrm{T}$ is temperature and $\rho(\mathrm{S}, \mathrm{T})$ is the density of sea-water in meter-kilogram-second units (mks). The potential density difference of $.01 \mathrm{~kg} / \mathrm{m}^{3}$ from the surface to some depth is used in this study, and is the "de facto standard" for finding the mixed layer depth (Thomson and Fine, 2003). Some scientists who have used this criterion to define the mixed layer depth include Peters et al. (1988), Schneider and Muller (1990), Wijffels et al. (1994), Skyllingstad et al. 
(1999) and others.

\subsubsection{Drawbacks of the Threshold Method}

Using a potential density difference to define a mixed layer depth is widely used and relatively simple. However, this technique does have some drawbacks. One such limitation is that it ignores underlying water of nearly the same potential density; so the value is arbitrary in that sense.

Another drawback to using the threshold method with $\sigma_{\theta}$ is that it ignores the fact that "the retreat of turbulent mixing to shallower depths proceeds faster than the erosion of the stratification at the base" (Kara et al., 2000). In other words, the mixed layer may be different from the layer that is still actively mixing (mixing layer) even though they may have nearly identical densities. Brainerd and Gregg (1995) define the mixed layer as "the envelope of maximum depths reached by the mixing layer on time scales of a day or more and is the zone that has been mixed in the recent past." The "retreat" of the mixing layer to a shallower depth could result if the mixing mechanism decreased in intensity. For example, this could mean that the winds slackened or wave breaking subsided. Brainerd and Gregg (1995) found that during a daily cycle, the mixed layer can alternate between well-mixed during the night and weakly stratified during the day. This stratification they found was due to a lack of convection of water during the day below the diurnal thermocline. The diurnal thermocline is different than the seasonal thermocline in that it breaks down quickly on a daily basis. Typically, the conditions are such that the mixing layer and mixed layer are the same. For this study, the depth of the mixed layer is adequate, since in terms of a phytoplankton bloom, if the mixed layer is shallow enough, it will not matter biologically whether it is actively mixing or not (Fig. 1-7). 

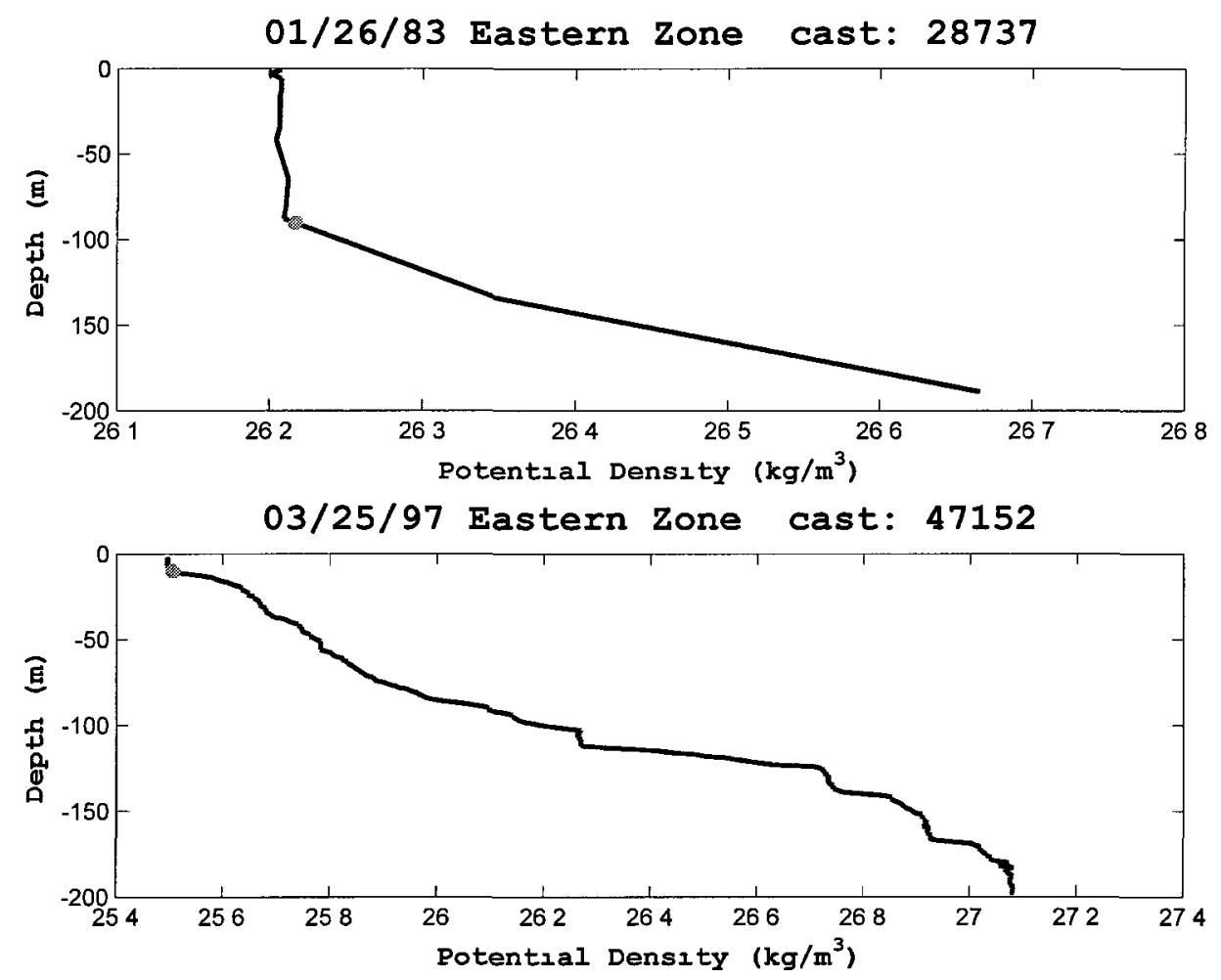

Figure 1-1: Potential density profiles from the Eastern Zone indicating mixed layer depth (marked with a red dot). Top: Typical deep winter mixed layer. Bottom: Shallow spring mixed layer. 


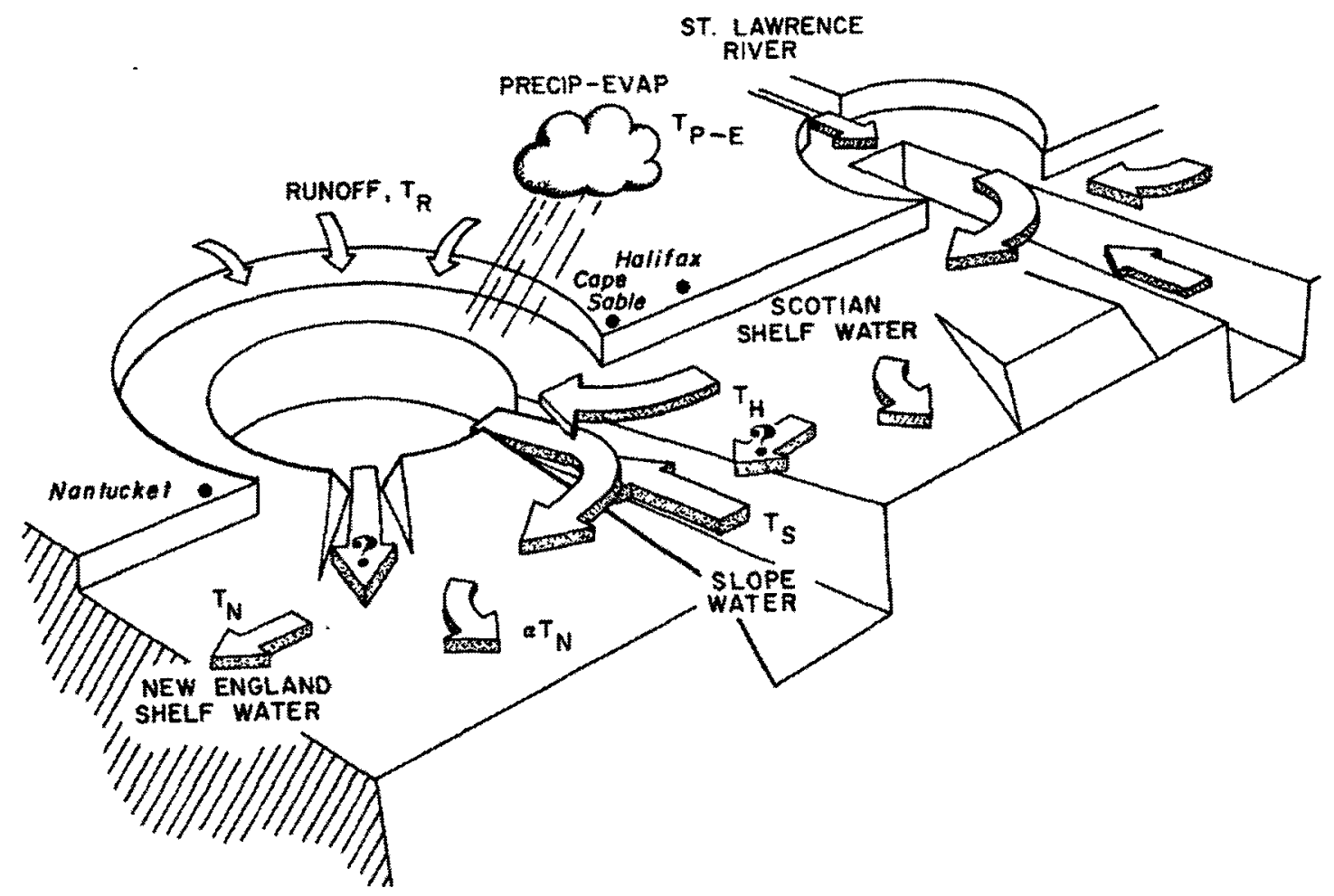

Figure 1-2: Figure from Brown and Beardsley (1978) (Fig. 4) showing sources of volume influx into the GOM. $T_{H}$ is the volume influx of SSW through the Halifax section; $\mathrm{T}_{s}$ is volume influx of slope water (WSW or LSW) through the Northeast Channel; $\mathrm{T}_{R}$ represents river runoff; and $\mathrm{T}_{P-E}$ indicates net precipitation minus evaporation. $\mathrm{T}_{N}$ shows volume outflux through the Great South Channel which lies between the Nantucket Shoals and Georges Bank. $\alpha \mathrm{T}_{N}$ indicates outflux of water through the seaward boundary. 


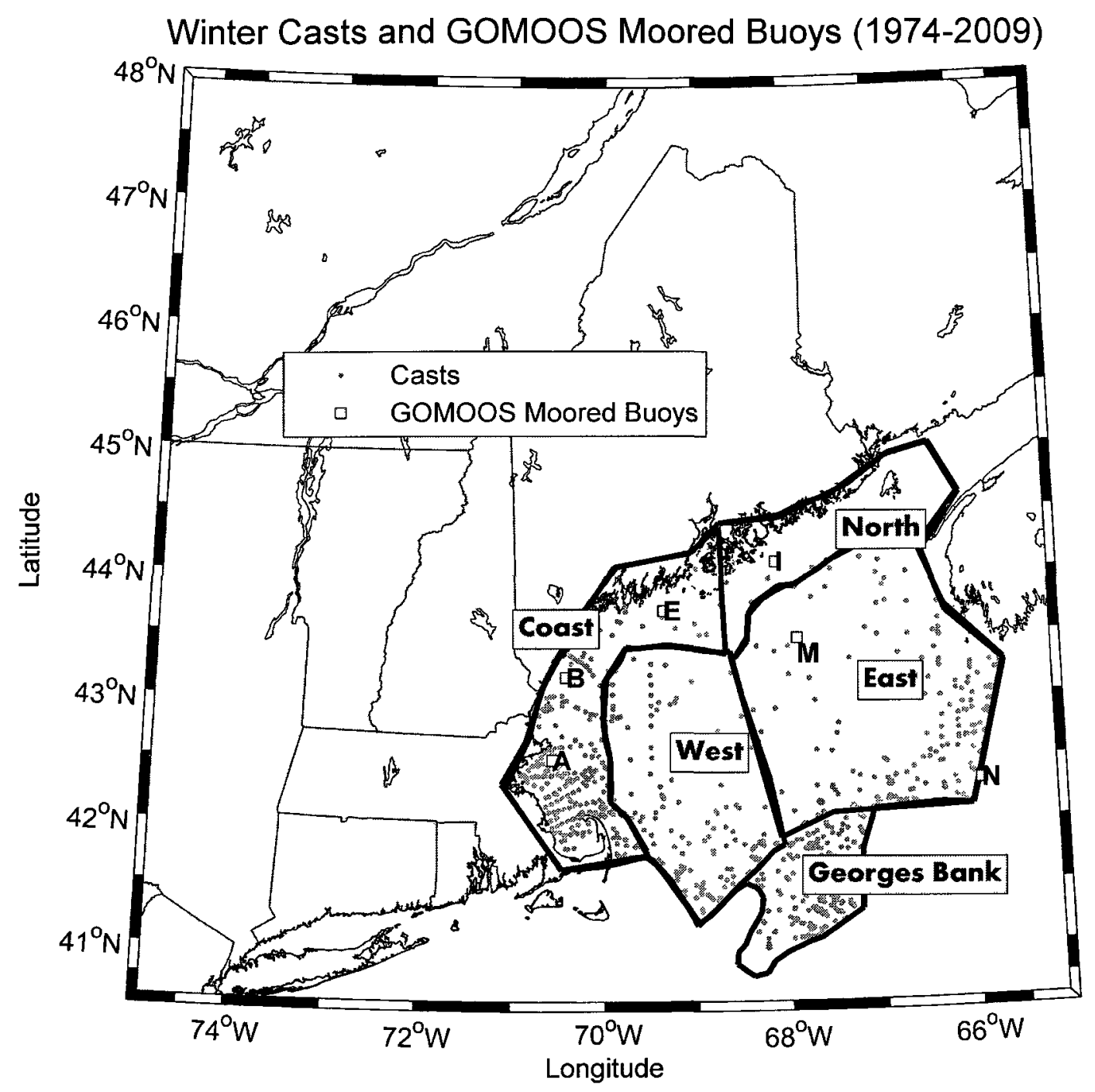

Figure 1-3: A map of the Gulf of Maine including the locations of all casts and GOMOOS buoys used in this study as well as the delineation of different "zones" outlined by black lines. Casts are indicated by red points and GOMOOS moorings are shown by green squares with black edges. 


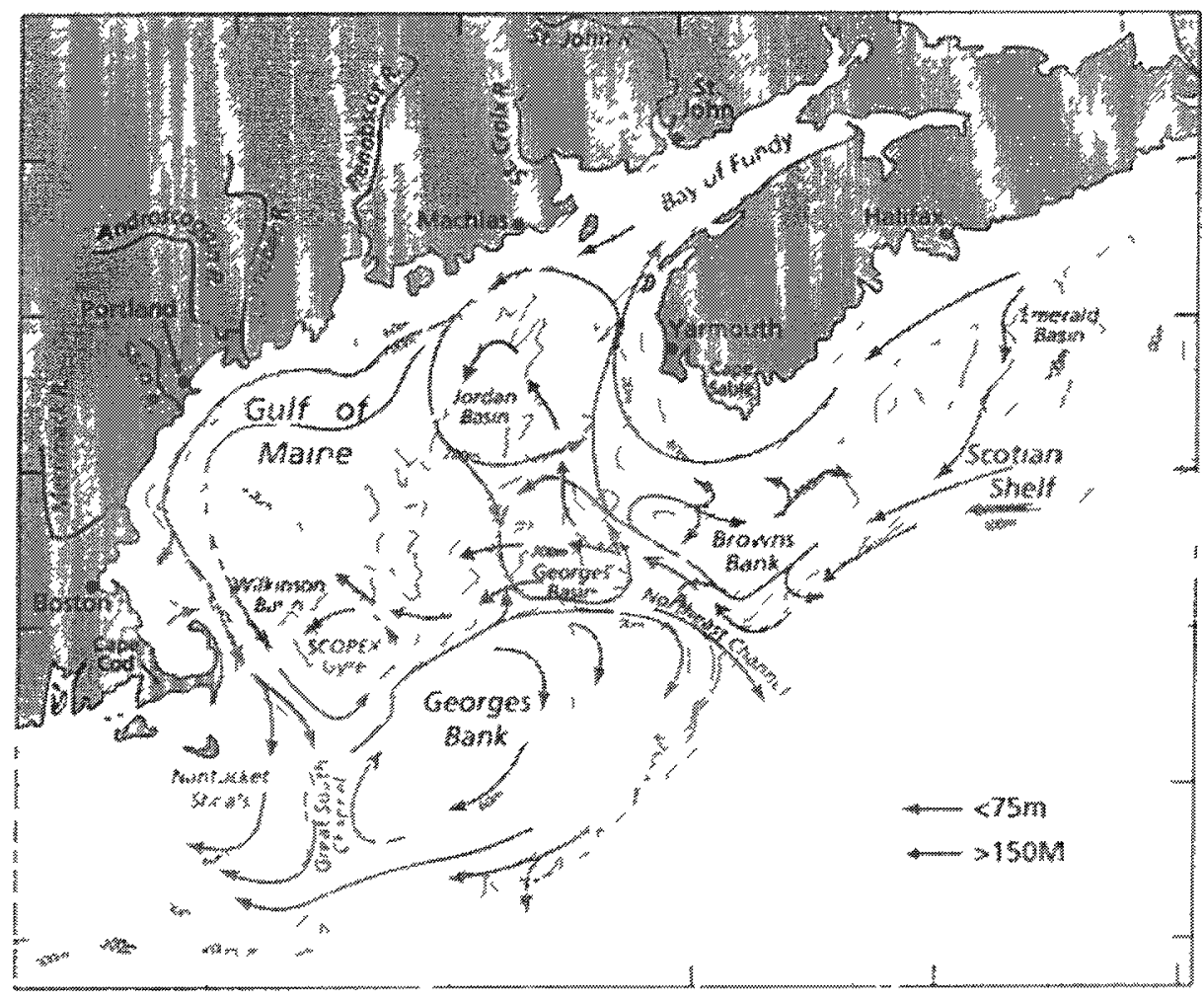

Figure 1-4: (Miller et al, 1998) representation of the surface $(<75 \mathrm{~m})$ and deep circulation $(>75 \mathrm{~m})$ in the GOM after thermal stratification has taken place in the spring. The GOM has a counter-clockwise circulation with a deep inflow of slope water (WSW or LSW) through the Northeast Channel as well a surface inflow of fresh, cold SSW near Cape Sable, Nova Scotia. Outflow from the GOM occurs through the Northeast Channel, the Great South Channel or with near-surface waters from the western GOM moving clockwise around Georges Bank and flowing westward past the Nantucket Shoals into the middle Atlantic Bight. 

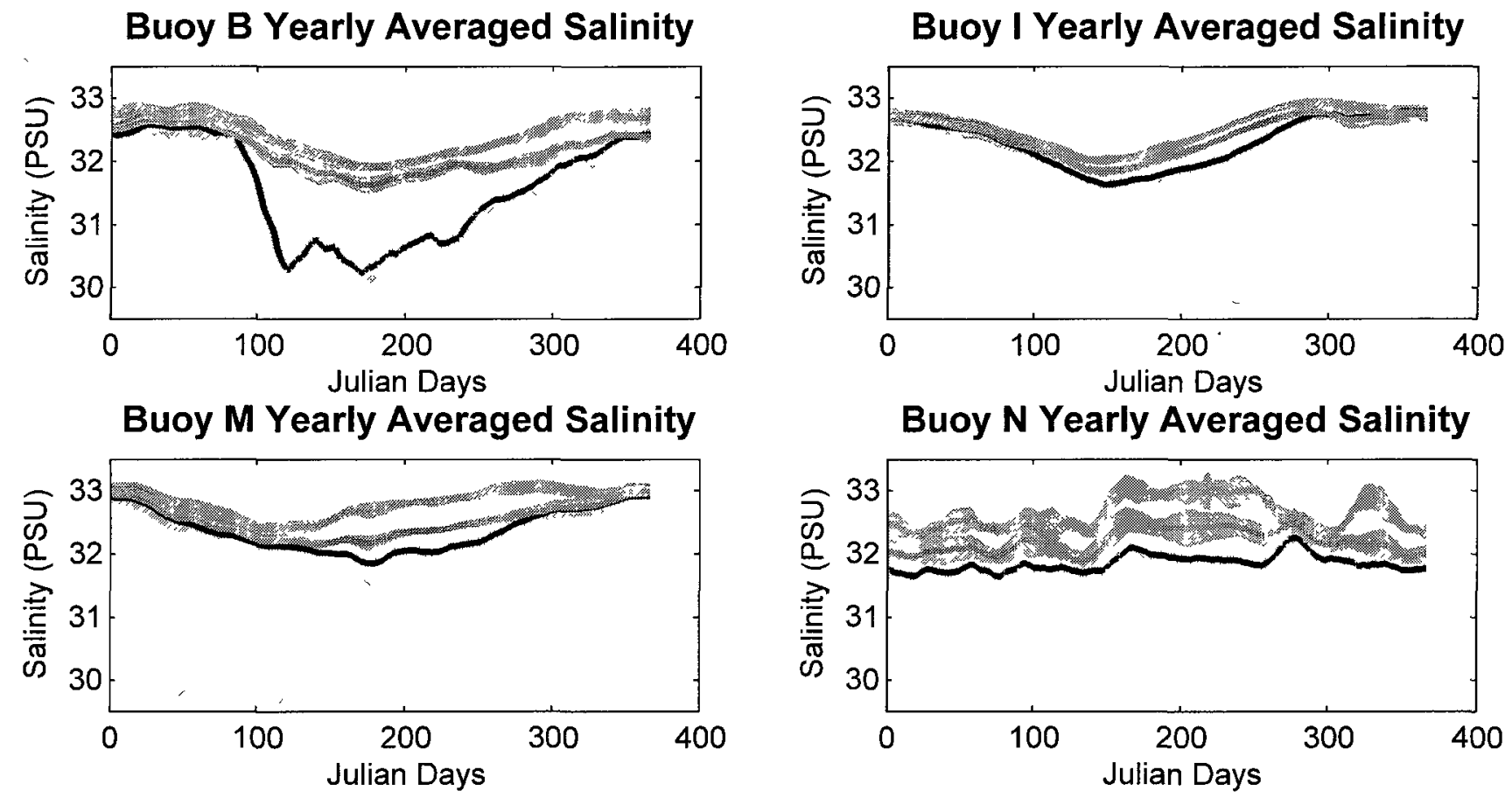

Figure 1-5: Yearly averaged salinities based on a 20 day rolling average for GOMOOS buoys $B, I, M$, and N. Filled region shows \pm 1 standard error calculated for each day based on the interannual variability in salinity values at $1 \mathrm{~m}, 20 \mathrm{~m}$, and $50 \mathrm{~m}$ for years with available data. 

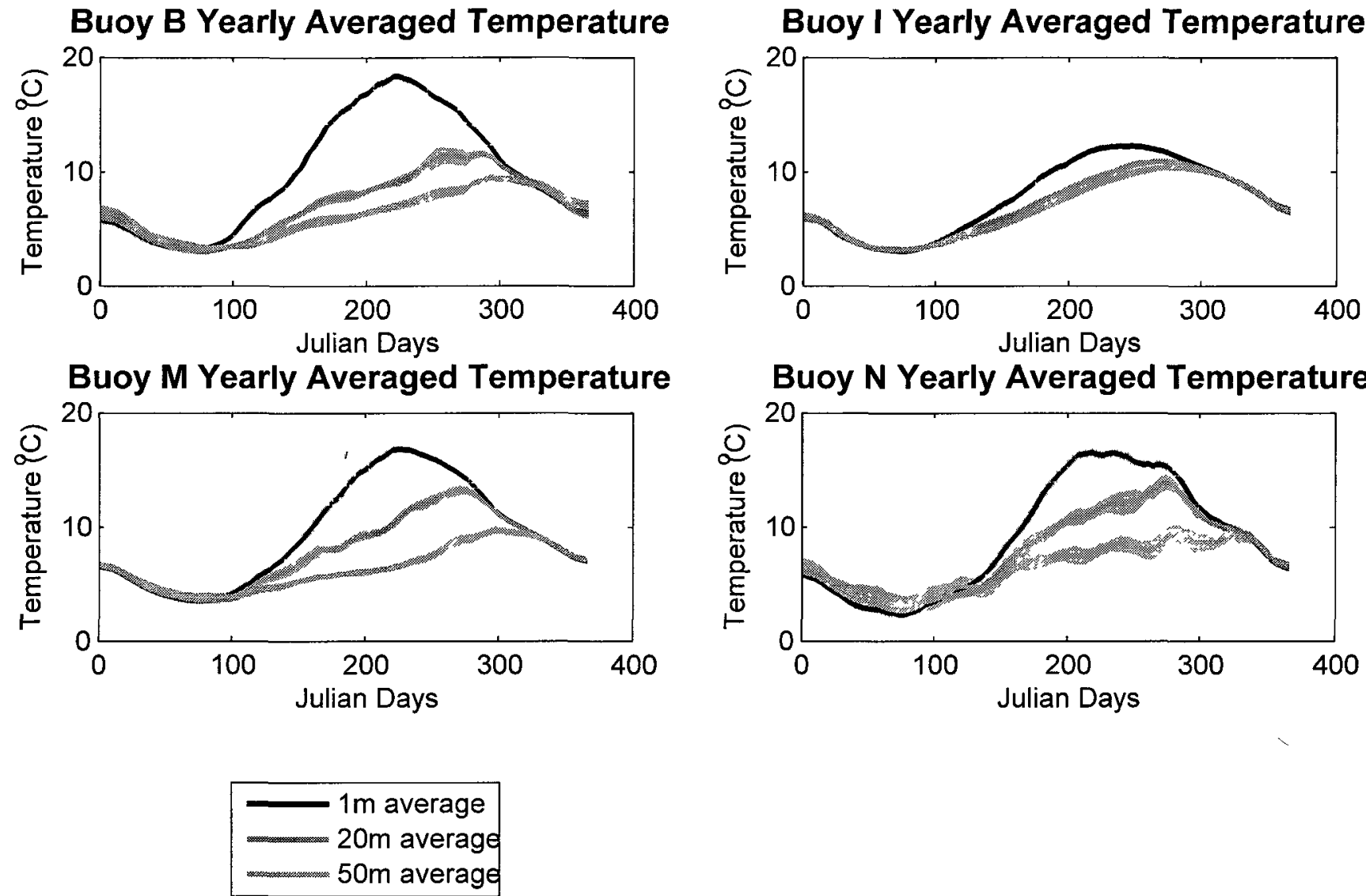

Figure 1-6: Yearly averaged temperatures based on a 20 day rolling average for GOMOOS buoys B, I, M, and N. Filled region shows \pm 1 standard error calculated for each day based on the interannual variability in temperature values at $1 \mathrm{~m}, 20 \mathrm{~m}$, and $50 \mathrm{~m}$ for years with available data. 


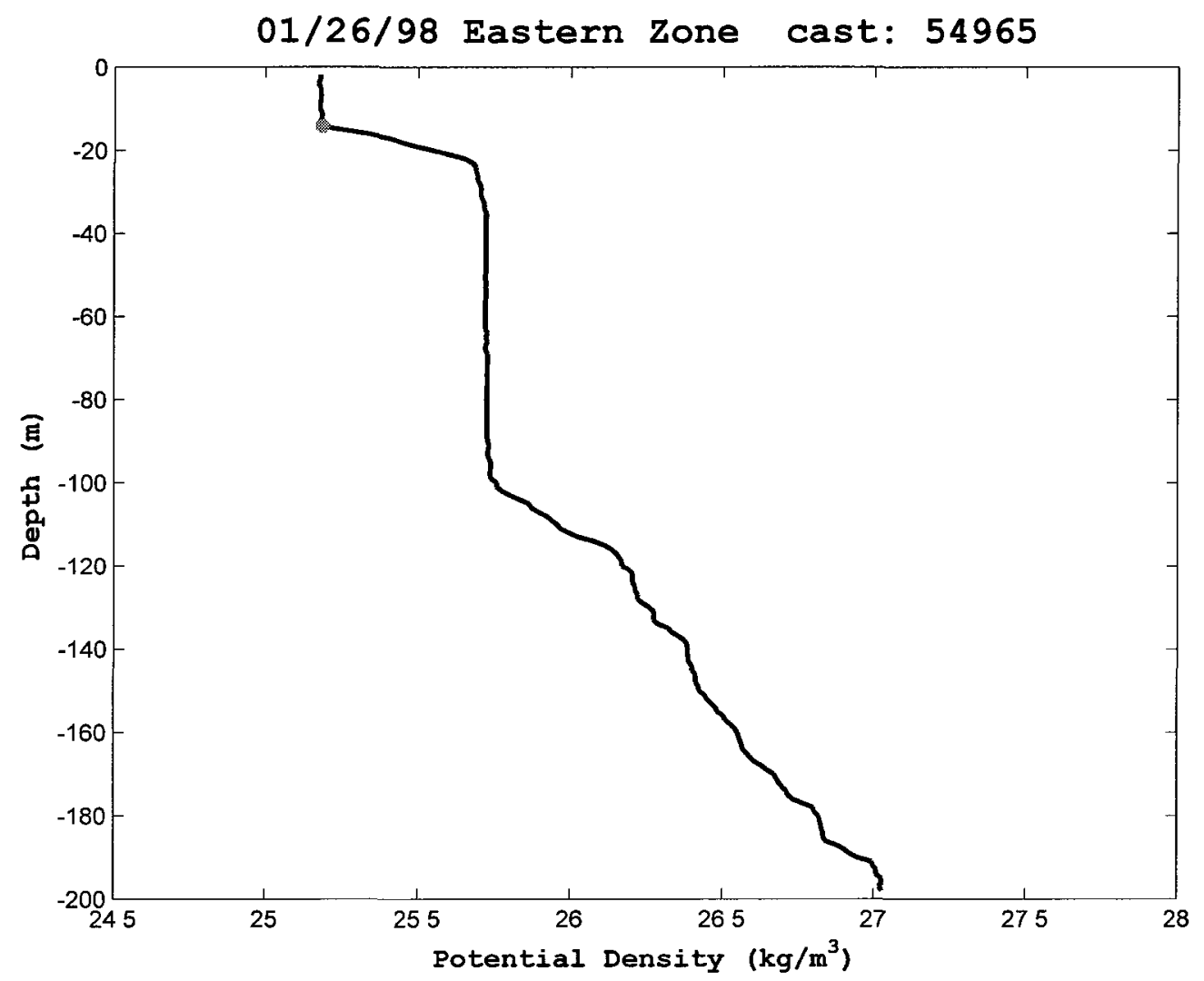

Figure 1-7: Mixed layer depth indicated by red dot. This density profile shows a shallow mixed layer during the winter in the eastern GOM present on top of a deeper fossil mixed layer that extends to about $100 \mathrm{~m}$ depth. The stability of the upper watercolumn shown in this figure may provide conditions suitable for a phytoplankton bloom. 


\section{CHAPTER 2}

\section{REGIONAL PATTERNS IN}

WINTERTIME SALINITY,

\section{TEMPERATURE, AND STABILITY}

\subsection{Hydrographic/Atmospheric Data}

\subsubsection{Gulf of Maine Ocean Observing System Buoy Data}

Historical time-series data from the Gulf of Maine Moored Buoy Program for buoys A, B, E, I, M, and N used in this study are available at http://gyre. umeoce.maine. edu/buoyhome.php. Buoys A, B, E, I, M, and N are representative of Cape Cod Bay, the Western Maine Shelf, the Central Maine Shelf, the Eastern Maine Shelf, Jordan Basin, and the Northeast Channel respectively (Fig 2-1). Hourly or finer resolution data are provided for most buoys for the years 2001-2010 at some standard depths depending on the buoy location and maximum water depth. Buoys A, B, E, I, M, and $\mathrm{N}$ have maximum depths of $65 \mathrm{~m}, 62 \mathrm{~m}, 100 \mathrm{~m}, 100 \mathrm{~m}, 285 \mathrm{~m}$, and $225 \mathrm{~m}$ respectively. Only hourly data with measurements at $1 \mathrm{~m}, 20 \mathrm{~m}$, and $50 \mathrm{~m}$ is considered for this study. Missing data for certain periods of time and at particular depths is common for all moorings, and was accounted for in data processing and analysis. I filtered GOMOOS data to remove all unrealistic salinity and temperatures measurements. All hourly data outside of the winter months (January, February, and March) were also eliminated and the remaining hourly data were averaged and binned by day. 
In order to focus on longer-term patterns, which may result in a more significant biological response, a 20 day rolling average was applied.

\subsubsection{Cast Data}

Cast data pertinent to this research comes from Coastal Ocean Observation and Analysis dataset (COOA) and from the Bedford Institute of Oceanography (BIO) hydrographic database. The BIO data spans 1970-2003 while the COOA data are more recent, 2005-2009. The BIO and COOA cast data are used in the spatial analysis of regional water-column stability, salinity/temperature patterns, and in determining the relative importance of salinity and temperature in affecting the density in the upper water-column (1-20m).

The COOA and BIO data were combined and organized using Matlabß). All casts not taken during the winter (January, February, and March), or those outside the GOM were removed. Casts missing all salinity or temperature measurements were also discarded because both data types are necessary to calculate potential density. As with the GOMOOS mooring data, casts were also rejected if salinity or temperature values fell outside realistic ranges. Another requirement was that casts must have a complete salinity and temperature profile. For example, casts were not used if the first measured depth was not within $5 \mathrm{~m}$ of the surface, or if there was only one recorded depth. Furthermore, since the change in density in the upper $20 \mathrm{~m}$ is a main focus of this study, casts were eliminated if the difference between the first and second depth was greater than $3 \mathrm{~m}$. A consequence of keeping casts with poor data resolution would be less confidence in the estimate of a mixed layer depth. Also, since the upper water-column is defined as the top $20 \mathrm{~m}$, casts are not used for analysis if a depth of $20 \mathrm{~m}$ is not reached.

For the remaining casts, salinity, temperature, pressure, and depth data are linearly interpolated using $.125 \mathrm{~m}$ resolution to make calculations of mixed layer depth 
as well as to find salinity, temperature, or potential density values at specific depths. The potential density at each depth is found by inputting interpolated data into the Matlab® function "sw_pden" developed by Phil Morgan in 1992, and part of the seawater toolbox for Matlabß). Calculations of potential density are based on the equation of state for seawater given by Gill (1982). A reference pressure of $0 \mathrm{db}$ is used in all potential density calculations. After finding the potential density for each depth for a particular cast, the next step is to define a mixed layer depth. For simplicity and consistency with the work of other researchers, the mixed layer is defined using a finite difference criterion of $.01 \mathrm{~kg} / \mathrm{m}^{3}$ (Thomson and Fine, 2003). In order to use this method, however, it is necessary to choose a surface depth. Because not all casts have data collected within a meter of the surface, the reference surface for mixed layer depth calculations is defined as the minimum depth data are available shallower than $5 \mathrm{~m}$.

In cases when maximum depths are less than $20 \mathrm{~m}$, physical factors such as bottom stress caused by the interaction of waves and tides with the seafloor will cause turbulent mixing and may overshadow the roles of temperature, salinity, and wind stress in governing stratification/destratification. Removing casts that do not reach $20 \mathrm{~m}$ also deals with cases of "artificially" shallow mixed layer depths found from incomplete depth profiles. In this case, the algorithm designed to find the mixed layer depth chooses the deepest value available for a particular cast to be the mixed layer depth if the $.01 \mathrm{~kg} / \mathrm{m}^{3}$ threshold is not met. Removing casts where the mixed layer depth coincides with the deepest recorded depth makes little difference in regional mixed layer depth averages in the Coastal, Western, and Eastern Zones. However, for areas with greater mixing such as Georges Bank and the Northern Zone, removing these casts does bias the average mixed layer depth toward shallower depths. Due to limitations in the cast data, regionally averaged mixed layer depths presented in this study should be considered as under-estimates. That is to say that mixed layer 
depths may be greater in some cases, but the true mixed layer depth is not resolvable with the available cast data. Algorithm derived differences in mixed layer depth are presented in the following chapter.

\subsubsection{NCEP-DOE Reanalysis II}

Daily averaged wind data from 2001-2010 were obtained from the National Center for Environmental Predictions Reanalysis II model put forth by the Earth Systems Research Laboratory at NOAA (National Oceanographic and Atmospheric Association). This gridded dataset is a model which incorporates observations and is updated continually in an effort to represent the state of the Earth's atmosphere. The NCEPDOE Reanalysis II is an updated version of the previous NCEP/NCAR Reanalysis I model that fixed errors and updated parameterizations of physical processes (Kanamitsu et al., 2002). Wind-speed magnitudes squared (pseudo-stress) and direction in degrees from North are calculated for all daily data. The grid coverage of NCEP wind data is $42.856^{\circ} \mathrm{N}$ to $44.76^{\circ} \mathrm{N}$ and $65.6250^{\circ} \mathrm{W}$ to $69.375^{\circ} \mathrm{W}$. Daily wind averages represent the spatial average over the gridded area. The area covered by the NCEP grid defined above provides good spatial coverage of the GOM. Similar to the GOMOOS data, a 20 day rolling average is applied to daily and directional data in order to focus on longer term patterns that affect stratification in the upper $20 \mathrm{~m}$.

\subsection{Methods}

\subsubsection{Defining Zones within the Gulf of Maine}

For the purpose of this study, the Gulf of Maine is divided into five distinct regions (Fig. 1-3). These regions include the Coastal, Western, Northern, and Eastern Zones as well as Georges Bank. Regions were chosen based on spatial patterns in averaged wintertime salinities and temperatures at 2 and $25 \mathrm{~m}$. Salinity and temperature 
values come from the Bedford Institute of Oceanography and represent all available

hydrographic data collected between 1970-2003. Sources of data include the National Marine Fisheries Surveys, Canadian and U.S Government surveys, and U.S. and Canadian academic sources (Pringle, 2006). Monthly climatologies compiled by Dr. James Pringle are available at http://oxbow.sr.unh.edu/nogoogle/hydro_clim/.

The Coastal Zone extends from just east of Cape Cod to Penobscot Bay and is defined as the area from the coastline to the $150 \mathrm{~m}$ depth contour. The Northern Zone similarly follows the $150 \mathrm{~m}$ depth contour and extends from Penobscot Bay into the Bay of Fundy. The Western Zone is adjacent to the Coastal Zone. It is bounded to the south by Georges Bank and includes the Wilkinson Basin. The Eastern Zone is adjacent to the Northern Zone and includes both Georges and Jordan Basin. The Eastern Zone also includes much of the area southwest of Nova Scotia and extends eastward to $65.5^{\circ} \mathrm{W}$. Again this region is bounded to the south by Georges Bank. Georges Bank is unique in that it is relatively shallow $(\sim 70 \mathrm{~m})$ and is heavily influenced by tidal mixing. The number of casts used from the Coastal, Northern, Western, Georges Bank, and Eastern zones is 460, 58, 223, 385, and 257 respectively.

\subsubsection{Winter Decorrelation Time-Scales at GOMOOS Buoys}

At the GOMOOS moorings, decorrelation times for salinity, temperature, and potential density are found by determining the amount of time that needs to pass in order for one sample to be independent of another (Table 2.1). In order to remove natural trends within a time-series, all decorrelation times are calculated considering only the anomaly from the climatological values. In this case, climatologies are calculated for each day during the winter (calender days 1-90) using all available years. All decorrelation times are calculated by finding the time lag required for zero correlation between two samples. Decorrelation times are calculated for several applications of salinity, temperature, and potential density in order to find the standard error of cal- 
culated averages. Given the decorrelation time for a particular data type, the number of independent samples is defined as the the total number of winter days divided by the decorrelation time. The standard error is found by taking the standard deviation of a dataset and dividing it by the square root of the number of independent samples.

The decorrelation times of salinity and temperature at different depths and at different GOMOOS buoys are calculated using 20 day rolling averages. Only winter days are considered in this calculation. Decorrelation times are also calculated for the difference in potential density between 1 and $20 \mathrm{~m}$ as well as for the difference in salinity and temperature between 1 and $20 \mathrm{~m}$. Furthermore, decorrelation times are found for salinity, temperature, and relative contributions. These contributions will be discussed in the following chapter. To find the sensitivity of the decorrelation time to the 20 day rolling average, a 4 day rolling average is applied instead, and decorrelation times are re-calculated. Given that the averaging in both cases is on much shorter time-scales than the monthly to seasonal decorrelation time-scales for the data types considered, it is expected and found that the 20 and 4 day rolling averages have nearly the same decorrelation times.

\subsubsection{Calculating Average Salinity and Temperature}

\section{Calculating Average Salinity/Temperature at GOMOOS Buoys}

The average winter salinity and temperature at $1 \mathrm{~m}$ for the GOMOOS buoys is calculated using 20 day rolling averages for each winter day (1-90) and for all years with data. It is acceptable to use 20 day rolling averages since the decorrelation time for salinity and temperature at $1 \mathrm{~m}$ is typically on seasonal or longer time-scales (Table 2.1). Daily averages are binned by year and then averaged to find yearly winter averages at a specific buoy. Standard error is calculated by taking the standard deviation of the yearly averages and dividing by the square root of the number of independent samples. The number of independent samples is found by taking the 
total number of winter days at a particular mooring and dividing by the decorrelation time for the variable in question.

The salinity and temperature difference between $1 \mathrm{~m}$ and $20 \mathrm{~m}$, or $1 \mathrm{~m}$ and $50 \mathrm{~m}$, is found by subtracting the 20 day rolling averages of salinity/temperature at $1 \mathrm{~m}$ from the 20 day rolling averages of salinity/temperature at $20 \mathrm{~m} / 50 \mathrm{~m}$. In doing this subtraction the salinity/temperature values at the shallower depth are subtracted from the corresponding values at the deeper depth. Corresponding values refer to measurements taken on the same day and year. Since there is often less data at $20 \mathrm{~m}$ and $50 \mathrm{~m}$ than at $1 \mathrm{~m}$, the data from 20 and $50 \mathrm{~m}$ dictates the number of years available for calculating the salinity or temperature difference between two depths. Daily differences in salinity or temperature between two depths are averaged for the entire winter. Standard error is calculated using the yearly averages and applicable decorrelation times.

\section{Calculating Average Regional Salinity/Temperature using Cast Data}

Using the BIO and COOA datasets, the mean surface salinity and temperature of a region are found by averaging the shallowest measurement of salinity and temperature from each cast. The shallowest recorded measurement between $(0-5 \mathrm{~m})$ is used because of inconsistencies in starting depths between casts. Although averaging all years with data from 1970 to 2009 allows a good approximation of winter surface salinity and temperature within a particular zone, it ignores year to year variability. Due to limited data and small sample sizes for any particular year, however, it is difficult in many cases to say with any statistical confidence that one year is different from another. Where cast data are insufficient, however, the high resolution temporal data from the GOMOOS buoys helps to fill in the gaps. The standard error of the average is computed by finding the standard deviation of salinity/temperature data for all casts within a particular region divided by the square root of the number of years 
where data are available. It is appropriate to calculate the standard error in this way given that the decorrelation time of salinity and temperature is on seasonal timescales in the Coastal Zone (Table 2.1), and at least this long in the deep basins of the GOM (Pringle, 2006). In other words, it is a decent assumption that the salinity or temperature value in a given winter, in a particular zone, is representative of the entire winter.

The salinity and temperature difference between different depths is found by looking at differences within particular casts, and then averaging all casts by zone. The difference in salinity/temperature is calculated between the surface depth and $20 \mathrm{~m}$. Linearly interpolating salinity and temperature with $.125 \mathrm{~m}$ resolution is helpful in ensuring that a salinity/temperature value is available at or very close to $20 \mathrm{~m}$ even for casts which may have coarse depth resolution. The standard error of the average difference in salinity/temperature for all casts within a zone is found by dividing the standard deviation of the average differences by the square root of number of years with available data.

\subsubsection{Calculating Average Stability}

\section{Calculating Average Stability at GOMOOS Buoys}

For GOMOOS buoys, 20 day rolling average stability values are calculated as the rate of change of density with depth between 1 and $20 \mathrm{~m}$. The larger the gradient in potential densities between the surface and $20 \mathrm{~m}$, the greater the stability. Following the routine of Mountain and Manning (1994) as closely as possible, the stability is calculated by using the difference in potential density at the surface and $20 \mathrm{~m}$ depth divided by the difference in depth. The stability equation used in this study is based on the equation for stability $(\mathrm{E}=(-1 / \rho)(\mathrm{d} \rho / \mathrm{dz}))$ given by Stewart (2007), but considers $\left(\mathrm{d} \sigma_{\theta} / \mathrm{dz}\right) \operatorname{not}(\mathrm{d} \rho / \mathrm{dz})$. 


\section{Calculating Average Stability for Cast Data}

The average stability for the cast data is calculated in the same way as for the GOMOOS data. For each cast the stability is defined as the rate of change of density in the upper $20 \mathrm{~m}$. The potential density difference between the surface and $20 \mathrm{~m}$ is found by subtracting the $1 \mathrm{~m}$ density from the $20 \mathrm{~m}$ density and then dividing by the depth difference. The depth difference between the minimum surface depth $(0-5 \mathrm{~m})$ and $20 \mathrm{~m}$ is variable between casts. Any bias in stability values between casts resulting from using different surface depths is likely to be negligible, however, since the surface depth is restricted to a narrow depth range. The average stability of an entire region is found by averaging all stability values for casts in a particular region. As with the salinity and temperature cast data, the standard error for the stability data is found by dividing the standard deviation of the regional stability values by the square root of number of years with available data.

\subsubsection{Comparison of Averages}

\section{Comparing GOMOOS Statistics}

In order to determine whether a particular statistic is different between two GOMOOS buoys, it is necessary to consider only the times when data are present at both sites. For example the salinity value at $1 \mathrm{~m}$ at Buoy B on January $1^{\text {st }}, 2007$ cannot be compared with a similar value at Buoy M on January $1^{s t}$, 2008. Salinity, temperature, potential density, and changes in these variables with depth are not the same from one winter to the next. Interannual variability in these variables will be discussed in the following chapter. In comparing a particular statistic, the buoy which covers the smallest range of years is used to define what days of what years can be compared. The comparison of two buoys for a particular day and year is simply done by subtracting the value at one buoy from the corresponding value at the other 
buoy. Recall that each daily value is based on a 20 day rolling average. All values at one buoy are compared to corresponding values at another buoy to generate a list of differences that are binned and averaged by year. All yearly-averaged difference values for a particular buoy are averaged to provide an overall difference. The total standard error is calculated by first considering each mooring individually, taking the standard deviation of the yearly averaged difference values divided by the square root of the number of independent samples. The number of independent samples is dependant on the decorrelation time. Total error is then found using the formula $\sqrt{\frac{s_{1}^{2}}{n_{1}}+\frac{s_{2}^{2}}{n_{2}^{2}}}$ where $s_{1}$ and $s_{2}$ are standard deviations and $n_{1}$ and $n_{2}$ are the number of independent samples at each mooring. P-values are calculated using a 2 sample t-test (assuming unequal variance) with the yearly averaged difference values at both buoys being compared. The Welch-Satterthwaite Equation is used to determine the effective degrees of freedom.

\section{Comparing Cast Statistics}

Comparing cast statistics between different zones in the GOM is limited by the amount of available data. Since there are very few times when data were collected on the same day and year in different regions, it is generally not statistically robust, and often not possible, to make inter-region comparisons based on these casts. To deal with the sample size issue, it is better to simply compare the averages of cast data in each zone. A shortcoming of this is that the average in one region may be based on different years than in another zone. Although this limitation is not ideal, a general comparison can still be made since averaging reduces the effect of interannual variability. The average difference for a statistic between 2 zones is found by subtracting the total average in one zone from the average in the other. The total standard error is found in a similar way as for the GOMOOS data using the formula $\sqrt{\frac{s_{1}^{2}}{n_{1}}+\frac{s_{2}^{2}}{n_{2}^{2}}}$ where $\mathrm{s}_{\mathbf{1}}$ and $s_{2}$ are standard deviations and $n_{1}$ and $n_{2}$ are the number of independent samples 
for each zone. The number of independent samples is given by the number of years with data present in a particular zone. Seasonal decorrelation times are assumed for cast data throughout the GOM since the temporal variation in the density field are on longer time-scales than found in the coastal area (Pringle, 2006). Using seasonal decorrelation times provides an upper-estimate on error whereas using decorrelation times on shorter time-scales may inaccurately decrease error. P-values are calculated using a 2 sample t-test (assuming unequal variance) with the averages for each zone being compared. Again, the Welch-Satterthwaite Equation is used to determine the effective degrees of freedom.

\subsection{Results}

\subsubsection{Surface Salinity and Temperature}

The cast and GOMOOS mooring data show that the salinity at $1 \mathrm{~m}$ is lowest in the Coastal and Eastern Zones of the GOM (Fig. 1-3, Table 2.2, and Table 2.3). When comparing GOMOOS buoys, the average salinity at $1 \mathrm{~m}$ tends to decrease moving counter-clockwise from Buoy I, located along the Eastern Maine Shelf, to Buoy A east of Cape Anne (Table 2.4). Low salinities at Buoy A and B, in the southern Coastal Zone, are the result accumulated fresh river inflow from northern sources (DeeseRiordan, 2009). These sources included the Merrimack, Saco, Kennebec, Penobscot, St. Croix, and St. John Rivers. Buoy A is fresher than coastal GOMOOS buoys to the north since fresh river discharge becomes trapped against the coast and circulates from north to south (Fong et al., 1997). The comparison of Buoy A in the Coastal Zone, with Buoys B, E, and I located further north, and Buoy M further east, shows that the salinity at $1 \mathrm{~m}$ is significantly different at the $10 \%$ level. In the Eastern GOM, fresh SSW inflow, with Labrador Current and St. Lawrence River origins, is responsible for low surface salinities at Buoy N. The difference between Buoys A and 
$\mathrm{N}$ is not statistically significant at the $5 \%$ level with $\mathrm{P}=.11$ and 13 degrees of freedom. The difference in salinity, however, is highly significant $(\mathrm{P}<.01)$ when comparing Buoy $\mathrm{N}$, in the eastern GOM, with moorings on the Maine Shelf (B, E, and I) and Buoy M in Jordan Basin. Lowest average-winter surface salinities at Buoy A in the Coastal Zone, and at Buoy $\mathrm{N}$ in the Eastern Zone, illustrate the respective roles of river discharge and SSW inflow in affecting patterns in regional surface salinity.

Spatial patterns in surface salinity found from casts show the same pattern as those depicted by the GOMOOS data. The cast data goes beyond the GOMOOS mooring data, however, by providing information on average winter surface salinity in the Western Zone and over Georges Bank. Results from cast data indicate that longterm averaged salinity at $1 \mathrm{~m}$ is lowest in the Coastal, Northern, and Eastern zones, while higher values are found at Georges Banks and the Western Zone (Table 2.3). Higher average winter salinities in the Western Zone are the result of deepening mixing with more saline waters (Pringle, 2006). On Georges Bank, full water-column mixing in combination with the delayed arrival of fresh Scotian Shelf and river water until late summer results in relatively high winter surface salinities (Smith et al., 2001). The difference in surface salinity is highly significant $(\mathrm{P}<.01)$ when comparing either the Western Zone or Georges Bank to any other region (Table 2.5). The difference in surface salinity between the Coastal, Northern, and Eastern Zones, however, is not statistically significant $(\mathrm{P} \gg .05)$.

According to cast and GOMOOS mooring data the coolest water temperatures at $1 \mathrm{~m}$ are found in the Eastern, Northern, and Coastal Zones (Table 2.2 and 2.3). The differences in surface temperatures between buoys $\mathrm{A}, \mathrm{B}$, and $\mathrm{E}$ in the Coastal Zone are not statistically significant (P».05) (Table 2.6). For the GOMOOS data, the only temperature comparison significantly different from zero at the $5 \%$ level is found between Buoy M in Jordan Basin, and Buoy $\mathrm{N}$ over the Northeast Channel. Cast data shows that the warmest sea surface temperatures are found in the Western Zone 
and over Georges Bank. The difference in surface temperature is highly significant $(\mathrm{P}<.01)$ when comparing either the Western Zone or Georges Bank to any other region (Table 2.7). Greater mixing in the Western Zone and over Georges Bank may be partly responsible for the higher average surface temperatures. Although the relation between mixed layer depth and heat loss will be discussed in more detail in the following chapter, for now it should be mentioned that cooling occurs more readily when mixed layer depths are shallow and stratification in the upper water-column is strong (Deese-Riordan, 2009). It is also likely that high surface temperatures in the Western Zone and over Georges Bank are correlated with warmer air temperatures offshore that result from air mass modification by the ocean (Bunker, 1956).

Overall, analysis of surface temperature and salinity using cast and GOMOOS mooring data indicate distinct regional differences. The Coastal, Northern, and Eastern Zones are characterized by fresher and cooler conditions, while warmer, saltier conditions prevail in the Western Zone and over Georges Bank. Spatial variability in surface salinity and temperature is driven by the GOM's circulation, mixing, and inflow of both fresh SSW and river water (Mountain and Manning, 1994).

\subsubsection{Average Salinity/Temperature Difference with Depth}

Throughout the GOM, salinity increases with depth in the upper $20 \mathrm{~m}$ (Table 2.2 and Table 2.3). In the Western Zone and over Georges Bank, however, the increase in salinity in the upper water-column is less significant $(\mathrm{P}>.10)$ due to greater mixing. Mixing acts to homogenize the water-column. Both cast and GOMOOS mooring data agree that wintertime differences in salinity between 1 and $20 \mathrm{~m}$ are greatest in the Coastal and Eastern Zones (Table 2.8). Conversely, smaller changes in salinity with depth are found over Georges Bank and in the Northern and Western Zones. Inter-regional comparisons of salinity increase in the top $20 \mathrm{~m}$ are generally significant at at least the $20 \%$ level when comparing the Coastal and Eastern Zones with other 
regions. The difference between the Coastal and Eastern Zones, however, is not statistically significant $(\mathrm{P}=.71)$ with 37 degrees of freedom. Buoys $\mathrm{A}, \mathrm{B}$, and $\mathrm{E}$ in the Coastal Zone, and Buoy $\mathrm{N}$ in the Eastern Zone, agree with the cast data by displaying the greatest average increase in salinity in the upper $20 \mathrm{~m}$ (Table 2.9). Buoys I and M on the Eastern Maine Shelf and in Jordan Basin respectively, show the smallest increases in salinity with depth. In fact, the difference in salinity with depth at these moorings is not statistically different from zero at the $10 \%$ level. The difference in salinity between 1 and $20 \mathrm{~m}$ tends to decrease when moving clockwise in the Coastal Zone from Buoy A to I. The comparison of Buoys A, B, and E with Buoy I on the Eastern Maine Shelf, shows that the differences in salinity increase in the upper $20 \mathrm{~m}$ are significant at the $5 \%$ level (Table 2.9 ).

Cast and GOMOOS mooring data show that during the winter a temperature inversion is present in the Eastern Zone of the GOM (Table 2.2 and Table 2.3). The inflow of fresh, cold, and buoyant SSW over warm, salty slope water explains the pronounced temperature inversion at Buoy $\mathrm{N}$ over the Northeast Channel (Ramp et al., 1985)). SSW does not impact the temperature gradient in the upper watercolumn as strongly in other regions because it is mixed and modified by saline deep water as it circulates cyclonically around the GOM (Ji et al., 2008). For the other zones, averages from cast data indicate that temperature change in the upper $20 \mathrm{~m}$ is not significantly different from zero at the $10 \%$ level. Conversely, at GOMOOS Buoys B and E, on the Western and Central Maine Shelf respectively, a temperature inversion is present and significant at the $10 \%$ level. In addition, at all GOMOOS buoys temperature increase with depth between 1 and $50 \mathrm{~m}$ is significant at the $5 \%$ level. Although a complete temperature record is not available at $50 \mathrm{~m}$ for Buoy A, it is expected that a temperature inversion will also be found here since it is seen nearby, at Buoy B, on the Western Maine Shelf. Furthermore, since the physical processes affecting the water-column are similar throughout the Coastal Zone, it is expected 
that similar patterns in salinity and temperature will be found at all moorings in this region (Townsend, 1991).

Inter-regional comparison of average temperature change in the upper watercolumn $(0-20 \mathrm{~m})$ shows that the difference between the Eastern Zone and all other regions is statistically significant at the $20 \%$ level (Table 2.10). Although this result is not "significant" according to the usual definition $(\mathrm{P}<.05)$, it is noteable since P-values are close to 1 for all other inter-regional comparisons . Similarly, for the GOMOOS data, the difference between Buoy $\mathrm{N}$ in the Eastern Zone, and other GOMOOS buoys is significant at the $20 \%$ level (Table 2.11). The exception is the comparison of Buoys $\mathrm{N}$ and $\mathrm{B}$ where $(\mathrm{P}=.29)$ with 4 degrees of freedom.

\subsubsection{Average Stability}

Significant intcr-regional differences in water-column stability are found during the winter in the GOM. GOMOOS time-series data shows that during the winter salinity and temperature often work against each other. Increasing the salinity or decreasing the temperature increases water density, while decreasing salinity or increasing temperature decreases density. In the Coastal Zone at Buoys $\mathrm{A}, \mathrm{B}$, and $\mathrm{E}$, both temperature and salinity increase with depth. However, because the temperature gradient is typically small (Table 2.2 and Table 2.3 ), it is the salinity difference in the top $20 \mathrm{~m}$ that governs the degree of stability. Cast and GOMOOS mooring data agree that stability is greatest in the Coastal and Eastern Zones of the GOM (Table 2.12 and Table 2.13). Cast data shows that stability is the lowest over Georges Bank and in the Northern and Western Zones (Table 2.14). In fact, in the Western Zone and over Georges Bank the stability of the upper-water column (0-20m) is not significantly different from zero $(\mathrm{P}>.05)$. Greater water-column turnover in these regions breaks dowñ stratification and reduces stability (Townsend, 1991). Comparison of stability at the GOMOOS buoys shows that Buoys I and M in the Northern Zone 
and Jordan Basin have the lowest stabilities (Table 2.15). The difference in stability values for Buoys I and M compared with all other GOMOOS moorings is significant at the $10 \%$ level. GOMOOS moorings show that the areas with the greatest stability (i.e. the Coastal and Eastern Zones) are also the areas with the greatest average winter temperature inversions. Cooling of the surface layer is facilitated under conditions of high stability/stratification since mixing with deeper water is suppresed. Reduced vertical mixing causes continued cooling of the the upper-water column until an equilibrium is reached with the atmosphere (Deese-Riordan, 2009).

Since freshwater from rivers accumulates and circulates from north to south, from Buoy I to Buoy A, it is not surprising that stability values often increase southward in the Coastal Zone. From (Fig. 2-2), it is clear that Buoys A and $\mathrm{N}$ experience the greatest variability in stability. It is curious that Buoys $\mathrm{A}$ and $\mathrm{N}$ seem to be in sync with each other even though they are on separate sides of the GOM. During the winter Buoy $\mathrm{N}$ is mainly affected by fresh SSW, while Buoy A is affected by river runoff. The presence of SSW is not expected at Buoy A since it takes 2-3 months for this water mass to circulate from the eastern GOM to the southern Coastal Zone (Deese-Riordan, 2009). Since SSW does not reach the southern Coastal Zone until the end of winter, high winter stabilities cannot be attributed to the presence of this water mass. Instead, surface freshening and subsequent stratification at Buoy A is largely the result of discharge from the Merrimack River in combination with fresh input from rivers further to the north (Geyer et al., 2004). Freshening should occur earlier along the Eastern Maine Shelf than at Buoy A, east of Cape Anne. At Buoys E or I, on the Central and Eastern Maine Shelf respectively, both SSW and river discharge can affect the water-column stabilities during the winter (Deese-Riordan, 2009). Since SSW flows cyclonically around the GOM from the Scotian Shelf, to Buoy A in the Coastal Zone, it is expected that years of greater stability at Buoy N would also be seen at Buoy M in Jordan Basin. However from (Fig. 2-2), it appears greater 
stratification at Buoy $\mathrm{N}$ does not necessarily translate to Buoy $\mathrm{M}$ in Jordan Basin. For example, during the winter of 2006 high stabilities at Buoy $\mathrm{N}$ are not reflected by increased stratification at Buoy $\mathrm{M}$.

The 2006 case just described hints to complexities in winter circulation. For example, Jordan Basin is sometimes affected by cold, fresh plumes of water with SSW origin that form when the Eastern Maine Coastal Current (EMCC) separates from the coast near Penobscot Bay (Pettigrew et al., 1998). The EMCC flows from the southwestern Scotian Shelf, across the mouth of the Bay of Fundy, to the outlet of Penobscot Bay (Bisagni et al., 1996). Upon reaching the outlet of Penobscot Bay, part of the EMCC continues down the Maine coast to Cape Cod as the Western Maine Coastal Current (WMCC), while the remainder of the EMCC diverges from the coast and circulates cyclonically around Jordan Basin (Brooks, 1985) (Fig. 1-4). The exact divergence point of the EMCC and the volume of freshwater transported offshore is variable (Pettigrew et al., 1998). Although a detailed investigation of the circulation around Jordan Basin is beyond the scope of this study, it is clear that patterns in stratification in one area are not necessarily true of another. A variety of factors including interannual variability of SSW inflow, river discharge, patterns in local circulation, tidal mixing, air temperatures, and wind-induced mixing all affect the stability of the water-column (Townsend, 1991). Spatial and temporal patterns in stratification as well as the roles of salinity, temperature, and wind stress in affecting the density structure of the upper water-column will be explored in the following chapter. 


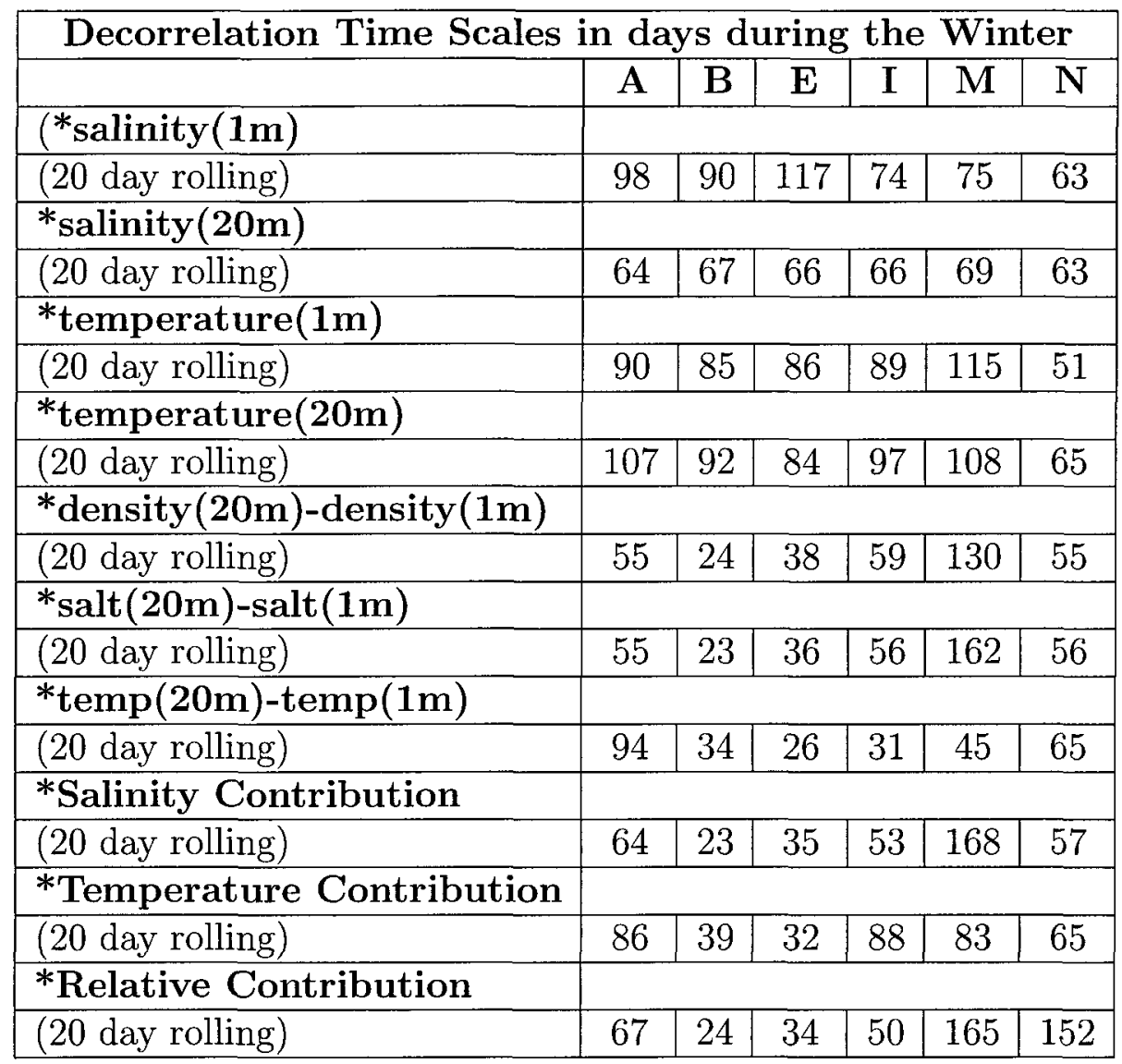

Table 2.1: Wintertime decorrelation times are calculated in days. Fields marked by an asterisk indicate that the decorrelation time is based on an anomaly from average difference. The anomaly from average difference is used to de-trend the time-series by removing the climatological average. Calculations of decorrelation times using a 4 day rolling average are nearly the same as those found using a 20 day rolling average. 


\begin{tabular}{|l|c|c|c|c|c|c|}
\hline \multicolumn{7}{|c|}{ Wintertime Salinity and Temperature Change with Depth } \\
\multicolumn{7}{|c|}{ at GOMOOS Buoys } \\
\hline & A & B & E & I & M & N \\
\hline & 32.11 & 32.50 & 32.56 & 32.53 & 32.57 & 31.72 \\
& \pm .18 & \pm .16 & \pm .13 & \pm .094 & \pm .16 & \pm .051 \\
\hline \multirow{2}{*}{ salinity(1m) } & $0.3009^{*}$ & $0.1693^{* *}$ & $0.1210^{* *}$ & $0.0456^{* *}$ & $.0609^{* *}$ & $.3501^{*}$ \\
& \pm .066 & \pm .010 & \pm .013 & \pm .0046 & \pm .024 & \pm .094 \\
\hline \multirow{2}{*}{ sal(20m)-sal(1m) } & & $.3606^{* *}$ & $.2314^{* *}$ & $.0945^{* *}$ & $.1887^{* *}$ & $.7214^{* *}$ \\
& & \pm .030 & \pm .026 & \pm .0091 & \pm .034 & \pm .048 \\
\hline \multirow{2}{*}{ sal(50m)-sal(1m) } & 4.139 & 4.125 & 4.176 & 4.199 & 4.600 & 3.533 \\
& \pm .30 & \pm .28 & \pm .27 & \pm .25 & \pm .28 & \pm .19 \\
\hline \multirow{2}{*}{ temperature(1m) } & .1045 & $.0938^{*}$ & $.1094^{* *}$ & .0186 & .0586 & $.6163^{*}$ \\
& \pm .0758 & \pm .026 & \pm .015 & \pm .006 & \pm .033 & \pm .250 \\
\hline \multirow{2}{*}{ temp(20m)-temp(1m) } & & $.5541^{* *}$ & $.3850^{* *}$ & $.0983^{*}$ & $.3395^{* *}$ & $1.328^{* *}$ \\
& & \pm .081 & \pm .041 & \pm .025 & \pm .064 & \pm .21 \\
\hline \multirow{2}{*}{ temp(50m)-temp(1m) } & & & & &
\end{tabular}

Table 2.2: The salinity and temperature difference between $1 \mathrm{~m}$ and $20 \mathrm{~m}$, or $1 \mathrm{~m}$ and $50 \mathrm{~m}$, is found by subtracting the 20 day rolling averages of salinity/temperature at $1 \mathrm{~m}$ from the 20 day rolling averages of salinity/temperature at $20 \mathrm{~m} / 50 \mathrm{~m}$. All differences are averaged by year. Yearly averages of differences are then averaged and \pm 1 standard error is found from the yearly averages and appropriate decorrelation time. Salinity and temperature units are given in PSU and ${ }^{\circ} \mathrm{C}$, respectively. "**" indicates significance at $10 \%$ level and " **" indicates significance at the $5 \%$ level. 


\begin{tabular}{|l|c|c|c|c|c|}
\hline \multicolumn{7}{|c|}{ Salinity, Temperature, and Potential Density Change for Casts } \\
during the Winter \\
\hline & Coast & West & East & North & G. Bank \\
\hline \multirow{2}{*}{ salinity(1m) } & 32.29 & 32.80 & 32.15 & 32.12 & 32.76 \\
& \pm .13 & \pm .102 & \pm .138 & \pm .112 & \pm .089 \\
\hline \multirow{2}{*}{ salinity(20m)-salinity(1m) } & $.1273^{* *}$ & .0186 & $.0972^{* *}$ & $.0289^{* *}$ & .0058 \\
& \pm .071 & \pm .016 & \pm .042 & \pm .012 & \pm .006 \\
\hline \multirow{2}{*}{ temperature(1m) } & 4.094 & 5.640 & 4.092 & 3.486 & 5.466 \\
& \pm .0 .22 & \pm 0.243 & \pm .321 & \pm .368 & \pm .253 \\
\hline \multirow{2}{*}{ temp(20m)-temp(1m) } & -.0100 & -.0035 & $.1532^{*}$ & .0125 & .0025 \\
& \pm .062 & \pm .027 & \pm .096 & \pm .031 & \pm .0066 \\
\hline \multirow{2}{*}{$\sigma_{\theta}(\mathbf{2 0 m})-\sigma_{\theta}(\mathbf{1 m})$} & $.1025^{* *}$ & $.0152^{*}$ & $.0615^{* *}$ & $.0218^{* *}$ & .0044 \\
& \pm .057 & \pm .012 & \pm .025 & \pm .008 & \pm .009 \\
\hline
\end{tabular}

Table 2.3: The salinity, temperature, and potential density difference between different depths is found by looking at differences within particular casts. Differences are averaged by zone. Salinity and temperature units are given in PSU and ${ }^{\circ} \mathrm{C}$, respectively. Standard error $( \pm 1)$ is found by averaging all casts within a particular zone and dividing by the number of years with data. Seasonal decorrelation times are assumed and provide an upper-estimate on error. "**" indicates significance at $10 \%$ level and "**" indicates significance at the $5 \%$ level. 


\begin{tabular}{|c|c|c|c|c|c|}
\hline \multicolumn{6}{|c|}{ Comparison of Wintertime Salinity at $1 \mathrm{~m}$ between GOMOOS Buoys } \\
\hline & $\mathrm{B}$ & $\mathbf{E}$ & $\mathbf{I}$ & $\mathrm{M}$ & $\mathbf{N}$ \\
\hline $\mathbf{A}$ & $\begin{array}{c}(\mathrm{B}-\mathrm{A})= \\
0.273 \pm .042 \\
\mathrm{p}=.15 \\
\mathrm{df}=15\end{array}$ & $\begin{array}{c}(\mathrm{E}-\mathrm{A})= \\
0.450 \pm .069 \\
\mathrm{p}=.06 \\
\mathrm{df}=16\end{array}$ & $\begin{array}{c}(\mathrm{I}-\mathrm{A})= \\
0.418 \pm .11 \\
\mathrm{p}=.06 \\
\mathrm{df}=16\end{array}$ & $\begin{array}{c}(\mathrm{M}-\mathrm{A})= \\
0.613 \pm .12 \\
\mathrm{p}=.09 \\
\mathrm{df}=14\end{array}$ & $\begin{array}{c}(\mathrm{A}-\mathrm{N})= \\
0.1211 \pm .23 \\
\mathrm{p}=.11 \\
\mathrm{df}=13\end{array}$ \\
\hline B & & $\begin{array}{c}(\mathrm{E}-\mathrm{B})= \\
0.126 \pm .03 \\
\mathrm{p}=.57 \\
\mathrm{df}=14\end{array}$ & $\begin{array}{c}(\mathrm{I}-\mathrm{B})= \\
0.081 \pm .089 \\
\mathrm{p}=.55 \\
\mathrm{df}=15\end{array}$ & $\begin{array}{c}(\mathrm{M}-\mathrm{B})= \\
0.290 \pm .13 \\
\mathrm{p}=.41 \\
\mathrm{df}=13\end{array}$ & $\begin{array}{c}(\mathrm{B}-\mathrm{N})= \\
0.549 \pm .25 \\
\mathrm{p}=.004 \\
\mathrm{df}=11\end{array}$ \\
\hline $\mathbf{E}$ & & & $\begin{array}{c}(\mathrm{E}-\mathrm{I})= \\
0.0357 \pm .063 \\
\mathrm{p}=.83 \\
\mathrm{df}=16\end{array}$ & $\begin{array}{c}(\mathrm{M}-\mathrm{E})= \\
0.120 \pm .10 \\
\mathrm{p}=.99 \\
\mathrm{df}=14\end{array}$ & $\begin{array}{c}(\mathrm{E}-\mathrm{N})= \\
0.641 \pm .19 \\
\mathrm{p}<.001 \\
\mathrm{df}=13\end{array}$ \\
\hline $\mathbf{I}$ & & & & $\begin{array}{c}(\mathrm{M}-\mathrm{I})= \\
0.071 \pm .081 \\
\mathrm{p}=.83 \\
\mathrm{df}=14\end{array}$ & $\begin{array}{c}(\mathrm{I}-\mathrm{N})= \\
0.708 \pm .17 \\
\mathrm{p}=<.001 \\
\mathrm{df}=13\end{array}$ \\
\hline M & & & & & $\begin{array}{c}(\mathrm{M}-\mathrm{N})= \\
0.810 \pm .24 \\
\mathrm{p}<.001 \\
\mathrm{df}=11\end{array}$ \\
\hline
\end{tabular}

Table 2.4: The method used to compare average wintertime salinity values at $1 \mathrm{~m}$ between GOMOOS buoys is described in section 2.2.5. Results are considered significant for $\mathrm{p}<.05$. 


\begin{tabular}{|c|c|c|c|c|}
\hline \multicolumn{5}{|c|}{ Comparison of Wintertime Salinity at 1m between Zones } \\
\hline & West & East & North & G. Bank \\
\hline \multirow{4}{*}{ Coast } & $(\mathrm{W}-\mathrm{C})=$ & $(\mathrm{C}-\mathrm{E})=$ & $(\mathrm{C}-\mathrm{N})=$ & $(\mathrm{GB}-\mathrm{C})=$ \\
& $.5088 \pm .165$ & $0.1353 \pm .189$ & $0.1706 \pm .171$ & $.4733 \pm .158$ \\
& $\mathrm{p}=0.004$ & $\mathrm{p}=.48$ & $\mathrm{p}=.33$ & $\mathrm{p}=.005$ \\
& $\mathrm{df}=37.98$ & $\mathrm{df}=42.28$ & $\mathrm{df}=37.81$ & $\mathrm{df}=35.81$ \\
\hline \multirow{4}{*}{ West } & & $(\mathrm{W}-\mathrm{E})=$ & $(\mathrm{W}-\mathrm{N})=$ & $(\mathrm{W}-\mathrm{GB})=$ \\
& & $0.6441 \pm .171$ & $.6794 \pm .152$ & $.0356 \pm .136$ \\
& & $\mathrm{p}<.001$ & $\mathrm{p}<.001$ & $\mathrm{p}=.80$ \\
& & $\mathrm{df}=34.24$ & $\mathrm{df}=29.72$ & $\mathrm{df}=27.92$ \\
\hline \multirow{4}{*}{ East } & & & $(\mathrm{E}-\mathrm{N})=$ & $(\mathrm{GB}-\mathrm{E})=$ \\
& & & $0.0353 \pm .178$ & $0.6085 \pm .164$ \\
& & & $\mathrm{p}=.85$ & $\mathrm{p}<.001$ \\
& & & $\mathrm{df}=34.89$ & $\mathrm{df}=31.81$ \\
\hline \multirow{3}{*}{ North } & & & & $(\mathrm{GB}-\mathrm{N})=$ \\
& & & & $.6438 \pm .144$ \\
& & & & $\mathrm{p}<.001$ \\
& & & & $\mathrm{df}=27.40$ \\
\hline
\end{tabular}

Table 2.5: The method used to compare average wintertime salinity values at $1 \mathrm{~m}$ between zones in the GOM is described in section 2.2.5. Results are considered significant for $\mathrm{p}<.05$. 


\begin{tabular}{|c|c|c|c|c|c|}
\hline \multicolumn{6}{|c|}{ Comparison of Wintertime Temperature at $1 \mathrm{~m}^{\circ}$ between GOMOOS Buoys } \\
\hline & $\mathbf{B}$ & $\mathbf{E}$ & $\mathbf{I}$ & $\mathbf{M}$ & $\mathbf{N}$ \\
\hline $\mathbf{A}$ & $\begin{array}{c}(\mathrm{B}-\mathrm{A})= \\
0.0975 \pm .085 \\
\mathrm{p}=.88 \\
\mathrm{df}=15\end{array}$ & $\begin{array}{c}(\mathrm{E}-\mathrm{A})= \\
0.0950 \pm .11 \\
\mathrm{p}=.77 \\
\mathrm{df}=16\end{array}$ & $\begin{array}{c}(\mathrm{I}-\mathrm{A})= \\
0.0260 \pm .078 \\
\mathrm{p}=.91 \\
\mathrm{df}=16\end{array}$ & $\begin{array}{c}(\mathrm{M}-\mathrm{A})= \\
0.643 \pm .15 \\
\mathrm{p}=.20 \\
\mathrm{df}=14\end{array}$ & $\begin{array}{c}(\mathrm{A}-\mathrm{N})= \\
0.561 \pm .29 \\
\mathrm{p}=.18 \\
\mathrm{df}=13\end{array}$ \\
\hline B & & $\begin{array}{c}(\mathrm{E}-\mathrm{B})= \\
0.0296 \pm .10 \\
\mathrm{p}=.94 \\
\mathrm{df}=14\end{array}$ & $\begin{array}{c}(\mathrm{B}-\mathrm{I})= \\
0.0846 \pm .11 \\
\mathrm{p}=.75 \\
\mathrm{df}=15\end{array}$ & $\begin{array}{c}(\mathrm{M}-\mathrm{B})= \\
0.624 \pm .15 \\
\mathrm{p}=.30 \\
\mathrm{df}=13\end{array}$ & $\begin{array}{c}(\mathrm{B}-\mathrm{N})= \\
0.658 \pm .41 \\
\mathrm{p}=.12 \\
\mathrm{df}=11\end{array}$ \\
\hline $\mathbf{E}$ & & & $\begin{array}{c}(\mathrm{E}-\mathrm{I})= \\
0.0644 \pm .15 \\
\mathrm{p}=.84 \\
\mathrm{df}=16\end{array}$ & $\begin{array}{c}(\mathrm{M}-\mathrm{E})= \\
0.623 \pm .17 \\
\mathrm{p}=.30 \\
\mathrm{df}=14\end{array}$ & $\begin{array}{c}(\mathrm{E}-\mathrm{N})= \\
0.498 \pm .33 \\
\mathrm{p}=.10 \\
\mathrm{df}=13\end{array}$ \\
\hline $\mathbf{I}$ & & & & $\begin{array}{c}(\mathrm{M}-\mathrm{I})= \\
0.546 \pm .19 \\
\mathrm{p}=.19 \\
\mathrm{df}=14\end{array}$ & $\begin{array}{c}(\mathrm{I}-\mathrm{N})= \\
0.630 \pm .21 \\
\mathrm{p}=.11 \\
\mathrm{df}=13\end{array}$ \\
\hline M & & & & & $\begin{array}{c}(\mathrm{M}-\mathrm{N})= \\
1.20 \pm .34 \\
\mathrm{p}=.01 \\
\mathrm{df}=11\end{array}$ \\
\hline
\end{tabular}

Table 2.6: The method used to compare average wintertime temperature values at $1 \mathrm{~m}$ between zones in the GOM is described in section 2.2.5. Results are considered significant for $\mathrm{p}<.05$. 


\begin{tabular}{|c|c|c|c|c|}
\hline \multicolumn{5}{|c|}{ Comparison of Wintertime Temperature at 1m between Zones } \\
\hline & West & East & North & G. Bank \\
\hline \multirow{4}{*}{ Coast } & $(\mathrm{W}-\mathrm{C})=$ & $(\mathrm{C}-\mathrm{E})=$ & $(\mathrm{C}-\mathrm{N})=$ & $(\mathrm{GB}-\mathrm{C})=$ \\
& $1.546 \pm .325$ & $0.0025 \pm .387$ & $0.6089 \pm .427$ & $1.371 \pm .333$ \\
& $\mathrm{p}<.001$ & $\mathrm{p}=.99$ & $\mathrm{p}=.17$ & $\mathrm{p}<.001$ \\
& $\mathrm{df}=34.21$ & $\mathrm{df}=35.87$ & $\mathrm{df}=25.20$ & $\mathrm{df}=29.90$ \\
\hline \multirow{4}{*}{ West } & & $(\mathrm{W}-\mathrm{E})=$ & $(\mathrm{W}-\mathrm{N})=$ & $(\mathrm{W}-\mathrm{GB})=$ \\
& & $1.548 \pm .403$ & $2.155 \pm .441$ & $0.1745 \pm .351$ \\
& & $\mathrm{p}<.001$ & $\mathrm{p}<.001$ & $\mathrm{p}=.62$ \\
& & $\mathrm{df}=34.42$ & $\mathrm{df}=25.98$ & $\mathrm{df}=27.64$ \\
\hline \multirow{3}{*}{ East } & & & $(\mathrm{E}-\mathrm{N})=$ & $(\mathrm{GB}-\mathrm{E})=$ \\
& & & $0.6065 \pm .488$ & $1.374 \pm .409$ \\
& & & $\mathrm{p}=.22$ & $\mathrm{p}=.002$ \\
& & & $\mathrm{df}=32.42$ & $\mathrm{df}=32.99$ \\
\hline \multirow{3}{*}{ North } & & & & $(\mathrm{GB}-\mathrm{N})=$ \\
& & & & $1.980 \pm .447$ \\
& & & & $\mathrm{p}<.001$ \\
& & & & $\mathrm{df}=25.88$ \\
\hline
\end{tabular}

Table 2.7: The method used to compare average wintertime temperature values at $1 \mathrm{~m}$ between zones in the GOM is described in section 2.2.5. Results are considered significant for $\mathrm{p}<.05$. 


\begin{tabular}{|c|c|c|c|c|}
\hline \multicolumn{5}{|c|}{$\begin{array}{c}\text { Comparison of Wintertime Salinity Difference (20m-1m) } \\
\text { betwen Zones }\end{array}$} \\
\hline & West & East & North & G. Bank \\
\hline Coast & $\begin{array}{c}(\mathrm{C}-\mathrm{W})= \\
0.1088 \pm .072 \\
\mathrm{p}=0.1458 \\
\mathrm{df}=25.2264\end{array}$ & $\begin{array}{c}(\mathrm{C}-\mathrm{E})= \\
0.0301 \pm .082 \\
\mathrm{p}=.7171 \\
\mathrm{df}=36.9936\end{array}$ & $\begin{array}{c}(\mathrm{C}-\mathrm{N})= \\
0.0984 \pm .072 \\
\mathrm{p}=.1823 \\
\mathrm{df}=24.2360\end{array}$ & $\begin{array}{c}(\mathrm{C}-\mathrm{GB})= \\
.1215 \pm .072 \\
\mathrm{p}=.1026 \\
\mathrm{df}=24.1707\end{array}$ \\
\hline West & & $\begin{array}{c}(\mathrm{E}-\mathrm{W})= \\
0.0787 \pm .045 \\
\mathrm{p}=.0941 \\
\mathrm{df}=25.2291\end{array}$ & $\begin{array}{c}(\mathrm{N}-\mathrm{W})= \\
0.0104 \pm .019 \\
\mathrm{p}=.6020 \\
\mathrm{df}=27.6735\end{array}$ & $\begin{array}{c}(\mathrm{W}-\mathrm{GB})= \\
0.0128 \pm .0194 \\
\mathrm{p}=.5139 \\
\mathrm{df}=26.4438\end{array}$ \\
\hline East & & & $\begin{array}{c}(\mathrm{E}-\mathrm{N})= \\
0.0683 \pm .0439 \\
\mathrm{p}=0.1342 \\
\mathrm{df}=22.9591\end{array}$ & $\begin{array}{c}(\mathrm{E}-\mathrm{GB})= \\
0.0914 \pm .0438 \\
\mathrm{p}=.0489 \\
\mathrm{df}=22.7903\end{array}$ \\
\hline North & & & & $\begin{array}{c}(\mathrm{N}-\mathrm{GB})= \\
0.0231 \pm .0162 \\
\mathrm{p}=0.1662 \\
\mathrm{df}=27.9415\end{array}$ \\
\hline
\end{tabular}

Table 2.8: The method used to compare average wintertime salinity difference between 1 and $20 \mathrm{~m}$ between zones in the GOM is described in section 2.2.5. Results are considered significant for $\mathrm{p}<.05$. 


\begin{tabular}{|c|c|c|c|c|c|}
\hline \multicolumn{6}{|c|}{$\begin{array}{c}\text { Comparison of Wintertime Salinity Difference (20m-1m) } \\
\text { between GOMOOS Buoys }\end{array}$} \\
\hline & B & $\mathrm{E}$ & $I$ & $\mathbf{M}$ & $\mathbf{N}$ \\
\hline $\mathbf{A}$ & $\begin{array}{c}(\mathrm{A}-\mathrm{B})= \\
0.1275 \pm .068 \\
\mathrm{p}=0.27 \\
\mathrm{df}=5.40\end{array}$ & $\begin{array}{c}(\mathrm{A}-\mathrm{E})= \\
0.2065 \pm .067 \\
\mathrm{p}=0.07 \\
\mathrm{df}=6.64\end{array}$ & $\begin{array}{c}(\mathrm{A}-\mathrm{I})= \\
0.2821 \pm .066 \\
\mathrm{p}=0.02 \\
\mathrm{df}=6.05\end{array}$ & $\begin{array}{c}(\mathrm{A}-\mathrm{M})= \\
0.2666 \pm .068 \\
\mathrm{p}=0.03 \\
\mathrm{df}=6.79\end{array}$ & $\begin{array}{c}(\mathrm{N}-\mathrm{A})= \\
0.0613 \pm .14 \\
\mathrm{p}=0.88 \\
\mathrm{df}=9.82\end{array}$ \\
\hline B & & $\begin{array}{c}(\mathrm{B}-\mathrm{E})= \\
0.0458 \pm .015 \\
\mathrm{p}=0.19 \\
\mathrm{df}=9.65\end{array}$ & $\begin{array}{c}(\mathrm{B}-\mathrm{I})= \\
0.1234 \pm .011 \\
\mathrm{p}=0.001 \\
\mathrm{df}=6.09\end{array}$ & $\begin{array}{c}(\mathrm{B}-\mathrm{M})= \\
0.1034 \pm .021 \\
\mathrm{p}=0.014 \\
\mathrm{df}=9.29\end{array}$ & $\begin{array}{c}(\mathrm{N}-\mathrm{B})= \\
0.1560 \pm .12 \\
\mathrm{p}=0.33 \\
\mathrm{df}=4.16\end{array}$ \\
\hline $\mathbf{E}$ & & & $\begin{array}{c}(\mathrm{E}-\mathrm{I})= \\
0.0754 \pm .014 \\
\mathrm{p}=0.011 \\
\mathrm{df}=6.90\end{array}$ & $\begin{array}{c}(\mathrm{E}-\mathrm{M})= \\
0.0602 \pm .023 \\
\mathrm{p}=0.083 \\
\mathrm{df}=11.86\end{array}$ & $\begin{array}{c}(\mathrm{N}-\mathrm{E})= \\
0.2356 \pm .12 \\
\mathrm{p}=0.114 \\
\mathrm{df}=5.32\end{array}$ \\
\hline I & & & & $\begin{array}{c}(\mathrm{M}-\mathrm{I})= \\
0.0159 \pm .019 \\
\mathrm{p}=0.55 \\
\mathrm{df}=6.72\end{array}$ & $\begin{array}{c}(\mathrm{N}-\mathrm{I})= \\
0.3107 \pm .094 \\
p=0.051 \\
d f=5.03\end{array}$ \\
\hline $\mathbf{M}$ & & & & & $\begin{array}{c}(\mathrm{N}-\mathrm{M})= \\
0.3094 \pm .12 \\
\mathrm{p}=0.0598 \\
\mathrm{df}=5.39\end{array}$ \\
\hline
\end{tabular}

Table 2.9: The method used to compare average wintertime salinity difference between 1 and $20 \mathrm{~m}$ between zones in the GOM is described in section 2.2.5. Results are considered significant for $\mathrm{p}<.05$. 


\begin{tabular}{|c|c|c|c|c|}
\multicolumn{6}{|c|}{ Comparison of Wintertime Temperature Difference (20m-1m) } \\
between Zones \\
\hline & West & East & North & G. Bank \\
\hline \multirow{4}{*}{ Coast } & $(\mathrm{W}-\mathrm{C})=$ & $(\mathrm{E}-\mathrm{C})=$ & $(\mathrm{N}-\mathrm{C})=$ & $(\mathrm{GB}-\mathrm{C})=$ \\
& $0.0065 \pm .067$ & $0.1632 \pm .114$ & $0.0225 \pm .069$ & $.0124 \pm .062$ \\
& $\mathrm{p}=.92$ & $\mathrm{p}=.16$ & $\mathrm{p}=.75$ & $\mathrm{p}=.84$ \\
& $\mathrm{df}=30.99$ & $\mathrm{df}=34.88$ & $\mathrm{df}=32.68$ & $\mathrm{df}=23.52$ \\
\hline \multirow{4}{*}{ West } & & $(\mathrm{E}-\mathrm{W})=$ & $(\mathrm{N}-\mathrm{W})=$ & $(\mathrm{GB}-\mathrm{W})=$ \\
& & $0.1567 \pm .099$ & $0.0160 \pm .041$ & $0.0059 \pm .028$ \\
& & $\mathrm{p}=.13$ & $\mathrm{p}=.70$ & $\mathrm{p}=.83$ \\
& & $\mathrm{df}=23.16$ & $\mathrm{df}=29.58$ & $\mathrm{df}=16.75$ \\
\hline \multirow{4}{*}{ East } & & & $(\mathrm{E}-\mathrm{N})=$ & $(\mathrm{E}-\mathrm{GB})=$ \\
& & & $0.1407 \pm .100$ & $0.1507 \pm .096$ \\
& & & $\mathrm{p}=.17$ & $\mathrm{p}=.13$ \\
& & & $\mathrm{df}=23.98$ & $\mathrm{df}=20.19$ \\
\hline \multirow{4}{*}{ North } & & & & $(\mathrm{N}-\mathrm{GB})=$ \\
& & & & $0.0100 \pm .0313$ \\
& & & & $\mathrm{p}=.75$ \\
& & & & $\mathrm{df}=16.38$ \\
\hline
\end{tabular}

Table 2.10: The method used to compare average wintertime temperature difference between 1 and $20 \mathrm{~m}$ between zones in the GOM is described in section 2.2.5. Results are considered significant for $\mathrm{p}<.05$. 


\begin{tabular}{|c|c|c|c|c|c|}
\hline & \multicolumn{5}{|c|}{$\begin{array}{c}\text { Comparison of Wintertime Temperature Difference (20m-1m) } \\
\text { between GOMOOS Buoys }\end{array}$} \\
\hline & $\mathbf{B}$ & $\mathbf{E}$ & I & $\mathbf{M}$ & $\mathbf{N}$ \\
\hline $\mathbf{A}$ & $\begin{array}{c}(\mathrm{A}-\mathrm{B})= \\
0.0777 \pm .086 \\
\mathrm{p}=0.43 \\
\mathrm{df}=7.33\end{array}$ & $\begin{array}{c}(\mathrm{A}-\mathrm{E})= \\
0.0162 \pm .078 \\
\mathrm{p}=0.86 \\
\mathrm{df}=7.24\end{array}$ & $\begin{array}{c}(\mathrm{A}-\mathrm{I})= \\
0.1066 \pm .076 \\
\mathrm{p}=0.25 \\
\mathrm{df}=6.17\end{array}$ & $\begin{array}{c}(\mathrm{A}-\mathrm{M})= \\
0.0670 \pm .081 \\
\mathrm{p}=0.50 \\
\mathrm{df}=9.38\end{array}$ & $\begin{array}{c}(\mathrm{N}-\mathrm{A})= \\
0.4182 \pm .22 \\
\mathrm{p}=0.16 \\
\mathrm{df}=5.84\end{array}$ \\
\hline B & & $\begin{array}{c}(\mathrm{E}-\mathrm{B})= \\
0.0218 \pm .031 \\
\mathrm{p}=0.68 \\
\mathrm{df}=9.30\end{array}$ & $\begin{array}{c}(\mathrm{B}-\mathrm{I})= \\
0.0717 \pm .026 \\
\mathrm{p}=0.15 \\
\mathrm{df}=5.75\end{array}$ & $\begin{array}{c}(\mathrm{B}-\mathrm{M})= \\
0.0296 \pm .037 \\
\mathrm{p}=0.68 \\
\mathrm{df}=9.31\end{array}$ & $\begin{array}{c}(\mathrm{N}-\mathrm{B})= \\
0.3505 \pm .21 \\
\mathrm{p}=0.29 \\
\mathrm{df}=4.16\end{array}$ \\
\hline $\mathbf{E}$ & & & $\begin{array}{c}(\mathrm{E}-\mathrm{I})= \\
0.0906 \pm .016 \\
\mathrm{p}=0.01 \\
\mathrm{df}=7.66\end{array}$ & $\begin{array}{c}(\mathrm{E}-\mathrm{M})= \\
0.0508 \pm .031 \\
\mathrm{p}=0.37 \\
\mathrm{df}=9.65\end{array}$ & $\begin{array}{c}(\mathrm{N}-\mathrm{E})= \\
0.4946 \pm .21 \\
\mathrm{p}=0.14 \\
\mathrm{df}=5.09\end{array}$ \\
\hline I & & & & $\begin{array}{c}(\mathrm{M}-\mathrm{I})= \\
0.0415 \pm .028 \\
\mathrm{p}=0.43 \\
\mathrm{df}=6.57\end{array}$ & $\begin{array}{c}(\mathrm{N}-\mathrm{I})= \\
0.5919 \pm .21 \\
\mathrm{p}=0.09 \\
\mathrm{df}=5.01\end{array}$ \\
\hline $\mathbf{M}$ & & & & & $\begin{array}{c}(\mathrm{N}-\mathrm{M})= \\
0.5939 \pm .21 \\
\mathrm{p}=0.11 \\
\mathrm{df}=5.26\end{array}$ \\
\hline
\end{tabular}

Table 2.11: The method used to compare average wintertime temperature difference between 1 and $20 \mathrm{~m}$ between GOMOOS buoys is described in section 2.2.5. Results are considered significant for $\mathrm{p}<.05$. 


\begin{tabular}{|c|c|c|c|c|c|c|}
\hline \multicolumn{6}{|c|}{ Density Change with Depth at GOMOOS Buoys during the Winter } \\
\hline & \multicolumn{3}{|c|}{ Coast } & North & \multicolumn{2}{c|}{ East } \\
\hline & A & B & E & I & M & N \\
\hline \multirow{2}{*}{$\sigma_{\theta}(\mathbf{5 0 m})-\sigma_{\theta}(\mathbf{1 m})$} & & $0.2283^{* *}$ & $0.1449^{* *}$ & $0.0646^{* *}$ & $0.1151^{* *}$ & $0.4342^{* *}$ \\
& & \pm .035 & \pm .026 & \pm .0069 & \pm .018 & \pm .023 \\
\hline \multirow{2}{*}{$\sigma_{\theta}(\mathbf{2 0 m})-\sigma_{\theta}(\mathbf{1 m})$} & $0.229^{* *}$ & $0.1250^{* *}$ & $0.0853^{* *}$ & $0.0342^{* *}$ & $0.0431^{* *}$ & $0.2095^{* *}$ \\
& \pm .063 & \pm .014 & \pm .015 & \pm .0045 & \pm .016 & \pm .070 \\
\hline \multirow{2}{*}{$\left.\mathbf{d} \sigma_{\theta} / \mathbf{d z} \mathbf{( k g} / \mathbf{m}^{4}\right)$} & $0.0121^{* *}$ & $0.0066^{* *}$ & $0.0045^{* *}$ & $0.0018^{* *}$ & $0.0023^{* *}$ & $0.0110^{* *}$ \\
& \pm .0026 & $\pm 4.0 e^{-4}$ & $\pm 5.0 e^{-4}$ & $\pm 2.0 e^{-4}$ & $\pm 8.0 e^{-4}$ & $\pm 3.0 e^{-3}$ \\
\hline
\end{tabular}

Table 2.12: The potential density difference between $1 \mathrm{~m}$ and $20 \mathrm{~m} / 50 \mathrm{~m}$, is found by subtracting the 20 day rolling averages of potential density at $1 \mathrm{~m}$ from the 20 day rolling averages of potential density at $20 \mathrm{~m} / 50 \mathrm{~m}$. All differences are averaged by year. Yearly averages of differences are then averaged and \pm 1 standard error is found using yearly averages in combination with calculated decorrelation times for the the anomaly from average density difference between 1 and $20 \mathrm{~m}$ (Table 2.1. Stability is represented by $\mathrm{d} \sigma_{\theta} / \mathrm{dz}$, and is calculated between 1 and $20 \mathrm{~m}$. At Buoy A not enough data are available to calculate the average difference of density $(1-50 \mathrm{~m})$. "**" indicates significance at $10 \%$ level and "**" indicates significance at the $5 \%$ level. 


\begin{tabular}{|c|c|c|c|c|c|}
\hline \multicolumn{6}{|c|}{ Regional Wintertime Stabilities } \\
\hline & Coast & West & East & North & G. Bank \\
\hline \multirow{2}{*}{ stability $\left(\mathrm{d} \sigma_{\theta} / \mathrm{dz}\right)$} & $.0056^{* *}$ & $8.0 e^{-4 *}$ & $.0035^{* *}$ & $.0012^{* *}$ & $2.0 e^{-4}$ \\
& \pm .003 & $\pm 6.0 e^{-4}$ & \pm .0014 & $\pm 5.0 e^{-4}$ & $\pm 5.0 e^{-4}$ \\
\hline
\end{tabular}

Table 2.13: Stability is calculated as the potential density difference between the surface and $20 \mathrm{~m}$ divided by the change in depth. Stability is given in $\mathrm{kg} / \mathrm{m}^{4}$. Wintertime stability values are averaged by zone over all years. Standard error $( \pm 1)$ is found by taking the standard deviation of all casts within a particular zone and dividing by the square root number of years with data. Seasonal decorrelation times are assumed and provide an upper-estimate on error. "*" indicates significance at $10 \%$ level and .***" indicates significance at the $5 \%$ level. 


\begin{tabular}{|c|c|c|c|c|}
\hline \multicolumn{5}{|c|}{ Comparison of Wintertime Stability Values between Zones } \\
\hline & West & East & North & G. Bank \\
\hline \multirow{4}{*}{ Coast } & $(\mathrm{C}-\mathrm{W})=$ & $(\mathrm{C}-\mathrm{E})=$ & $(\mathrm{C}-\mathrm{N})=$ & $(\mathrm{C}-\mathrm{GB})=$ \\
& $.0047 \pm .003$ & $0.0021 \pm .003$ & $0.0044 \pm .003$ & $.0054 \pm .003$ \\
& $\mathrm{p}=.13$ & $\mathrm{p}=.53$ & $\mathrm{p}=.16$ & $\mathrm{p}=.09$ \\
& $\mathrm{df}=24.86$ & $\mathrm{df}=32.83$ & $\mathrm{df}=24.06$ & $\mathrm{df}=24.19$ \\
\hline \multirow{3}{*}{ West } & & $(\mathrm{E}-\mathrm{W})=$ & $(\mathrm{N}-\mathrm{W})=$ & $(\mathrm{W}-\mathrm{GB})=$ \\
& & $0.0026 \pm .0016$ & $3.0 e^{-4} \pm 8.0 e^{-4}$ & $6.0 e^{-4} \pm 8.0 e^{-4}$ \\
& & $\mathrm{p}=.10$ & $\mathrm{p}=.60$ & $\mathrm{p}=.44$ \\
& & $\mathrm{df}=26.63$ & $\mathrm{df}=27.87$ & $\mathrm{df}=27.38$ \\
\hline \multirow{5}{*}{ East } & & & $(\mathrm{E}-\mathrm{N})=$ & $(\mathrm{E}-\mathrm{GB})=$ \\
& & & $0.0023 \pm .0015$ & $0.0032 \pm .0015$ \\
& & & $\mathrm{p}=.14$ & $\mathrm{p}=.04$ \\
& & & $\mathrm{df}=23.92$ & $\mathrm{df}=24.32$ \\
\hline \multirow{5}{*}{ North } & & & & $(\mathrm{N}-\mathrm{GB})=$ \\
& & & & $9.0 e^{-4} \pm 7.0 e^{-4}$ \\
& & & & $\mathrm{p}=.14$ \\
& & & & $\mathrm{df}=27.53$ \\
\hline
\end{tabular}

Table 2.14: The method used to compare average wintertime stability values between zones in the GOM is described in section 2.2.5. Results are considered significant for $\mathrm{p}<.05$. 


\begin{tabular}{|c|c|c|c|c|c|}
\hline \multicolumn{6}{|c|}{$\begin{array}{c}\text { Comparison of Wintertime Stability Values } \\
\text { between GOMOOS Buoys }\end{array}$} \\
\hline & $\mathbf{B}$ & $\mathbf{E}$ & I & $\mathbf{M}$ & $\mathbf{N}$ \\
\hline $\mathbf{A}$ & $\begin{array}{c}(\mathrm{A}-\mathrm{B})= \\
.0050 \pm .0026 \\
\mathrm{p}=0.26 \\
\mathrm{df}=5.34\end{array}$ & $\begin{array}{c}(\mathrm{A}-\mathrm{E})= \\
.0086 \pm .0026 \\
\mathrm{p}=0.06 \\
\mathrm{df}=6.56\end{array}$ & $\begin{array}{c}(\mathrm{A}-\mathrm{I})= \\
.0113 \pm .0026 \\
\mathrm{p}=0.02 \\
\mathrm{df}=6.05\end{array}$ & $\begin{array}{c}(\mathrm{A}-\mathrm{M})= \\
.0108 \pm .0027 \\
\mathrm{p}=0.02 \\
\mathrm{df}=6.62\end{array}$ & $\begin{array}{c}(\mathrm{A}-\mathrm{N})= \\
0 \pm .0045 \\
\mathrm{p}=0.70 \\
\mathrm{df}=10.89\end{array}$ \\
\hline B & & $\begin{array}{c}(\mathrm{B}-\mathrm{E})= \\
.0020 \pm 5.0 e^{-4} \\
\mathrm{p}=0.12 \\
\mathrm{df}=9.45\end{array}$ & $\begin{array}{c}(\mathrm{B}-\mathrm{I})= \\
.0048 \pm 4.0 e^{-4} \\
\mathrm{p}<.001 \\
\mathrm{df}=6.46\end{array}$ & $\begin{array}{c}(\mathrm{B}-\mathrm{M})= \\
.0041 \pm 8.0 e^{-4} \\
\mathrm{p}=0.007 \\
\mathrm{df}=9.34\end{array}$ & $\begin{array}{c}(\mathrm{N}-\mathrm{B})= \\
.0047 \pm 3.7 e^{-4} \\
\mathrm{p}=0.34 \\
\mathrm{df}=4.21\end{array}$ \\
\hline $\mathbf{E}$ & & & $\begin{array}{c}(\mathrm{E}-\mathrm{I})= \\
.0027 \pm 5.0 e^{-4} \\
\mathrm{p}=0.01 \\
\mathrm{df}=7.08\end{array}$ & $\begin{array}{c}(\mathrm{E}-\mathrm{M})= \\
.0022 \pm 8.0 e^{-4} \\
\mathrm{p}=0.07 \\
\mathrm{df}=11.97\end{array}$ & $\begin{array}{c}(\mathrm{N}-\mathrm{E})= \\
.0069 \pm 3.7 e^{-3} \\
\mathrm{p}=0.14 \\
\mathrm{df}=5.46\end{array}$ \\
\hline I & & & & $\begin{array}{c}(\mathrm{M}-\mathrm{I})= \\
5.0 e^{-4} \pm 7.0 e^{-4} \\
\mathrm{p}=0.60 \\
\mathrm{df}=6.98\end{array}$ & $\begin{array}{c}(\mathrm{N}-\mathrm{I})= \\
.0095 \pm 3.7 e^{-3} \\
\mathrm{p}=0.05 \\
\mathrm{df}=5.04\end{array}$ \\
\hline $\mathbf{M}$ & & & Y & & $\begin{array}{c}(\mathrm{N}-\mathrm{M})= \\
.0095 \pm 3.7 e^{-3} \\
\mathrm{p}=0.06 \\
\mathrm{df}=5.51\end{array}$ \\
\hline
\end{tabular}

Table 2.15: The method used to compare average wintertime stability values between GOMOOS buoys is described in section 2.2.5. Results are considered significant for $\mathrm{p}<.05$. 


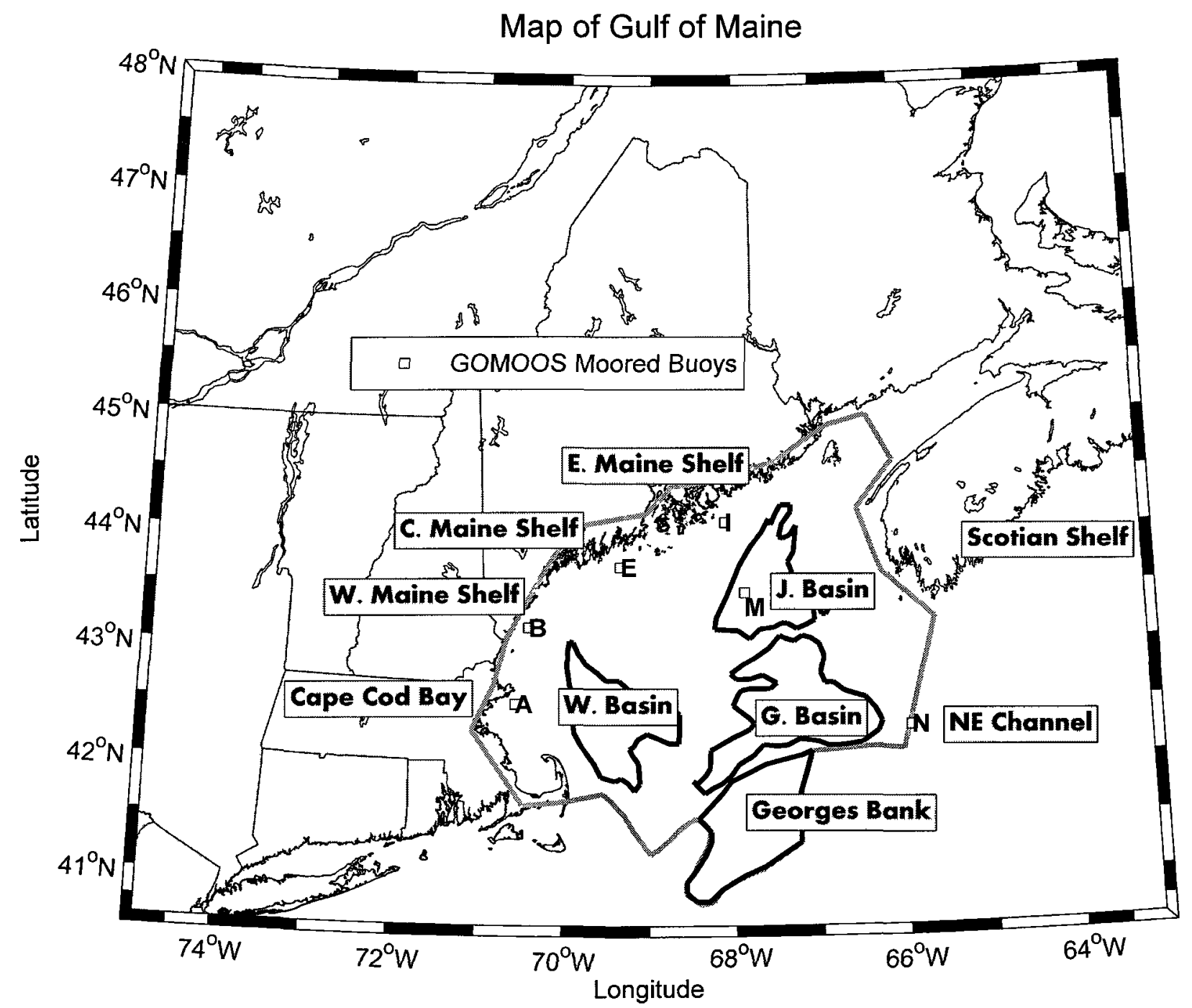

Figure 2-1: A map of the Gulf of Maine with GOMOOS mooring locations shown by green boxes. Labels show the representative area covered by each mooring. Bathymetric features including Georges Bank, the Scotian Shelf and major basins are labeled. 


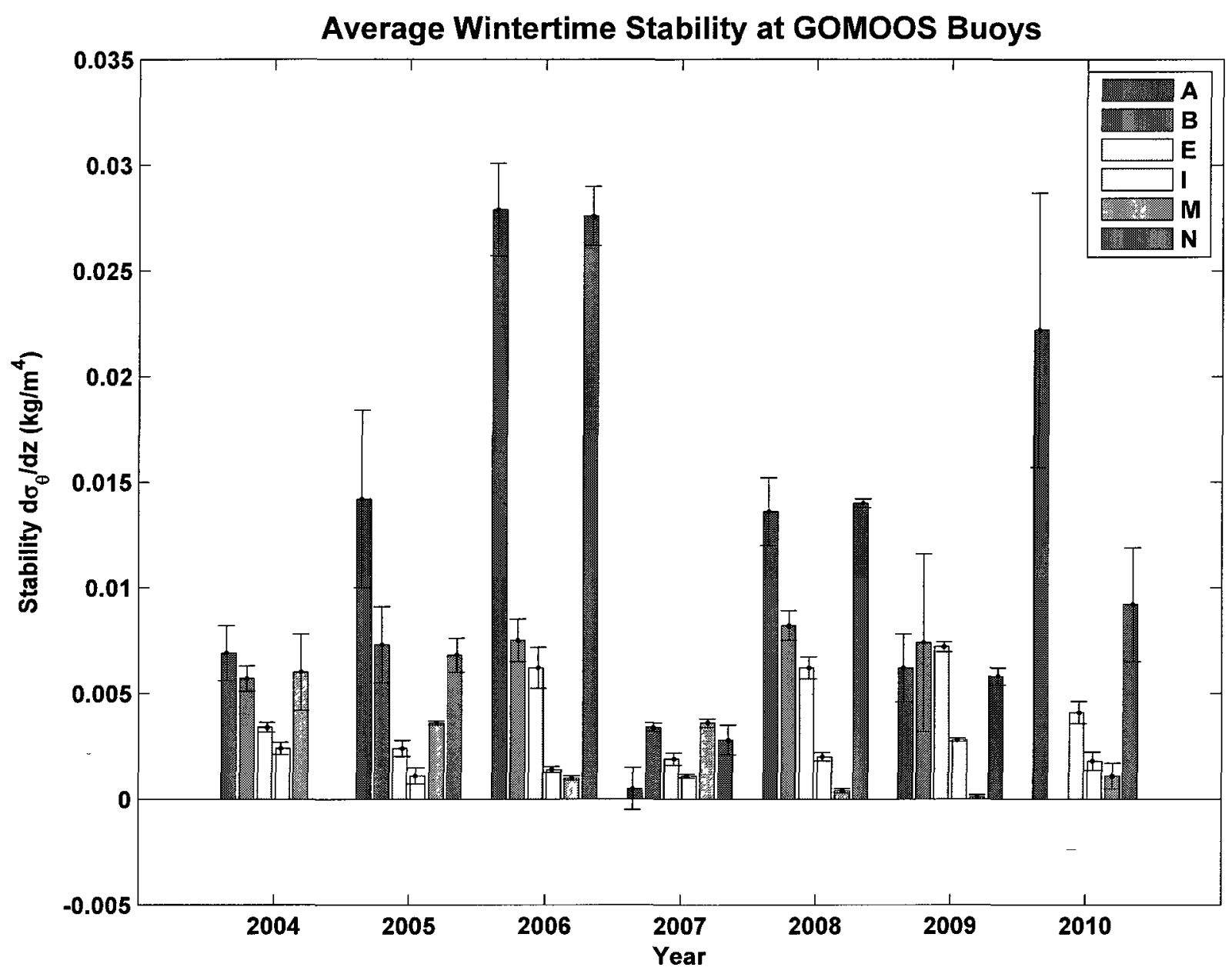

Figure 2-2: Yearly averaged winter stability values for GOMOOS buoys plotted from 2004-2009. Stability is calculated by taking the difference in potential densities between 1 and $20 \mathrm{~m}$ and dividing by 19 . Yearly averaged stability values are calcuated by averaging all 20 day rolling average stabilty values within a given year for each buoy. Standard error $( \pm 1)$ is calculated using decorrelation times of density difference between 1 and $20 \mathrm{~m}$ given in (Table 2.1). 


\section{CHAPTER 3}

\section{PATTERNS IN WINTERTIME \\ STRATIFICATION}

\subsection{Methods}

\subsubsection{Calculating the Relative Contributions of Salinity and Temperature}

Since both salinity and temperature affect the density of water, it is important to identify the individual contributions each has in affecting the density gradient in the upper water-column. The density gradient in the upper $20 \mathrm{~m}$ is of primary concern because it is the zone of highest phytoplankton growth rate (Smetacek and Passow, 1990). According to Smetacek and Passow (1990), under nutrient replete conditions "phytoplankton growth rates are a function of irradiance, which decreases exponentially with depth." Smetacek and Passow (1990) argue that in the GOM during the spring bloom, irradiance levels only permit "maximal division rates" in the upper $20 \mathrm{~m}$. During the winter it is assumed that the depths of maximal division rates will be shallower as solar incidence is at a lower angle. Durbin et al. (2003) found values of critical depth in the GOM during the winters of 1999 and 2000 less than 25m. Recall that according to Sverdrup's critical depth hypothesis that a phytoplankton bloom can occur when the mixed layer depth shoals above the critical depth. Durbin et al. (2003) defined the critical depth as the "depth at which the depth-averaged vertically integrated irradiance is equal to $20.9 \mathrm{~W} \mathrm{~m}^{-2}$." In this study, stratification 
is only considered in the upper $20 \mathrm{~m}$ since it is assumed that most winter primary production will take place in this region.

To find the contribution of salinity to the density gradient in the upper watercolumn, it is necessary to find the difference in potential densities between $20 \mathrm{~m}$ and the surface while holding temperature constant between these two depths. Here, the potential density $\left(\sigma_{\theta}\right)$ at $20 \mathrm{~m}$ is a function of salinity at $20 \mathrm{~m}\left(\mathrm{~S}_{d}\right)$, the potential temperature of water moved adiabatically from the surface to $20 \mathrm{~m}\left(\mathrm{~T}_{\theta}\right)$, the pressure at $20 \mathrm{~m}\left(\mathrm{P}_{d}\right)$, and the reference pressure $\left(\mathrm{R}_{p}\right) .\left(\mathrm{T}_{\theta}\right)$ is used since temperature increases adiabatically with depth. In order to hold temperature constant, it is necessary to calculate what the temperature of a parcel of water would be if it were at $20 \mathrm{~m}$. The potential density at the surface is a function of surface salinity $\left(\mathrm{S}_{s}\right)$, surface temperature $\left(\mathrm{T}_{s}\right)$, surface pressure $\left(\mathrm{P}_{s}\right)$, and $\mathrm{R}_{p}$. In all cases, $\mathrm{R}_{p}$ is defined as $0 \mathrm{db}$. The salinity contribution is found from (Equation 3.1), where $\left(\sigma_{\theta}\right)_{1 m}$ is subtracted from $\left(\sigma_{\theta}\right)_{20 m}$. In order to find the temperature contribution to the density gradient in the upper water-column, salinity is held constant between the surface and $20 \mathrm{~m}$. In this case the potential density at $20 \mathrm{~m}$ is a function of $\mathrm{S}_{s}$, temperature at $20 \mathrm{~m}\left(\mathrm{~T}_{d}\right)$, $\mathrm{P}_{d}$, and $\mathrm{R}_{p}$. The temperature contribution is found from (Equation 3.2), where $\left(\sigma_{\theta}\right)_{1 m}$ is subtracted from the $\left(\sigma_{\theta}\right)_{20 m}$ calculated assuming constant salinity with depth.

$$
\begin{array}{r}
\text { Salinity Contribution }=\sigma_{\theta(20 m)}\left(S_{d}, T_{\theta}, P_{d}, R_{p}\right)-\sigma_{\theta(1 m)}\left(S_{s}, T_{s}, P_{s}, R_{p}\right) \\
\text { Temperature Contribution }=\sigma_{\theta(20 m)}\left(S_{s}, T_{d}, P_{d}, R_{p}\right)-\sigma_{\theta(1 m)}\left(S_{s}, T_{s}, P_{s}, R_{p}\right)
\end{array}
$$

(Equation 3.1 and Equation 3.2) are used to determine what factor, salinity or temperature, has a bigger effect in increasing the density gradient in the upper $20 \mathrm{~m}$. A negative value for either the salinity or temperature contribution indicates that they are responsible for decreasing density with depth. Decreasing density with depth destabilizes the water-column and promotes vertical mixing. Alternatively, a positive value indicates that either salinity or temperature is increasing the density with depth. The greater the density increase with depth, the more resistant the water-column is to 
overturning. The relative contribution equation (Equation 3.3) compares the salinity and temperature contributions by subtracting them. If the relative contribution is positive then salinity is the dominant player in increasing stability. Conversely, negative values for the relative contribution indicate that temperature is more important in driving increased stability in the upper water-column. The greater the absolute value of the relative contribution, the larger the impact of salinity or temperature in influencing the density in the upper $20 \mathrm{~m}$. Although the equation of state for seawater given by Gill (1982) is non-linear, the assumption of linearity when subtracting the temperature contribution from the salinity contribution is adequate since the resulting error is small. Maximum error is found using typical wintertime salinity and temperatures in combination with the largest average salinity and temperature differences between 1 and $20 \mathrm{~m}$ found in (Table 2.2 and Table 2.3). Using (Equation 3.4), which compares the true potential density difference between 1 and $20 \mathrm{~m}$ with the difference calculated considering the individual contributions of salinity and temperature, it is found that the maximum difference between values is $\ll 1 \%$.

$$
\begin{gathered}
\text { Relative Contribution = Salinity Contribution - Temperature Contribution } \\
\sigma_{\theta(20 m)}-\sigma_{\theta(1 m)} \approx \sigma_{\theta(20 m)}\left(T_{d}, S_{s}, P_{d}, R_{p}\right)+\sigma_{\theta(20 m)}\left(T_{\theta}, S_{d}, P_{d}, R_{p}\right)-\left[2 \times \sigma_{\theta(1 m)}\right]
\end{gathered}
$$

In computing the relative contributions of salinity and temperature to density change in the upper water-column, the affect of pressure on the density of the water is negligible since its contribution is small and nearly the same in all calculations. Pressure is assumed to be uniform at $20 \mathrm{~m}$ throughout the GOM at $20 \mathrm{~m}$, varying at most $.005 \mathrm{db}$ due to differences in latitude for the casts and GOMOOS moorings. Holding the temperature and salinity constant between 1 and $20 \mathrm{~m}$ and only considering the affect of pressure on the change in potential density yields a difference of approximately $1.0 e^{-6} \mathrm{~kg} / \mathrm{m}^{3}$. This value was calculated using typical wintertime salinities and temperatures in the GOM. There was little variability over the range of 
common winter salinity and temperature values. For casts which have a first recorded depth deeper than $1 \mathrm{~m}$, the difference in potential density due to pressure will be even smaller. In all cases, the change in potential density due to pressure can be neglected since it is much smaller than the changes observed between 1 and $20 \mathrm{~m}$ (Table 2.3 and Table 2.12).

For the BIO and COOA data, the relative contributions of salinity and temperature for each cast are found and averaged regionally. For the GOMOOS mooring data, 20 day rolling averages of salinity and temperature contributions are generated. For a particular buoy, the contributions are averaged by year and \pm 1 standard error found using yearly averages and decorrelation times found in (Table 2.1). Relative contributions are founding using 20 day rolling average salinity and temperature contributions. In this case, temperature contributions are subtracted from corresponding salinity contribution values. Total average and standard error calculation for relative contributions are performed in the same way as for salinity/temperature contributions. Between-buoy and inter-regional comparison of salinity, temperature, and relative contribution values are done in the same way as described in section 2.2.5.

In this study, relative contribution values for casts are also used in the binary analysis of salinity versus temperature contributions. This binary approach considers only which factor is more important in increasing the density of the upper watercolumn. Regional results are reported in the form of a percent. Summing the percent of casts which have salinity contributions larger than temperature contributions and vice-versa yields $100 \%$. 


\subsubsection{Calculating Duration and Frequency of Shallow Mixed Layer Events}

Duration and frequency of shallow mixed layer events $(\leq 20 \mathrm{~m})$ are calculated using GOMOOS time-series data. In order to find the percent of time a shallow mixed layer is present at a mooring during the winter, all available hourly potential density data at 1 and $20 \mathrm{~m}$ is considered. If the difference in potential densities between 1 and $20 \mathrm{~m}$ is greater than $.01 \mathrm{~kg} / \mathrm{m}^{3}$, then the mixed layer is less than $20 \mathrm{~m}$ according to definition established in section 2.1.2. The percentage of time that the mixed layer is shallow is found by dividing the number of hours in which a shallow mixed layer exists at a particular mooring by the total number of hours with usable data. Usable data in this case refers to times when potential density values are available at both 1 and $20 \mathrm{~m}$.

In calculating the duration of shallow mixed layer events, 20 day rolling averages of potential density at 1 and $20 \mathrm{~m}$ are used. Although this method does not capture short-term variability in stratification, it is average stratification over a period of days, not hours, that will be most biologically significant (Salisbury personal communication). The duration of a shallow mixed event is simply found by counting consecutive days where the density at $20 \mathrm{~m}$ is at least $.01 \mathrm{~kg} / \mathrm{m}^{3}$ greater than the density at $1 \mathrm{~m}$. The frequency of shallow mixed layer events can be observed by plotting the density difference between $20 \mathrm{~m}$ and $1 \mathrm{~m}$ over time. The total number of days in a winter with a shallow mixed layer is the sum of all days where $\sigma_{\theta 20 m}-\sigma_{\theta 1 m} \geq .01 \mathrm{~kg} / \mathrm{m}^{3}$. The maximum number of days is restricted to the length of the study season, 90 days. For any GOMOOS buoy, using 4 day, rather than 20 day rolling averages of potential density at 1 and $20 \mathrm{~m}$, made little difference in the number of days a winter with a shallow mixed layer present. 


\subsubsection{Quantifying the Relationship Between Wind Stress and Stratification}

For the purpose of this study pseudo wind stress $\left(\mathrm{m}^{2} / \mathrm{sec}^{2}\right)$ is calculated as the square of the wind-speed. Pseudo-stress is considered since wind-speed squared is the biggest contributor to the actual wind stress. Daily averaged wintertime windspeeds at $10 \mathrm{~m}$ taken from the NCEP Reanalysis II dataset are used in calculations of pseudo-stress. Recall the the NCEP Reanalysis wind data used in this research comes from averaged daily winds in a rectangular grid covering $42.856^{\circ} \mathrm{N}$ to $44.76^{\circ} \mathrm{N}$ and $65.6250^{\circ} \mathrm{W}$ to $69.375^{\circ} \mathrm{W}$. North and easterly components of winds are used in calculating average daily wind-directions. Upwelling favorable southwesterly winds are important in the Coastal Zone, which is angled approximately $25^{\circ}$ from north. Decorrelation time-scales of wind stress are approximately 2 days (Pringle, 2006). In order to understand how wind stress affects stratification, the density difference between 1 and $20 \mathrm{~m}$ is compared before and after wind events each winter. At each GOMOOS mooring, the number of times when stratification decreases after a wind event is recorded and compared to the number of times when stratification increases after an event. The percentage of time that wind events coincide with destratification is then calculated. To determine the significance of this value, an alternate percentage based on random chance is needed for comparison. The alternative percentage is generated using a bootstrapping technique. Using this method, start and end dates from a particular wind event are used to determine if stratification values on the same calender days in a random year between 2004 and 2010 follow the same pattern. One thousand randomly chosen (stratification before-stratification after) values are generated for each wind event at a particular GOMOOS buoy. The number of wind events at a given buoy determines the sample size for the alternative percentage. Comparison of the actual percent of time when stratification decreased after a wind event to the alternative percentage based on random chance, is performed using a 
two sample Z-test for proportions.

For the purpose of this study, wind events are chosen based the average wind stress magnitude in the GOM during the winter $\left(70 \mathrm{~m}^{2} / \mathrm{sec}^{2}\right)$. This value is based on NCEP Reanalysis II wind data from 2004-2010. To compare the percents calculated using the average winter wind stress magnitude with other wind stress thresholds, stratification before and after events is investigated using pseudo wind stress magnitudes on either side of the wintertime mean. The wind stress threshold values chosen range from $60-80 \mathrm{~m}^{2} / \mathrm{sec}^{2}(17-20 \mathrm{mph})$. Choosing wind stress magnitudes outside of this range greatly limits the number of events that can be studied.

\subsection{Spatial and Temporal Patterns in Mixed Layer Depth}

All mixed layer depths presented in this section are based on an algorithm which removes artificially shallow mixed layers. Recall, artificially shallow mixed layers are sometimes found as a product of casts with a maximum depth less than $20 \mathrm{~m}$ where the $+.01 \mathrm{~kg} / \mathrm{m}^{3}$ criterion is not reached. For casts deeper than $20 \mathrm{~m}$, if the density criterion is not met, then the mixed layer is recorded as the deepest recorded depth. Mixed layer depths found using this routine are close to those found when removing casts for which the density criterion is not met (Table 3.1). In the latter case, casts are removed since a true mixed layer depth cannot be found given the available data. Removing these casts tends to bias average mixed layer depths to shallower depths. This bias is most evident in the Northern Zone and over Georges Bank where the greatest top-to-bottom mixing generally occurs. In these areas, mixed layer depths frequently represent the depth of the entire water-column. To minimize under-estimations of average regional mixed layer depth, it is best to keep casts that have data deeper than $20 \mathrm{~m}$ and also have a mixed layer depth "assigned" to the 
deepest depth. Given the similarities in regionally averaged mixed layer depths given by the two mentioned algorithms, it is assumed that calculated average mixed layer depths given in this study are a good approximation of actual mixed layer depths.

Spatially, shallow winter mixed layers are most prevalent in the Coastal and Eastern Zones of the GOM. In these zones, average winter mixed layer depth values with \pm 1 standard error are $22.06 \mathrm{~m} \pm 1.2 \mathrm{~m}$ and $29.60 \mathrm{~m} \pm 1.8 \mathrm{~m}$ respectively (Fig. $3-1$ and Table 3.1). In the Coastal and Eastern Zones, mixed layer depths less than 20m account for $66 \%$ and $50 \%$ respectively of all mixed layer depths (Fig. 3-2). On the other hand, in the Western Zone only $25 \%$ of all casts have a mixed layer less than $20 \mathrm{~m}$. In the Western Zone the average mixed layer depth is $57.37 \mathrm{~m} \pm 2.8 \mathrm{~m}$, and mixed layer depths greater than $40 \mathrm{~m}$ account for $59 \%$ of casts. With the exception of the Northern Zone, the difference in average mixed layer depth between the Western Zone and all zones is significant at better than the $10 \%$ level (Table 3.2).

The greater percentage of deep mixed layers in the Western Zone compared to other areas can be attributed to the mixing and modification of fresh SSW as it circulates counter-clockwise around the GOM (Brown and Beardsley, 1978; Pringle, 2006). Mixing acts to freshen deeper saline waters and thus reduces top-to-bottom stratification of the water-column. Weak stratification allows mixing to penetrate to greater depths. Mixing is initiated by events such as the passage of winter storms or atmosphere-induced cooling of surface waters (Brown and Beardsley, 1978). Although temperature-induced cooling of surface waters is expected to be more significant closer to the coast as the air-mass has undergone less warming due to modification by warmer sea surface temperatures, Hopkins and Garfield (1977) found that for one particular winter event in the Western GOM the "maximum surface heat transfer occurred about $50 \mathrm{~km}$ offshore". This finding shows that ocean-to-atmosphere heat flux and the resulting cooling of the surface ocean in the Western Zone may be enough to initiate deep mixing. Using the BIO cast data, Pringle (2006) found that the density 
in Wilkinson Basin, in the Western Zone, is positively correlated with winter cooling from $30-170 \mathrm{~m}$. Deeper mixing in the Western Zone is possible since the water-column is on average less stratified than other regions in the GOM (Pringle, 2006). Deep mixing, however, does not always occur in the Western Zone. For example, Taylor and Mountain (2009) found that years with fresher than average fall surface salinities in Wilkinson Basin were significantly correlated with the presence of shallower winter mixed layers. Taylor and Mountain (2009) concluded that during these years salinityinduced stratification reduced deep convective overturn.

Cast data shows that the majority of mixed layer depths over Georges Banks lie between 20 and $75 \mathrm{~m}$ in agreement with strong, top-to-bottom tidal mixing. In the Northern Zone the pattern of mixed layer depths is less clear than in the other zones. On one hand, mixed layers shallower than $20 \mathrm{~m}$ account for $50 \%$ of casts, while on the other hand, mixed layer depths greater than $40 \mathrm{~m}$ represent $29 \%$ of casts in this region. This variability might be the product of insufficient data (58 casts), or it might reflect a situation where mixed layer depth in this region is affected by year to year variability in the EMCC or changes in the volume of river discharge (Pettigrew et al., 1998).

Time-series data gathered from the GOMOOS buoys is in accord with cast data findings, showing that shallow mixed layers are common in the Coastal and Eastern Zones of the GOM. At buoys A, B, E, I, M, and $\mathrm{N}$ the percentage of time a shallow mixed layer was present $(\leq 20 \mathrm{~m})$ during the winter was $86,92,89,85,56$, and $89 \%$ respectively. To test the validity of this result, the percent of time with a shallow mixed layer was re-calculated for each GOMOOS buoy using double and triple the mixed layer threshold $\left(+.01 \mathrm{~kg} / \mathrm{m}^{3}\right.$ from the surface). The comparison of different thresholds shows that the results are not highly sensitive to even a tripling of the $.01 \mathrm{~kg} / \mathrm{m}^{3}$ threshold (Table 3.3). The lower percentage of time with a shallow mixed layer at Buoy M, in Jordan Basin, agrees with cast data taken in this area (Fig. 3-1). 
For example, Fig. 3-1 shows a number of casts with deep mixed layers in the Western Zone and western portion of the Eastern Zone.

Analysis of wintertime shallow mixed layer events at the GOMOOS buoys reveals a pattern of persistent stratification at most buoys and in all years. The strength of stratification, however, is variable both spatially and temporally. This variability will be explored in section 3.4. At the GOMOOS buoys considered in this study, stratification is often present for the entire winter (90 days) (Table 3.4). Buoy M in Jordan Basin is the exception, and typically has fewer days during the winter with a shallow mixed layer. No information on the duration of wintertime shallow mixed layer events is available for the Western Zone or over Georges Bank since no GOMOOS moorings are located in these areas. Based on spatial patterns in mixed layer depth given by the cast data, however, it appears that the Western Zone and Georges Bank are characterized by deeper mixing and will likely have fewer days a year with a shallow mixed layer than the Coastal or Eastern Zones (Fig. 3-1).

\subsection{Spatial Patterns in Salinity and Temperature Contribution}

Each zone has casts which owe their upper-water column density increase to salinity, temperature, or both. On year-to-year timescales, interannual variability of forcing factors such as changes in air temperature, GOM circulation, and volume of river inflow will affect the observed spatial patterns in salinity and temperature contributions. Over longer time-scales, however, stratification/lack of stratification in different zones within the GOM is driven by different mechanisms. Namely, on average the upper water-column density increase in the Coastal, Northern, and Eastern regions of the GOM is attributable to salinity increase with depth, while in the Western Zone and over Georges Bank temperature decrease with depth is more important (Fig. 3-3 
and Fig. 3-4).

In contrast to the binary approach, which only gives the percent of salinity versus temperature dominated casts in a particular region, averaging the salinity and temperature contributions, respectively, gives insight on how each impacts the density of the upper water-column (0-20m) (Table 3.1). Recall that an average positive salinity or temperature contribution indicates that density is increasing with depth while a negative contribution reflects the opposite. Using the cast data, it is found that in all regions of the GOM the average temperature contribution is not significantly different from zero at the $10 \%$ level. Furthermore, all inter-region comparisons of average temperature contribution values are insignificant with $\mathrm{P}$-values often close to 1 (Table 3.5). Conversely, the contribution of salinity to increasing the density in the upper $20 \mathrm{~m}$ is significant at the $5 \%$ level in the Coastal, Eastern, and Northern Zones. Average salinity contribution is not significant at the $10 \%$ level in the Western Zone and over Georges Bank. Inter-regional comparison of salinity contributions shows that the Coastal and Eastern Zones are significantly different from the Western Zone and Georges Bank at atleast the $15 \%$ level (Table 3.6). This is notable since P-values are much higher when comparing the Coastal and Eastern Zones or the Western Zone and Georges Bank $(\mathrm{P}=.72$ and $\mathrm{P}=.52$, respectively).

The average relative contribution (salinity contribution - temperature contribution) values in the Western Zone and over Georges Bank are not significantly different from zero $(\mathrm{P}>10)$. As discussed, these areas are less stratified and experience cooling or tidally-induced deep mixing (Pringle, 2006). Interannual variability in the density structure and circulation in the GOM's interior related to year-to-year differences in inflow volumes of SSW and saline slope water provides one possible explanation for the temporal and spatial variability in salinity versus temperature dominated casts in the Western Zone (Pringle, 2006; Taylor and Mountain, 2009) (Fig. 3-3). An alternative explanation is that warm-core Gulf Stream rings or fresh, off-shoots of 
the EMCC/WMCC can also occasionally affect the density structure of the upper water-column in the Western Zone (Brooks, 1985). Relative contribution values of salinity and temperature are not significantly different over Georges Bank because heavy tidal mixing homogenizes the water-column (Townsend, 1991).

The dominance of salinity in increasing the density in the top $20 \mathrm{~m}$ in the Coastal and Eastern zones is in agreement with the relative contribution averages from the GOMOOS buoys (Table 3.7). At all GOMOOS buoys, salinity contributions are positive and greater than temperature contributions. In fact, except for Buoy E, temperature contributions are not significantly different from zero $(\mathrm{P}>.10)$. On the other hand, all salinity contributions are positive and significant $(\mathrm{P}<.05)$. The fact that the temperature change in the upper $20 \mathrm{~m}$ is either statistically insignificant, ( $\mathrm{P}>10$ at Buoys $\mathrm{A}, \mathrm{I}$, and $\mathrm{M})$ or increases with depth $(\mathrm{P}<.10$ at Buoys $\mathrm{B}, \mathrm{E}$, and $\mathrm{N})$ shows that salinity is the lone factor contributing to the persistent wintertime stratification present $(0-20 \mathrm{~m})$ at all GOMOOS buoys (Table 2.2). This finding is in agreement with Deese-Riordan (2009) who found that "the temperature inversions do not exert a substantial destabilizing influence on the density structure because the haline contraction coefficient is 10-15 times larger than the thermal expansion coefficient during winter." In other words, given typical wintertime salinity and temperature values in the GOM, a small change in salinity with depth has a far greater impact on density than a small change in temperature (Knauss, 1996).

Average salinity contributions are the greatest at Buoys A and N, in the Coastal and Eastern Zones respectively (Table 3.8). As mentioned, strong salinity gradients caused by a surface lens of river discharge at Buoy A, and by inflow of fresh SSW at Buoy $\mathrm{N}$, result in pronounced salinity differences between the surface and $20 \mathrm{~m}$. At Buoy N, over the Northeast Channel, the increase in density with depth in the upper water-column, and persistent winter-stratification is remarkable given that this area has the greatest average negative temperature contribution (Table 3.9). This 
observation is not unexpected, however, as under conditions of strong salinity stratification temperature inversions may be further augmented by continued heat loss to the overlying atmosphere until the system reaches an equilibrium (Deese-Riordan, 2009).

\subsection{Winter Stratification and its Causes}

\subsubsection{Trends in Stratification and Interannual Variability in Salinity and Temperature}

Time-series plots of salinity and temperature at GOMOOS buoys reveal significant year-to-year variability (Fig. 3-5 to Fig. 3-10). Data from 2004-2010 shows that this interannual variability in salinity and temperature manifests itself at all depths considered $(1,20$, and $50 \mathrm{~m})$. Furthermore, the observed approximately 3 year variability is consistent between GOMOOS moorings. Generally, depth averaged salinities and temperatures fell from 2004-2005, increased from 2005-2007, and then fell again from 2007-2009 (Table 3.10). Changes in salinity and temperature may be a function of local ocean-atmosphere interactions, year-to-year changes in the inflow volumes of SSW and WSW, or large-scale changes in the westward transport of Labrador Slope waters (Petrie and Drinkwater, 1993). Recall that cold, relatively fresh Labrador Current waters sometimes contribute to the deep water that enters the GOM through the Northeast Channel (Gatien, 1976). Cold, fresh deep waters can impact patterns in salinity and temperature throughout the GOM by mixing with overlying water masses (Brown and Beardsley, 1978). Based on results from the GOMOOS data, there does not appear to a clear relationship between the observed variability in salinity and temperature variability and stratification in the upper water-column $(0-20 \mathrm{~m})$. For example at Buoy B, on the Western Maine Shelf, stratification is strong during the winter of 2006 and weak in 2007, even though both years have higher salinities and 
temperatures than other years (Fig. 3-6). This finding is expected because stratification in the Coastal Zone will instead be driven by local factors including wind/tidal mixing, ocean-atmosphere heat exchange, and river discharge. A detailed investigation of the cause of interannual variability in salinity and temperature observed at the GOMOOS moorings is beyond the scope of this study.

\subsubsection{The Impacts of Salinity, Temperature, and Wind Stress on Stratification}

The primary focus of this study is not on interannual variability in salinity, temperature, and wind stress, but rather on how the effects of salinity, temperature, and wind stress are reflected in the degree of stratification during a particular year. Stratification can be interpreted from (Fig. $3-5$ to Fig. $3-10)$ as $\left(\sigma_{\theta}(20 m)-\sigma_{\theta}(1 m)\right)$. The greater the density difference between 1 and $20 \mathrm{~m}$, the greater the stratification. All days with differences greater than $.01 \mathrm{~kg} / \mathrm{m}^{3}$ represent times with a shallow mixed layer. Stratification and shallow mixed layer events can be found at all GOMOOS buoys. Stratification events appear to be frequent and pronounced in the Coastal Zone (Buoys A, B, and E), and over the Northeast Channel (Buoy N). At Buoy M, in Jordan Basin, stratification is generally weaker, but still persists throughout much of the winter. Times of increased stratification at the coastal GOMOOS moorings translate from one buoy to the next. For example, pronounced stratification events are visible during 2006 and 2008 at Buoys A, B, and E (Fig. 3-5 to Fig. 3-7). These stratification events are not as pronounced at Buoys I and $\mathrm{M}$ as at Buoys $\mathrm{A}, \mathrm{B}$, and $\mathrm{E}$ further south. In fact, the water-column remains relatively unstratified for the majority of the winter in 2008 at Buoy M (Fig. 3-9 and Table 3.4). Deese-Riordan (2009) found that the strong stratification events during the winters of 2006 and 2008 in the Coastal Zone were the result of high river discharge (Fig. 3-11). High river discharge

can result in "coastally trapped fresh plumes" (Shcherbina and Gawarkiewicz, 2008). 
Buoy A appears to be affected most strongly by these coastal plumes, as it experiences greater stratification between 1 and $20 \mathrm{~m}$ than either Buoys B or E further north (Fig. $3-5)$. This is expected since fresh water from rivers to the north accumulates near the coast and flows southward consistent with the GOM's circulation (Fong et al., 1997). The proximity and location of Buoy A relative to the mouth of the Merrimack River also contributes to the comparatively high degrees of stratification seen in this area following river discharge events (Geyer et al., 2004).

The Eastern Zone of the GOM generally remains stratified throughout the winter (Fig. 3-10). Strong salinity and temperature gradients in the upper $20 \mathrm{~m}$ are set up by the surface inflow of fresh, cool SSW (Mountain and Manning, 1994). An influx of SSW appears to have caused a strong stratification event during the winter of 2006 . During this event, salinity and temperature at 1,20, and $50 \mathrm{~m}$ fell. Salinity increased between 1 and $50 \mathrm{~m}$. The difference between 1 and $20 \mathrm{~m}$, however, was much bigger than the difference between $20 \mathrm{~m}$ and $50 \mathrm{~m}$. Similarly, for temperature, the difference between 1 and $20 \mathrm{~m}$ was much greater than between $20 \mathrm{~m}$ and $50 \mathrm{~m}$. The presence of a distinct temperature and salinity gradient in the upper $20 \mathrm{~m}$ is consistent with inflow of SSW. Salinity and temperature gradients are established because SSW is fresh and cool in comparison to the warm, salty water it overrides. Similar events in which SSW water likely impacted Buoy N, occurred in 2008 and 2009.

A comparison of upper water-column stratification before and after wind stress events shows that increased winds do not necessarily result in decreased stratification at a particular location (Table 3.11). In fact, in many cases, stratification at the GOMOOS buoys was greater following above-average wind stress events, than it was prior to the event. This trend is also reflected using wind event thresholds above and below the GOM wintertime average. Analysis of stratification before and after a wind event using 4 day rolling averages of wind stress and density difference between 1 and $20 \mathrm{~m}$ made little difference. 
GOMOOS buoys show that strong stratification events occur during both times of high and low wind stress (Fig. 3-5 to Fig. 3-10). For example, in January of 2006, the upper water-column at Buoys $\mathrm{A}, \mathrm{B}$, and $\mathrm{E}$ was very stratified even though wind stress values were also high. As Deese-Riordan (2009) postulated, the lack of correlation may be the product of wind stress values that are relatively high and fairly constant (using 20 day rolling averages) throughout the winter compared to other times of the year. It is also possible that at certain locations, such as in the Coastal or Eastern Zones, that salinity-driven stratification is great enough that the water-column will resist total overturn even under periods of increased wind stress. 


\begin{tabular}{|l|c|c|c|c|c|}
\hline \multicolumn{6}{|c|}{ Relative Contributions by Zone during the Winter } \\
\hline & Coast & West & East & North & G. Bank \\
\hline \multirow{2}{*}{ Salinity Contribution } & $.1006^{* *}$ & .0135 & $.0765^{* *}$ & $.0223^{* *}$ & .0034 \\
& \pm .057 & \pm .012 & \pm .034 & \pm .009 & \pm .0090 \\
\hline \multirow{2}{*}{ Temperature Contribution } & -.0010 & $5.0 e^{-4}$ & -.0156 & -.0012 & $-2.0 e^{-4}$ \\
& \pm .0056 & \pm .0030 & \pm .012 & \pm .0031 & $\pm 7.0 e^{-4}$ \\
\hline \multirow{2}{*}{ Relative Contribution } & $.0996^{* *}$ & .0130 & $.0922^{* *}$ & $.0236^{* *}$ & .0036 \\
& \pm .057 & \pm .014 & \pm .043 & \pm .011 & \pm .0090 \\
\hline \multirow{2}{*}{ Mixed Layer Depth (m) } & 22.06 & 57.34 & 29.60 & 43.92 & 35.75 \\
& \pm 1.2 & \pm 2.8 & \pm 1.8 & \pm 4.9 & \pm .60 \\
\hline \multirow{2}{*}{ *Mixed Layer Depth* $(\mathbf{m})$} & 17.00 & 50.40 & 25.82 & 26.59 & 18.50 \\
& \pm .99 & \pm 2.60 & \pm 1.72 & \pm 4.19 & \pm 1.97 \\
\hline
\end{tabular}

Table 3.1: Wintertime salinity and temperature contribution values are averaged by zone over all years. All averages are bounded by \pm 1 standard error calculated as the standard deviation of all values within a particular zone divided by the square root of the number of years with available data. Relative contributions are calculated by subtracting the temperature contribution from the salinity contribution for each cast. Mixed layer depth is defined as the depth at which the potential density is $+.01 \mathrm{~kg} / \mathrm{m}^{3}$ greater than the surface depth. All mixed layer depths within a zone are averaged and \pm 1 standard error found by dividing the standard deviation of mixed layer depths by the square root of the number of casts. "*Mixed Layer Depth*" shows regionally averaged mixed layer depths when casts are discarded because the density criterion is not met and the mixed layer depth is equivalent to the maximum recorded depth. This removes deeper mixed layers and results in a shallowing bias to all averages. The difference between "Mixed Layer Depth" and "**Mixed Layer Depth*" is especially large in areas where total water-column mixing is greater, such as in the Northern Zone and over Georges Bank. "**" indicates significance at $10 \%$ level and "**" indicates significance at the $5 \%$ level. 


\begin{tabular}{|c|c|c|c|c|}
\hline \multicolumn{5}{|c|}{ Comparison of Average Wintertime Mixed Layer Depth } \\
\multicolumn{5}{|c|}{ between Zones } \\
\hline & West & East & North & G. Bank \\
\hline \multirow{4}{*}{ Coast } & $(\mathrm{W}-\mathrm{C})=$ & $(\mathrm{E}-\mathrm{C})=$ & $(\mathrm{N}-\mathrm{C})=$ & $(\mathrm{GB}-\mathrm{C})=$ \\
& $35.31 \pm 11.8$ & $7.53 \pm 8.0$ & $21.86 \pm 10.7$ & $13.69 \pm 6.0$ \\
& $\mathrm{p}=.007$ & $\mathrm{p}=.35$ & $\mathrm{p}=.05$ & $\mathrm{p}=.03$ \\
& $\mathrm{df}=21$ & $\mathrm{df}=40$ & $\mathrm{df}=23$ & $\mathrm{df}=34$ \\
\hline \multirow{4}{*}{ West } & & $(\mathrm{W}-\mathrm{E})=$ & $(\mathrm{W}-\mathrm{N})=$ & $(\mathrm{W}-\mathrm{GB})=$ \\
& & $27.78 \pm 12.3$ & $13.45 \pm 14.2$ & $21.62 \pm 11.1$ \\
& & $\mathrm{p}=.03$ & $\mathrm{p}=.35$ & $\mathrm{p}=.07$ \\
& & $\mathrm{df}=24$ & $\mathrm{df}=29$ & $\mathrm{df}=17$ \\
\hline \multirow{4}{*}{ East } & & & $(\mathrm{N}-\mathrm{E})=$ & $(\mathrm{GB}-\mathrm{E})=$ \\
& & & $14.32 \pm 11.2$ & $6.15 \pm 6.9$ \\
& & & $\mathrm{p}=.21$ & $\mathrm{p}=.38$ \\
& & & $\mathrm{df}=27$ & $\mathrm{df}=28$ \\
\hline \multirow{4}{*}{ North } & & & & $(\mathrm{N}-\mathrm{GB})=$ \\
& & & & $8.17 \pm 9.9$ \\
& & & & $\mathrm{p}=.41$ \\
& & & & $\mathrm{df}=18$ \\
\hline
\end{tabular}

Table 3.2: The method used to compare average wintertime mixed layer depth between zones is described in section 2.2.5. Differences and \pm 1 standard error are given in meters. Results are considered significant for $\mathrm{p}<.05$. 


\begin{tabular}{|l|c|c|c|c|c|c|}
\hline \multicolumn{6}{|c|}{$\begin{array}{c}\text { Sensitivity with Respect to Defined Threshold (.01kg/m } \\
\text { \% of time with a Shallow Mixed Layer (<20m) }\end{array}$} \\
\hline & \multicolumn{3}{|c|}{ Coast } & North & \multicolumn{2}{c|}{ East } \\
\hline & A & B & E & I & M & N \\
\hline & $86.01 \%$ & $92.15 \%$ & $89.21 \%$ & $85.45 \%$ & $56.27 \%$ & $89.43 \%$ \\
\hline 1 x theshold & $82.44 \%$ & $88.31 \%$ & $73.20 \%$ & $59.22 \%$ & $49.10 \%$ & $87.38 \%$ \\
\hline 3 x threshold & $76.05 \%$ & $83.89 \%$ & $64.72 \%$ & $40.47 \%$ & $43.35 \%$ & $86 \%$ \\
\hline
\end{tabular}

Table 3.3: The percent of time with a shallow mixed layer $(<20 \mathrm{~m})$ is calculated by finding all hours when the density at $20 \mathrm{~m}$ is atleast $.01 \mathrm{~kg} / \mathrm{m}^{3}$ greater than the density at $1 \mathrm{~m}$. The number of hours with a shallow mixed layer is then divided by the total number of hours of available data for a particular site. 


\begin{tabular}{|c|c|c|c|c|c|c|}
\hline \multicolumn{7}{|c|}{$\begin{array}{c}\text { Number of Winter Days with a Shallow Mixed Layer } \\
\text { During the Winter }\end{array}$} \\
\hline & \multicolumn{3}{|c|}{ Coast } & \multirow{2}{*}{$\begin{array}{c}\text { North } \\
\text { I }\end{array}$} & \multicolumn{2}{|c|}{ East } \\
\hline & $\mathbf{A}$ & B & $\mathrm{E}$ & & $\bar{M}$ & $\mathbf{N}$ \\
\hline 2004 & 90 & 90 & 90 & 87 & 90 & \\
\hline 2005 & 90 & 90 & 90 & 58 & 90 & 90 \\
\hline 2006 & 90 & 90 & 87 & 90 & 87 & 90 \\
\hline 2007 & 38 & 90 & 90 & 90 & 90 & 90 \\
\hline 2008 & 90 & 90 & 90 & 90 & 22 & 90 \\
\hline 2009 & 90 & $* 74$ & 90 & 90 & 8 & 90 \\
\hline 2010 & 90 & & 90 & 90 & 41 & \\
\hline
\end{tabular}

Table 3.4: The number of days with a shallow mixed layer $(<20 \mathrm{~m})$ at each buoy was found using the potential density difference between $20 \mathrm{~m}$ and $1 \mathrm{~m}$ based on 20 day rolling averages. The asterick indicates that the value within the box is the max number of days with good data. 


\begin{tabular}{|c|c|c|c|c|}
\hline \multicolumn{5}{|c|}{ Comparison of Wintertime Temperature Contribution between Zones } \\
\hline & West & East & North & G. Bank \\
\hline \multirow{4}{*}{ Coast } & $(\mathrm{C}-\mathrm{W})=$ & $(\mathrm{C}-\mathrm{E})=$ & $(\mathrm{C}-\mathrm{N})=$ & $(\mathrm{C}-\mathrm{GB})=$ \\
& $5.0 e^{-4} \pm .0064$ & $0.0167 \pm .0128$ & $0.0023 \pm .0064$ & $.0012 \pm .0057$ \\
& $\mathrm{p}=.94$ & $\mathrm{p}=.21$ & $\mathrm{p}=.73$ & $\mathrm{p}=.83$ \\
& $\mathrm{df}=33.80$ & $\mathrm{df}=29.30$ & $\mathrm{df}=34.25$ & $\mathrm{df}=23.77$ \\
\hline \multirow{4}{*}{ West } & & $(\mathrm{W}-\mathrm{E})=$ & $(\mathrm{W}-\mathrm{N})=$ & $(\mathrm{W}-\mathrm{GB})=$ \\
& & $0.0161 \pm .012$ & $0.0018 \pm .004$ & $7.0 e^{-4} \pm .003$ \\
& & $\mathrm{p}=.19$ & $\mathrm{p}=.70$ & $\mathrm{p}=.82$ \\
& & $\mathrm{df}=22.70$ & $\mathrm{df}=29.97$ & $\mathrm{df}=16.76$ \\
\hline \multirow{4}{*}{ East } & & & $(\mathrm{N}-\mathrm{E})=$ & $(\mathrm{GB}-\mathrm{E})=$ \\
& & & $0.0144 \pm .012$ & $0.0155 \pm .012$ \\
& & & $\mathrm{p}=.24$ & $\mathrm{p}=.20$ \\
& & & $\mathrm{df}=22.87$ & $\mathrm{df}=20.16$ \\
\hline \multirow{4}{*}{ North } & & & & $(. \mathrm{GB}-\mathrm{N})=$ \\
& & & & $0.0011 \pm .003$ \\
& & & & $\mathrm{p}=.76$ \\
& & & & $\mathrm{df}=16.66$ \\
\hline
\end{tabular}

Table 3.5: The method used to compare average wintertime temperature contribution values between zones is described in section 2.2.5. Results are considered significant for $\mathrm{p}<.05$. 


\begin{tabular}{|c|c|c|c|c|}
\hline \multicolumn{6}{|c|}{ Comparison of Wintertime Salinity Contribution between Zones } \\
\hline & West & East & North & G. Bank \\
\hline \multirow{4}{*}{ Coast } & $(\mathrm{C}-\mathrm{W})=$ & $(\mathrm{C}-\mathrm{E})=$ & $(\mathrm{C}-\mathrm{N})=$ & $(\mathrm{C}-\mathrm{GB})=$ \\
& $0.0871 \pm .058$ & $0.0241 \pm .066$ & $0.0783 \pm .057$ & $.0972 \pm .057$ \\
& $\mathrm{p}=.14$ & $\mathrm{p}=.72$ & $\mathrm{p}=.18$ & $\mathrm{p}=.10$ \\
& $\mathrm{df}=25.20$ & $\mathrm{df}=36.91$ & $\mathrm{df}=24.23$ & $\mathrm{df}=24.15$ \\
\hline \multirow{3}{*}{ West } & & $(\mathrm{E}-\mathrm{W})=$ & $(\mathrm{N}-\mathrm{W})=$ & $(\mathrm{W}-\mathrm{GB})=$ \\
& & $0.0630 \pm .036$ & $0.0088 \pm .016$ & $.0101 \pm .015$ \\
& & $\mathrm{p}=.09$ & $\mathrm{p}=.58$ & $\mathrm{p}=.52$ \\
& & $\mathrm{df}=25.21$ & $\mathrm{df}=27.75$ & $\mathrm{df}=26.42$ \\
& & & $(\mathrm{E}-\mathrm{N})=$ & $(\mathrm{E}-\mathrm{GB})=$ \\
East & & & $0.0542 \pm .035$ & $0.0731 \pm .035$ \\
& & & $\mathrm{p}=.14$ & $\mathrm{p}=.05$ \\
& & & $\mathrm{df}=22.98$ & $\mathrm{df}=22.76$ \\
\hline \multirow{3}{*}{ North } & & & & $(\mathrm{N}-\mathrm{GB})=$ \\
& & & & $0.0189 \pm .0129$ \\
& & & & $\mathrm{p}=.15$ \\
& & & & $\mathrm{df}=27.96$ \\
\hline
\end{tabular}

Table 3.6: The method used to compare average wintertime salinity contribution between zones is described in section 2.2.5. Results are considered significant for $\mathrm{p}<.05$. 


\begin{tabular}{|l|c|c|c|c|c|c|}
\hline \multicolumn{7}{|c|}{ Wintertime Contributions of Salinity and Temperature } \\
at GOMOOS Buoys \\
\hline & \multicolumn{3}{|c|}{ Coast } & North & \multicolumn{2}{c|}{ East } \\
\hline & A & B & E & I & M & N \\
\hline \multirow{2}{*}{ salinity contribution } & $.2402^{* *}$ & $.1361^{* *}$ & $.0980^{* *}$ & $.0375^{* *}$ & $.0494^{* *}$ & $.2814^{* *}$ \\
& \pm .053 & \pm .0077 & \pm .0098 & \pm .0033 & \pm .018 & \pm .070 \\
\hline \multirow{2}{*}{ temp. contribution } & -.0091 & -.0083 & $-.0094^{* *}$ & $-7.963 \mathrm{e}^{-4}$ & -.0043 & -.0617 \\
& \pm .007 & \pm .003 & \pm .002 & \pm .001 & \pm .003 & \pm .025 \\
\hline \multirow{2}{*}{ relative contribution } & $.2492^{*}$ & $.1443^{* *}$ & $.1073^{* *}$ & $.0383^{* *}$ & $.0537^{*}$ & $.3431^{* *}$ \\
& \pm .058 & \pm .0009 & \pm .011 & \pm .004 & \pm .021 & \pm .114 \\
\hline
\end{tabular}

Table 3.7: The contribution of salinity and temperature to the density gradient in the upper water column $(1-20 \mathrm{~m})$ is calculated using the salinity and temperature contribution equations respectively. Contributions are based on 20 day rolling averages. All 20 day rolling averages are binned by year and the years are averaged The relative contribution is found for each day of each winter by subtracting all 20 day rolling average temperature contributions from all 20 day rolling average salinity contributions. An average positive relative contribution indicates that salinity is more important in increasing the density gradient in the upper $20 \mathrm{~m}$. Error $( \pm 1$ standard error) is based on the standard deviation of yearly averages divided by the number of independent observations. The number of independent observations is determined by the decorrelation times found in (Table 2.1). "**" indicates significance at $10 \%$ level and "**" indicates significance at the $5 \%$ level. 


\begin{tabular}{|c|c|c|c|c|c|}
\hline \multicolumn{6}{|c|}{$\begin{array}{c}\text { Comparison of Wintertime Salinity Contribution } \\
\text { between GOMOOS Buoys }\end{array}$} \\
\hline & B & $\mathbf{E}$ & I & $\mathbf{M}$ & $\mathbf{N}$ \\
\hline $\mathbf{A}$ & $\begin{array}{c}(\mathrm{A}-\mathrm{B})= \\
.1012 \pm .055 \\
\mathrm{p}=0.27 \\
\mathrm{df}=5.40\end{array}$ & $\begin{array}{c}(\mathrm{A}-\mathrm{E})= \\
.1635 \pm .054 \\
\mathrm{p}=0.07 \\
\mathrm{df}=6.63\end{array}$ & $\begin{array}{c}(\mathrm{A}-\mathrm{I})= \\
.2241 \pm .053 \\
\mathrm{p}=0.02 \\
\mathrm{df}=6.05\end{array}$ & $\begin{array}{c}(\mathrm{A}-\mathrm{M})= \\
.2121 \pm .055 \\
\mathrm{p}=0.03 \\
\mathrm{df}=6.81\end{array}$ & $\begin{array}{c}(\mathrm{N}-\mathrm{A})= \\
.051 \pm .103 \\
\mathrm{p}=0.87 \\
\mathrm{df}=9.79\end{array}$ \\
\hline B & & $\begin{array}{c}(\mathrm{B}-\mathrm{E})= \\
.0362 \pm .011 \\
\mathrm{p}=0.19 \\
\mathrm{df}=9.68\end{array}$ & $\begin{array}{c}(\mathrm{B}-\mathrm{I})= \\
.0983 \pm .0081 \\
\mathrm{p}=0.001 \\
\mathrm{df}=6.06\end{array}$ & $\begin{array}{c}(\mathrm{B}-\mathrm{M})= \\
.0828 \pm .016 \\
\mathrm{p}=0.01 \\
\mathrm{df}=9.23\end{array}$ & $\begin{array}{c}(\mathrm{N}-\mathrm{B})= \\
.1260 \pm .089 \\
\mathrm{p}=0.32 \\
\mathrm{df}=4.16\end{array}$ \\
\hline $\mathbf{E}$ & & & $\begin{array}{c}(\mathrm{E}-\mathrm{I})= \\
.0605 \pm .010 \\
\mathrm{p}=0.01 \\
\mathrm{df}=6.88\end{array}$ & $\begin{array}{c}(\mathrm{E}-\mathrm{M})= \\
.0486 \pm .017 \\
\mathrm{p}=0.08 \\
\mathrm{df}=11.81\end{array}$ & $\begin{array}{c}(\mathrm{N}-\mathrm{E})= \\
.1886 \pm .090 \\
\mathrm{p}=0.11 \\
\mathrm{df}=5.31\end{array}$ \\
\hline I & & & & $\begin{array}{c}(\mathrm{M}-\mathrm{I})= \\
.0124 \pm .014 \\
\mathrm{p}=0.56 \\
\mathrm{df}=6.69\end{array}$ & $\begin{array}{c}(\mathrm{N}-\mathrm{I})= \\
.2488 \pm .089 \\
\mathrm{p}=0.05 \\
\mathrm{df}=5.02\end{array}$ \\
\hline $\mathbf{M}$ & & & & & $\begin{array}{c}(\mathrm{N}-\mathrm{M})= \\
.2482 \pm .09 \\
\mathrm{p}=.06 \\
\mathrm{df}=5.40\end{array}$ \\
\hline
\end{tabular}

Table 3.8: The method used to compare average wintertime salinity contribution values between GOMOOS buoys is described in section 2.2.5. Results are considered significant for $\mathrm{p}<.05$. 


\begin{tabular}{|c|c|c|c|c|c|}
\hline \multicolumn{6}{|c|}{$\begin{array}{c}\text { Comparison of Wintertime Temperature Contribution } \\
\text { between GOMOOS Buoys }\end{array}$} \\
\hline & B & $\mathbf{E}$ & I & $\mathbf{M}$ & $\mathrm{N}$ \\
\hline A & $\begin{array}{c}(\mathrm{B}-\mathrm{A})= \\
.0074 \pm .0078 \\
\mathrm{p}=0.443 \\
\mathrm{df}=7.51\end{array}$ & $\begin{array}{c}(\mathrm{E}-\mathrm{A})= \\
.0017 \pm .0070 \\
\mathrm{p}=0.84 \\
\mathrm{df}=7.57\end{array}$ & $\begin{array}{c}(\mathrm{I}-\mathrm{A})= \\
.0103 \pm .007 \\
\mathrm{p}=0.26 \\
\mathrm{df}=6.19\end{array}$ & $\begin{array}{c}(\mathrm{M}-\mathrm{A})= \\
.0069 \pm .008 \\
\mathrm{p}=0.47 \\
\mathrm{df}=8.49\end{array}$ & $\begin{array}{c}(\mathrm{A}-\mathrm{N})= \\
.0433 \pm .029 \\
\mathrm{p}=0.18 \\
\mathrm{df}=5.65\end{array}$ \\
\hline B & & $\begin{array}{c}(\mathrm{B}-\mathrm{E})= \\
.0018 \pm .0032 \\
\mathrm{p}=0.75 \\
\mathrm{df}=9.63\end{array}$ & $\begin{array}{c}(\mathrm{I}-\mathrm{B})= \\
.0071 \pm .0026 \\
\mathrm{p}=0.16 \\
\mathrm{df}=5.74\end{array}$ & $\begin{array}{c}(\mathrm{M}-\mathrm{B})= \\
.0035 \pm .0044 \\
\mathrm{p}=0.58 \\
\mathrm{df}=9.96\end{array}$ & $\begin{array}{c}(\mathrm{B}-\mathrm{N})= \\
.0317 \pm .0287 \\
\mathrm{p}=0.34 \\
\mathrm{df}=4.16\end{array}$ \\
\hline $\mathbf{E}$ & & & $\begin{array}{c}(\mathrm{I}-\mathrm{E})= \\
.0086 \pm .0018 \\
\mathrm{p}=0.03 \\
\mathrm{df}=7.41\end{array}$ & $\begin{array}{c}(\mathrm{M}-\mathrm{E})= \\
.0051 \pm .0039 \\
\mathrm{p}=0.31 \\
\mathrm{df}=11.34\end{array}$ & $\begin{array}{c}(\mathrm{E}-\mathrm{N})= \\
.0509 \pm .0286 \\
\mathrm{p}=0.16 \\
\mathrm{df}=5.09\end{array}$ \\
\hline I & & & & $\begin{array}{c}(\mathrm{I}-\mathrm{M})= \\
.0036 \pm .0037 \\
\mathrm{p}=0.41 \\
\mathrm{df}=6.87\end{array}$ & $\begin{array}{c}(\mathrm{I}-\mathrm{N})= \\
.0603 \pm .0286 \\
\mathrm{p}=0.12 \\
\mathrm{df}=5.01\end{array}$ \\
\hline $\mathbf{M}$ & & & & & $\begin{array}{c}(\mathrm{M}-\mathrm{N})= \\
.0600 \pm .029 \\
\mathrm{p}=.13 \\
\mathrm{df}=5.14\end{array}$ \\
\hline
\end{tabular}

Table 3.9: The method used to compare average wintertime temperature contribution values between GOMOOS buoys is described in section 2.2.5. Results are considered significant for $\mathrm{p}<.05$. 


\begin{tabular}{|l|c|c|c|c|c|c|c|}
\hline \multicolumn{7}{|c|}{ Depth-Averaged Wintertime Salinity and Temperature } \\
\hline \multicolumn{7}{|c|}{ at GOMOOS Buoys } \\
\hline \multirow{2}{*}{ salinity (A) } & $\mathbf{2 0 0 4}$ & $\mathbf{2 0 0 5}$ & $\mathbf{2 0 0 6}$ & $\mathbf{2 0 0 7}$ & $\mathbf{2 0 0 8}$ & $\mathbf{2 0 0 9}$ & $\mathbf{2 0 1 0}$ \\
& 32.69 & 31.76 & 31.95 & 32.60 & 32.05 & 32.18 & 31.58 \\
& \pm 0.18 & \pm 0.12 & \pm 0.21 & \pm 0.30 & \pm 0.31 & \pm 0.14 & \pm 0.77 \\
\hline \multirow{2}{*}{ temperature (A) } & 3.14 & 3.44 & 4.72 & 5.08 & 3.78 & 3.61 & 4.38 \\
& \pm 0.82 & \pm 1.03 & \pm 0.65 & \pm 1.28 & \pm 0.71 & \pm 0.65 & \pm 0.61 \\
\hline \multirow{2}{*}{ salinity (B) } & 33.05 & 31.97 & 32.37 & 33.03 & 32.40 & 32.50 & \\
& \pm 0.18 & \pm 0.13 & \pm 0.12 & \pm 0.09 & \pm 0.19 & \pm 0.04 & \\
\hline \multirow{2}{*}{ temperature (B) } & 3.60 & 3.57 & 5.03 & 5.43 & 3.88 & 3.83 & \\
& \pm 1.12 & \pm 1.22 & \pm 0.79 & \pm 1.65 & \pm 0.72 & \pm 0.82 & \\
\hline \multirow{2}{*}{ salinity (E) } & 33.04 & 32.03 & 32.44 & 33.03 & 32.55 & 32.63 & 32.31 \\
& \pm 0.17 & \pm 0.09 & \pm 0.07 & \pm 0.11 & \pm 0.12 & \pm 0.06 & \pm 0.19 \\
\hline \multirow{2}{*}{ temperature (E) } & 3.68 & 3.24 & 4.76 & 5.31 & 3.78 & 3.75 & 4.46 \\
& \pm 1.40 & \pm 1.28 & \pm 0.90 & \pm 1.81 & \pm 0.59 & \pm 1.18 & \pm 0.74 \\
\hline \multirow{2}{*}{ salinity (I) } & 32.91 & 32.06 & 32.44 & 32.91 & 32.55 & 32.64 & 32.28 \\
& \pm 0.20 & \pm 0.10 & \pm 0.13 & \pm 0.07 & \pm 0.22 & \pm 0.12 & \pm 0.27 \\
\hline \multirow{2}{*}{ temperature (I) } & 3.34 & 3.37 & 4.82 & 4.73 & 3.96 & 3.70 & 4.68 \\
& \pm 1.41 & \pm 0.97 & \pm 0.99 & \pm 1.54 & \pm 0.81 & \pm 0.80 & \pm 0.83 \\
\hline \multirow{2}{*}{ salinity (M) } & 32.95 & 31.96 & 32.62 & 33.11 & 32.87 & 32.89 & 32.19 \\
& \pm 0.36 & \pm 0.14 & \pm 0.33 & \pm 0.17 & \pm 0.22 & \pm 0.18 & \pm 0.27 \\
\hline \multirow{2}{*}{ temperature (M) } & 4.19 & 3.76 & 5.15 & 5.87 & 4.69 & 4.85 & 4.62 \\
& \pm 1.26 & \pm 1.21 & \pm 0.97 & \pm 1.24 & \pm 0.76 & \pm 0.86 & \pm 0.99 \\
\hline \multirow{2}{*}{ salinity (N) } & & 32.16 & 32.46 & 31.75 & 32.10 & 31.92 & \\
\hline \multirow{2}{*}{ temperature (N) } & & 3.75 & 5.57 & 3.57 & 3.77 & 3.50 & \\
\hline & & \pm 0.73 & \pm 0.98 & \pm 1.80 & \pm 0.85 & \pm 1.20 & \\
\hline
\end{tabular}

Table 3.10: Depth-averaged wintertime values of salinity and temperature are calculated for 2004-2010 using 20 day rolling average values from 1, 20, and $50 \mathrm{~m}$. Salinity is given in PSU and temperature in ${ }^{\circ} \mathrm{C}$. Standard error $( \pm 1)$ is found by taking the standard deviation of depth-averaged values for a particular year and dividing by the decorrelation time. Seasonal decorrelation times are assumed. 


\begin{tabular}{|c|c|c|c|}
\hline \multicolumn{4}{|c|}{$\begin{array}{c}\text { Percent of the Time after a Wind Event that } \\
\text { Stratification Decreased }\end{array}$} \\
\hline & $\tau=60 \mathrm{~m}^{2} / \mathrm{sec}^{2}$ & ${ }^{*} \tau=70 \mathrm{~m}^{2} / \mathrm{sec}^{2}$ & $\tau=80 \mathrm{~m}^{2} / \mathrm{sec}^{2}$ \\
\hline $\mathbf{A}$ & 42 & 45 & $40^{* *}$ \\
\hline $\mathbf{B}$ & $33^{*}$ & 50 & $44^{*}$ \\
\hline $\mathbf{E}$ & $26^{* *}$ & 45 & 45 \\
\hline $\mathbf{I}$ & $26^{* *}$ & $35^{* *}$ & $41^{* *}$ \\
\hline $\mathbf{M}$ & 37 & $30^{* *}$ & $18^{* *}$ \\
\hline $\mathbf{N}$ & $26^{* *}$ & $25^{* *}$ & $23^{* *}$ \\
\hline
\end{tabular}

Table 3.11: Values of stratification are compared for the upper water-column (0$20 \mathrm{~m}$ ) before and after wind events of various magnitudes. The percent of time that stratification decreased after a wind event is calculated for each GOMOOS buoy using different wind stress thresholds. The wind stress thresholds chosen represent both sides of the average wintertime wind stress magnitude $\left({ }^{*} \tau\right)$. The average is based on wind stress magnitudes during the winter for 2004-2010.*" indicates significance at $10 \%$ level and "**" indicates significance at the $5 \%$ level. 


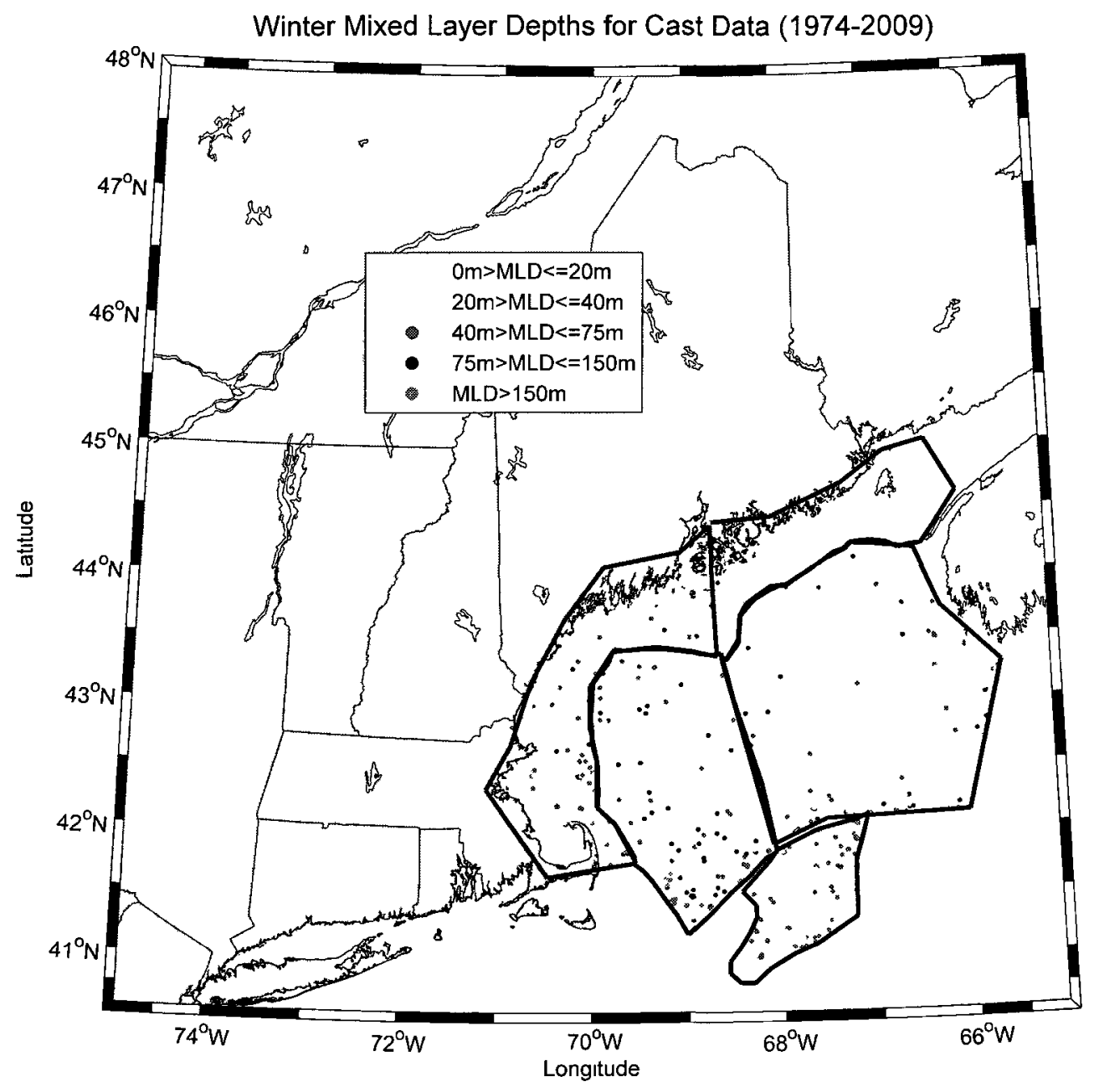

Figure 3-1: Map of wintertime mixed layer depths generated from BIO and COOA cast data. Mixed layer depths are generally shallowest in the Coastal and Eastern Zones. 

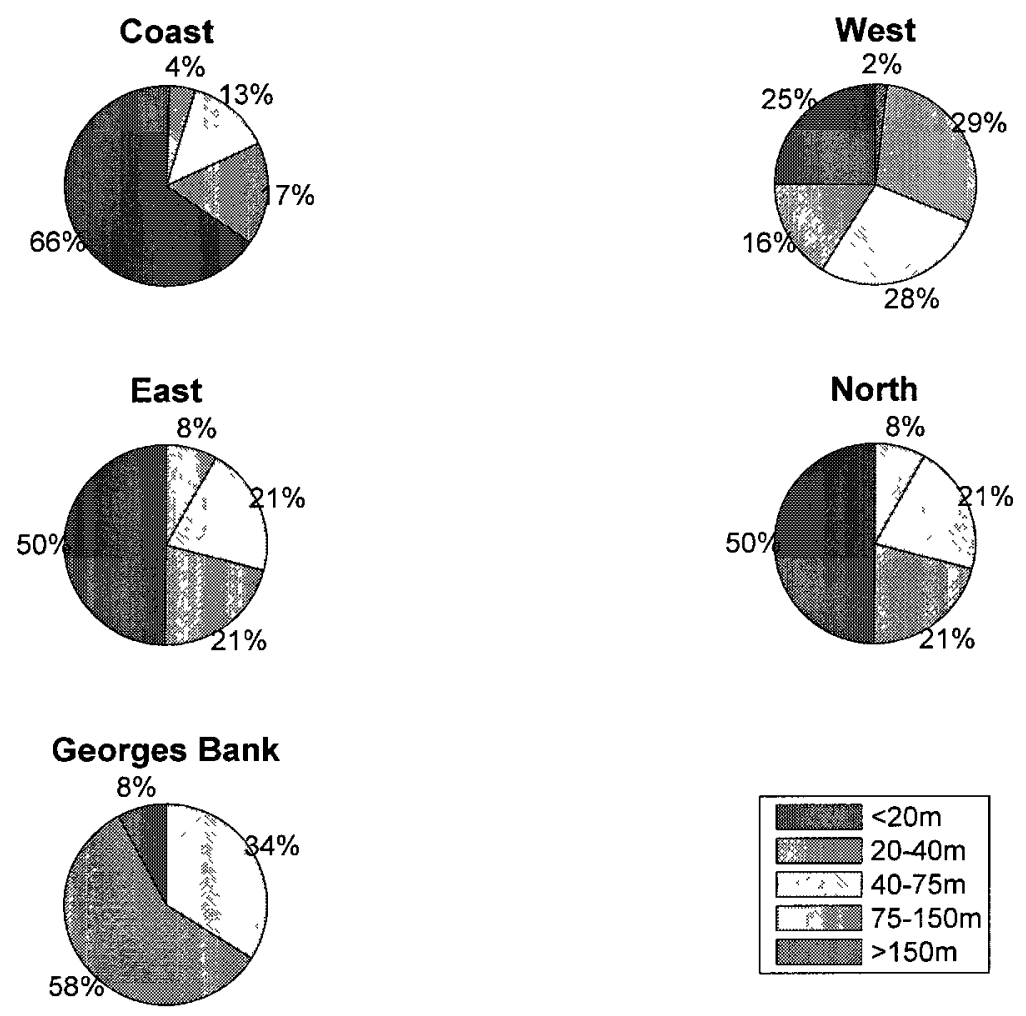

\begin{tabular}{|c|c|}
\hline 11707\% & 霝 $<20 \mathrm{~m}$ \\
\hline - & $20-40 \mathrm{~m}$ \\
\hline$\% 2$ & $40-75 \mathrm{~m}$ \\
\hline 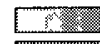 & $75-150 \mathrm{~m}$ \\
\hline 0 & $>150 \mathrm{~m}$ \\
\hline
\end{tabular}

Figure 3-2: Percentage of wintertime mixed layers within given depth ranges. Percentages come from BIO and COOA cast data. 


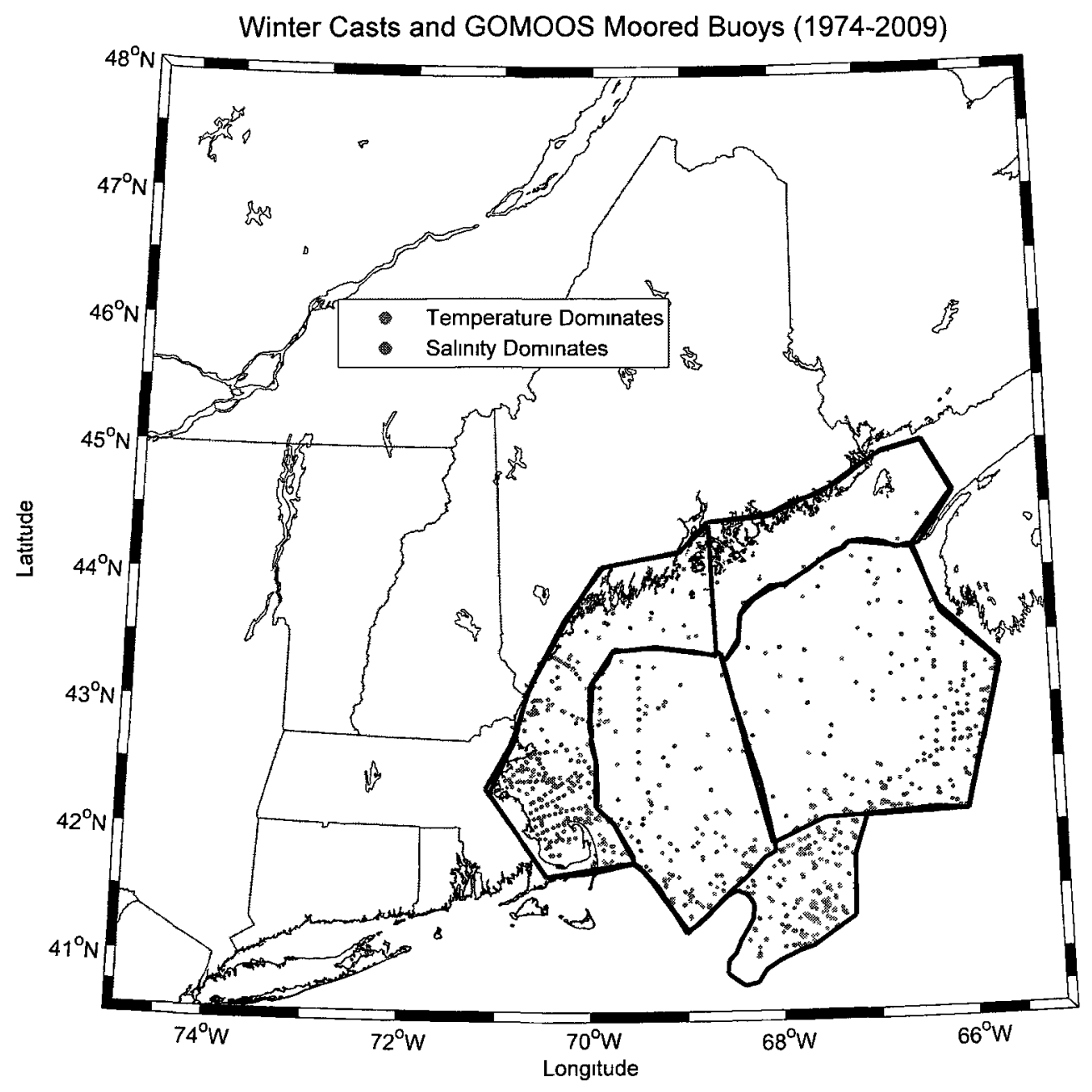

Figure 3-3: A map of the GOM, showing for each winter cast between 1974-2009 the dominating factor (salinity or temperature) in controlling the density increase in the upper $20 \mathrm{~m}$ of the water-column. 


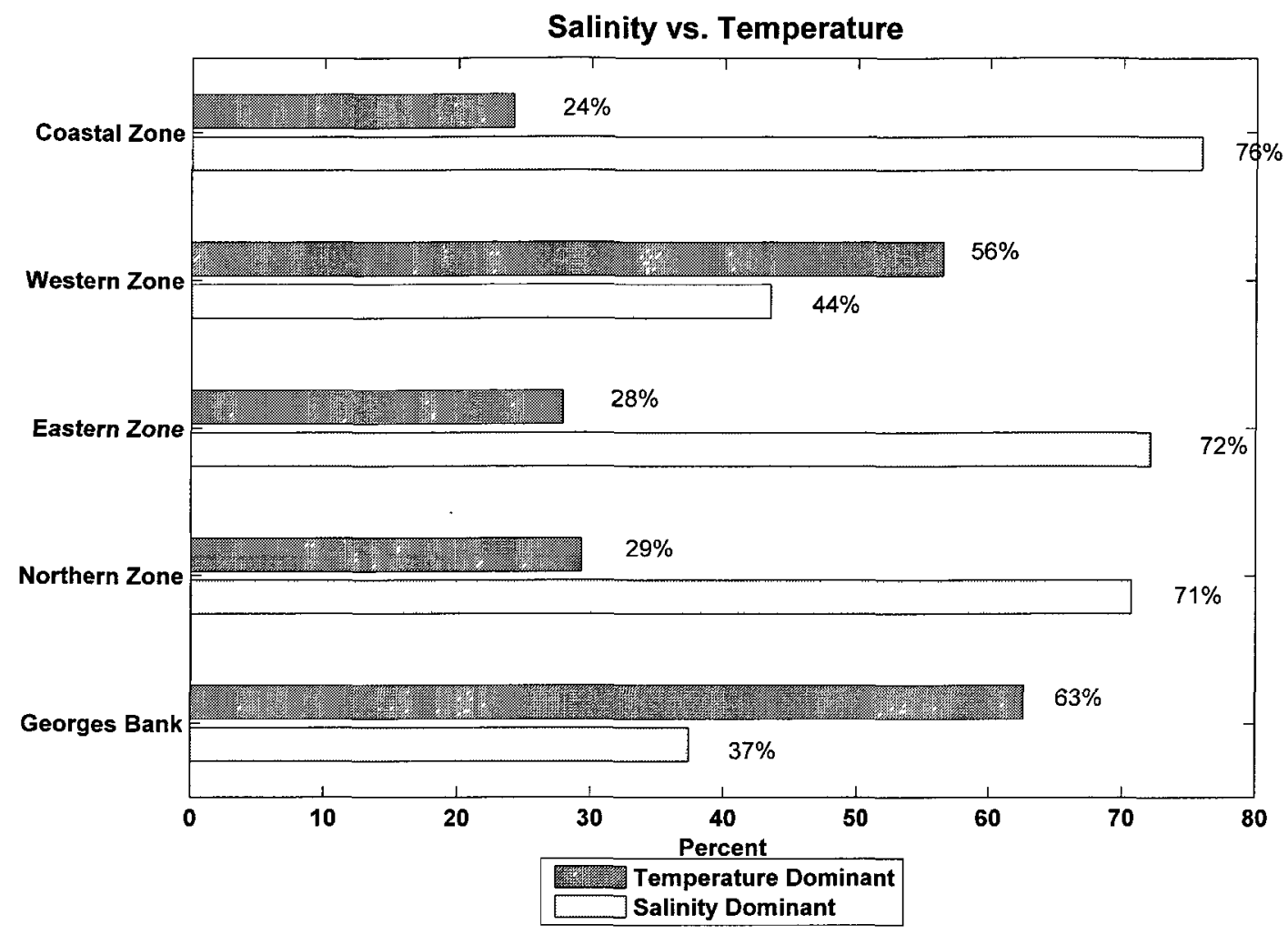

Figure 3-4: Percentage of casts within each zone which owe density increase in the upper $20 \mathrm{~m}$ to salinity or temperature. 

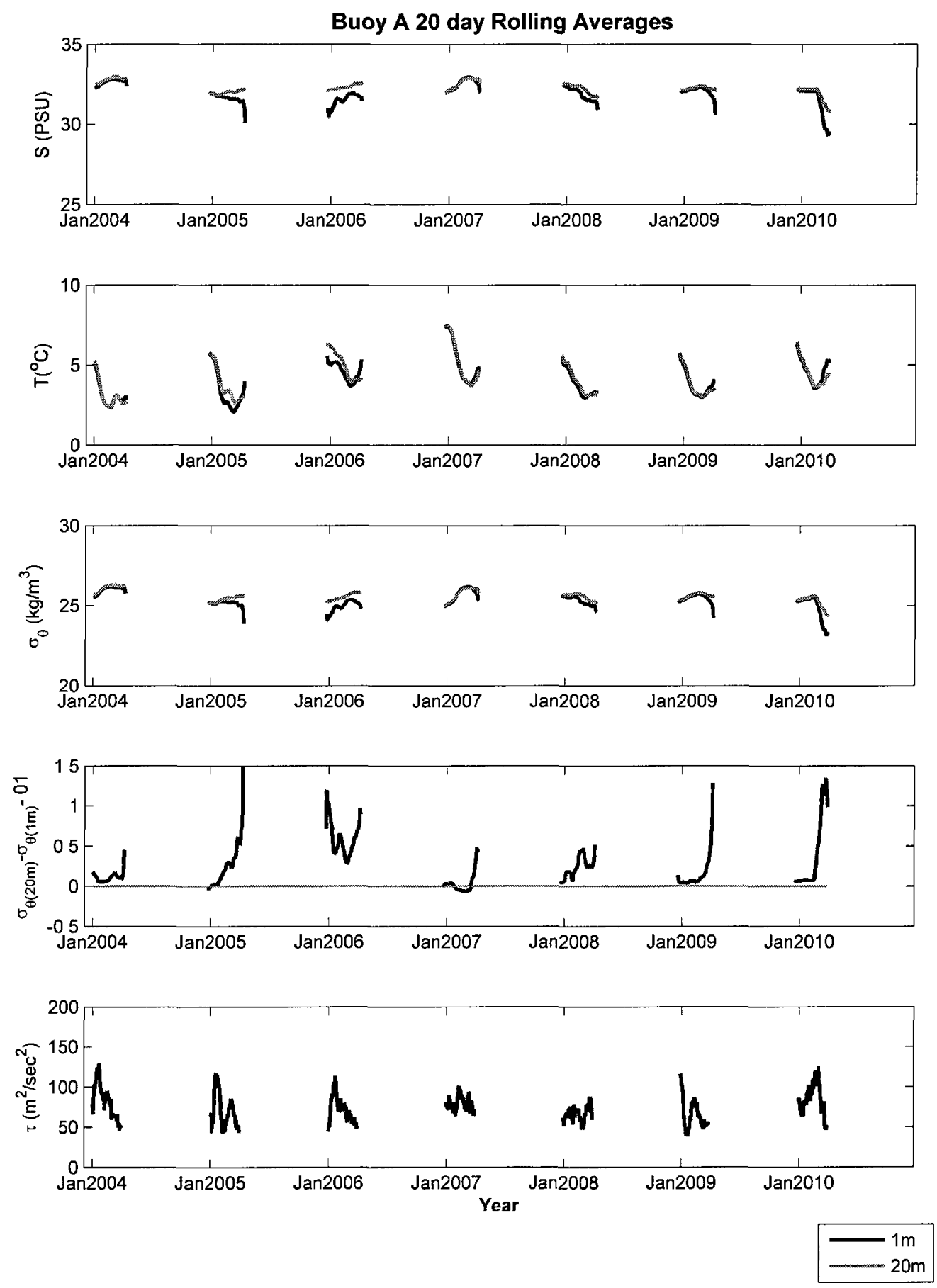

Figure 3-5: 20 day rolling averages of salinity, temperature, potential density, and pseudo wind stress are plotted at 1 and $20 \mathrm{~m}$ for $2004-2010$. Data from $50 \mathrm{~m}$ is not available for many years, and is thus not included. The plot of $\left(\sigma_{\theta}(20 m)-\sigma_{\theta}(1 m)-.01\right)$ (solid black line) above the horizontal red line at zero shows times when a shallow mixed layer was present. 

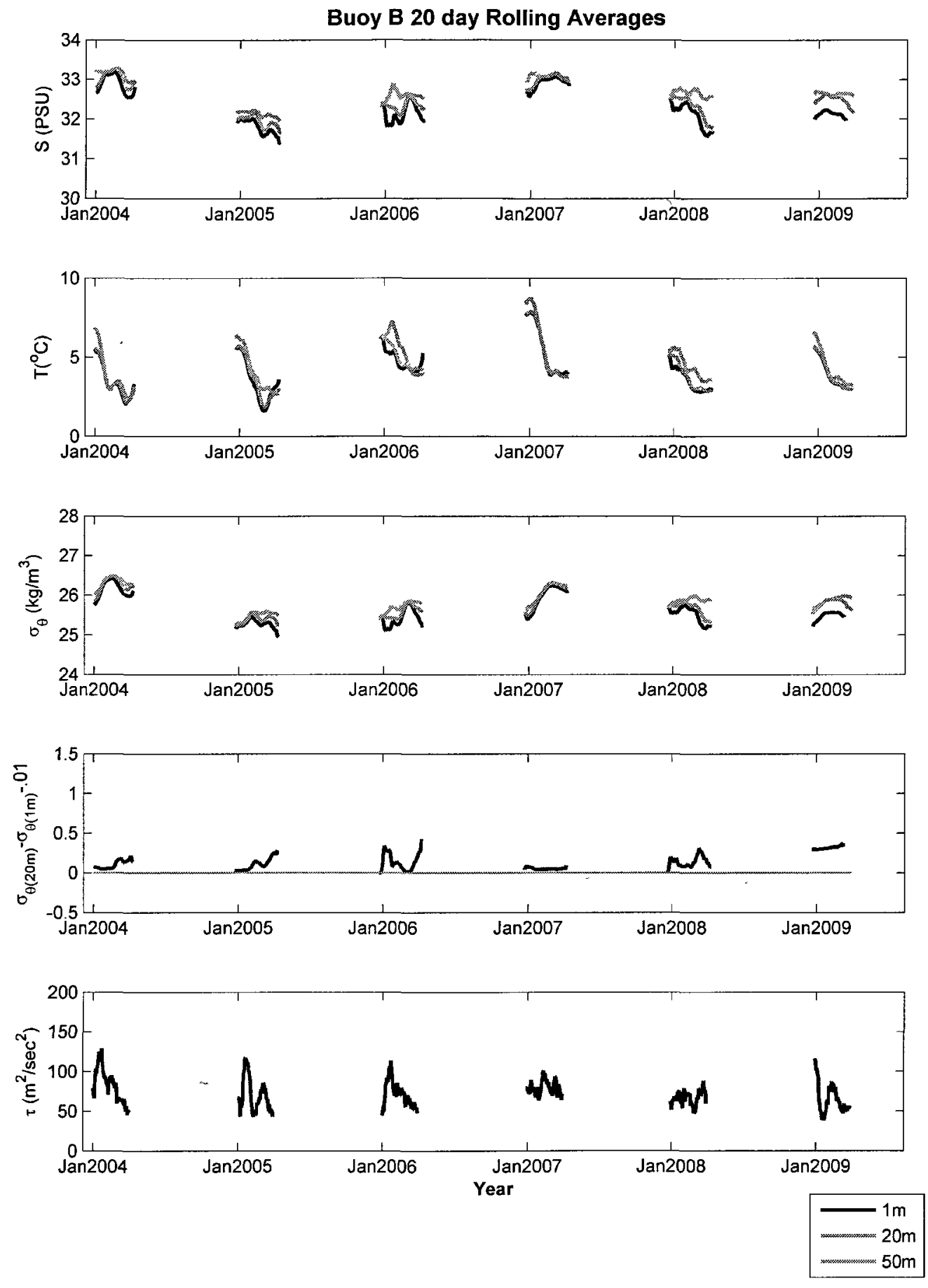

Figure 3-6: 20 day rolling averages of salinity, temperature, potential density, and pseudo wind stress are plotted at 1,20, and 50m for 2004-2009. Bad data at the end of 2009 prematurely terminates the salinity, temperature, and density record at $1 \mathrm{~m}$. The plot of $\left(\sigma_{\theta}(20 m)-\sigma_{\theta}(1 m)-.01\right)$ (solid black line) above the horizontal red line at zero shows times when a shallow mixed layer was present. 

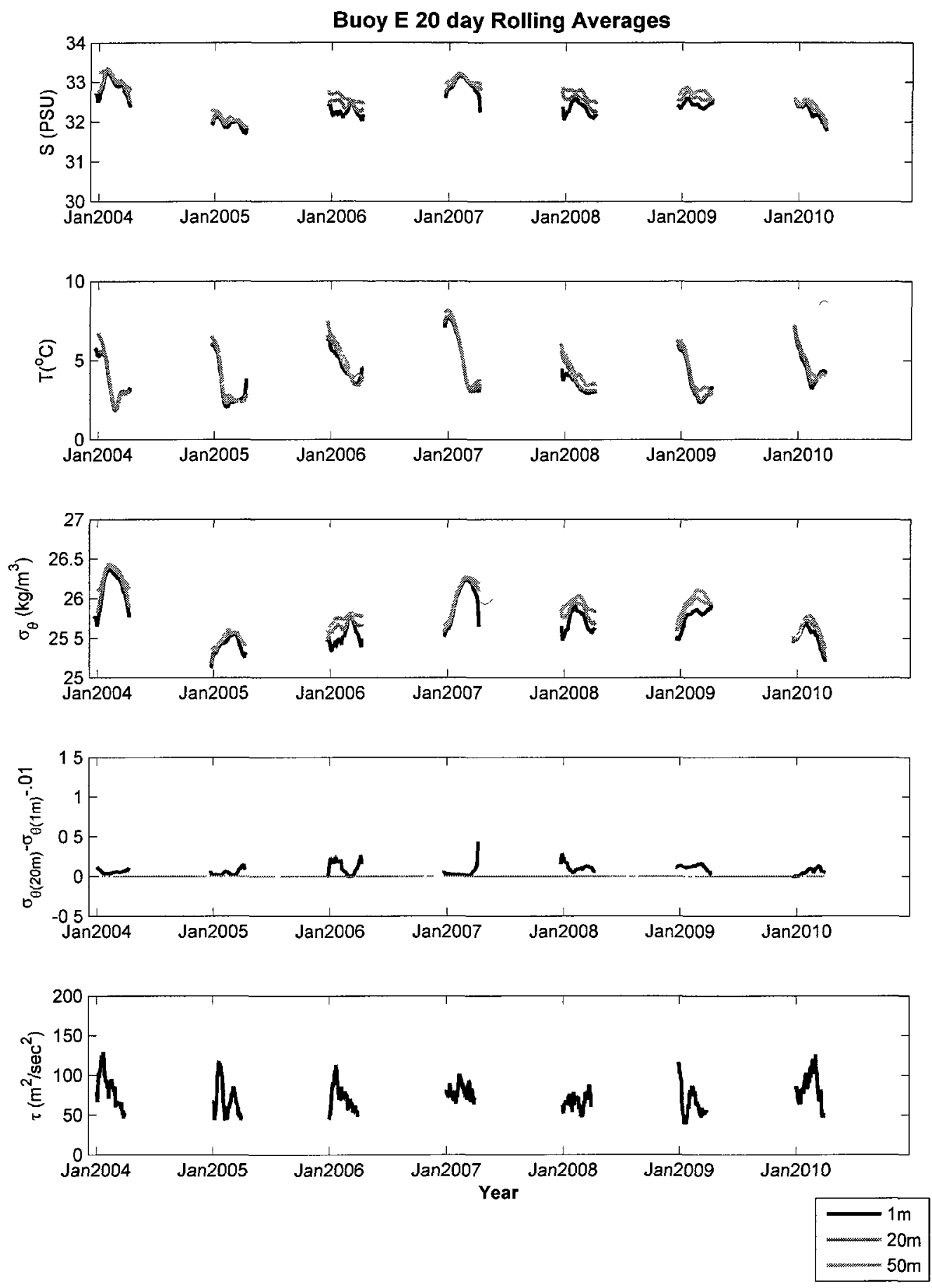

Figure 3-7: 20 day rolling averages of salinity, temperature, potential density, and pseudo wind stress are plotted at 1,20 , and $50 \mathrm{~m}$ for 2004-2010. The plot of $\left(\sigma_{\theta}(20 \mathrm{~m})\right.$ $\left.\sigma_{\theta}(1 m)-.01\right)$ (solid black line) above the horizontal red line at zero shows times when a shallow mixed layer was present. 

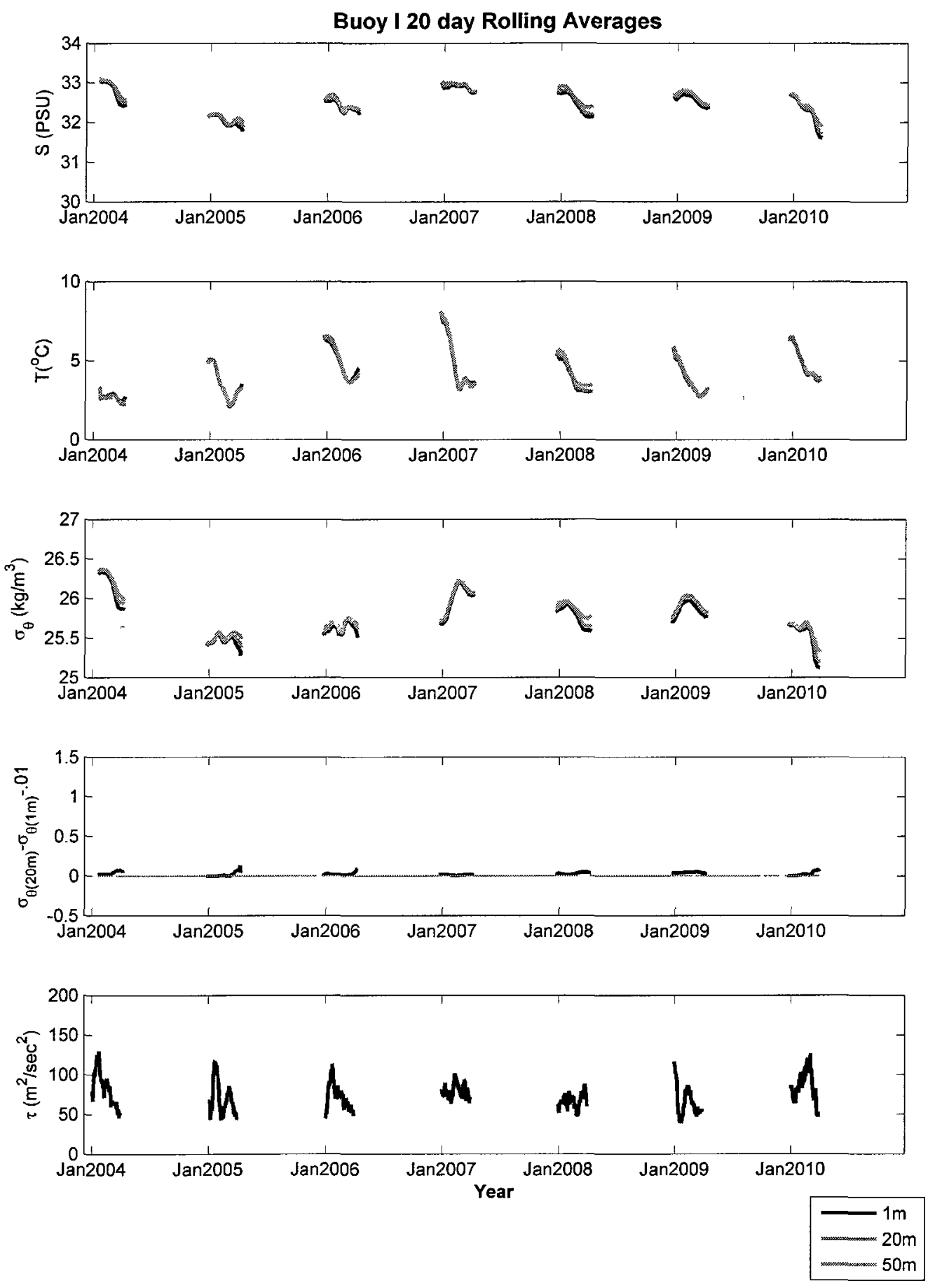

Figure 3-8: 20 day rolling averages of salinity, temperature, potential density, and pseudo wind stress are plotted at 1,20 , and $50 \mathrm{~m}$ for 2004-2010. The plot of $\left(\sigma_{\theta}(20 \mathrm{~m})\right.$ $\left.\sigma_{\theta}(1 m)-.01\right)$ (solid black line) above the horizontal red line at zero shows times when a shallow mixed layer was present. 

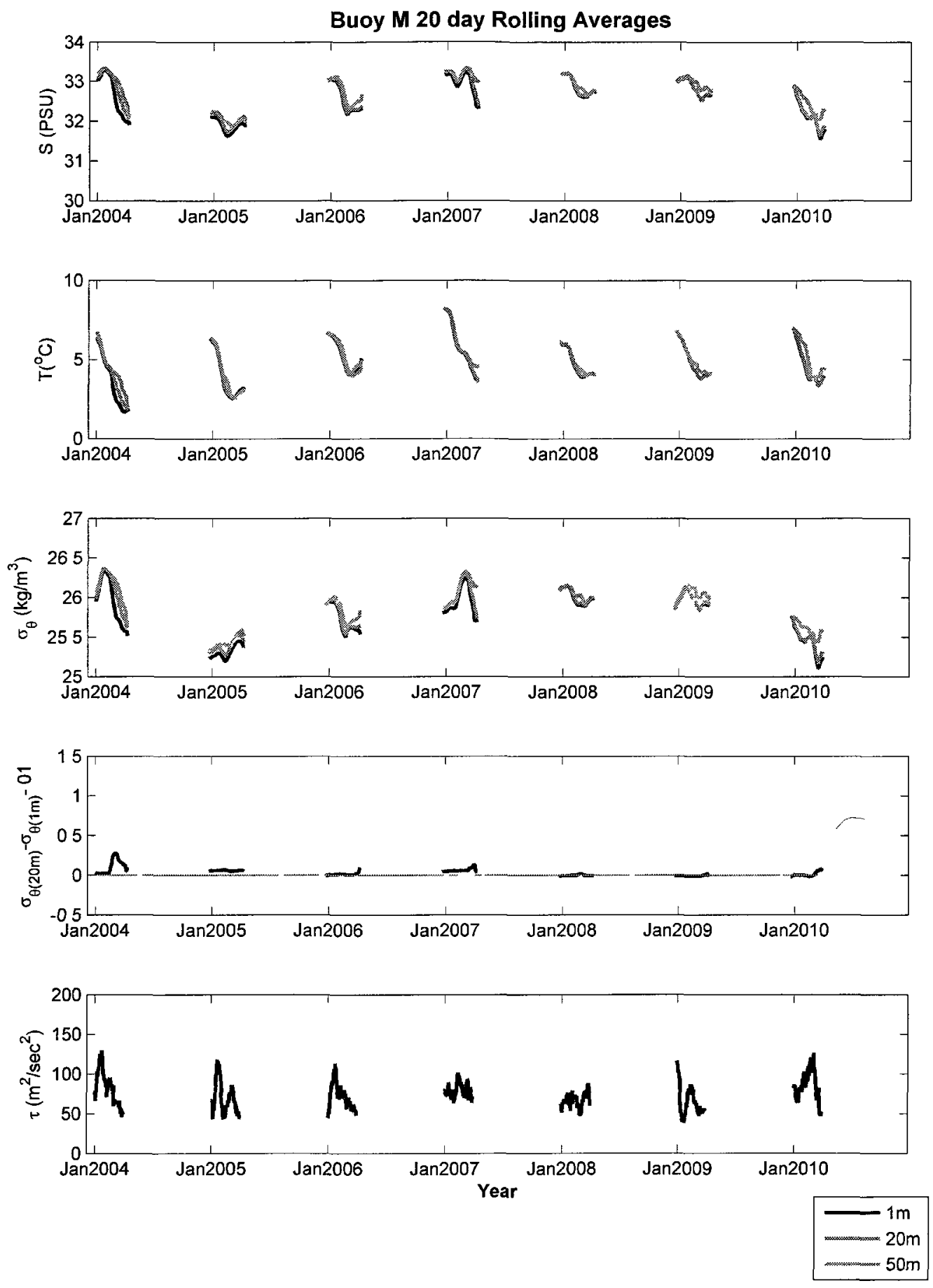

Figure 3-9: 20 day rolling averages of salinity, temperature, potential density, and pseudo wind stress are plotted at 1,20 , and $50 \mathrm{~m}$ for 2004-2010. The plot of $\left(\sigma_{\theta}(20 \mathrm{~m})\right.$ $\left.\sigma_{\theta}(1 m)-.01\right)$ (solid black line) above the horizontal red line at zero shows times when a shallow mixed layer was present. 

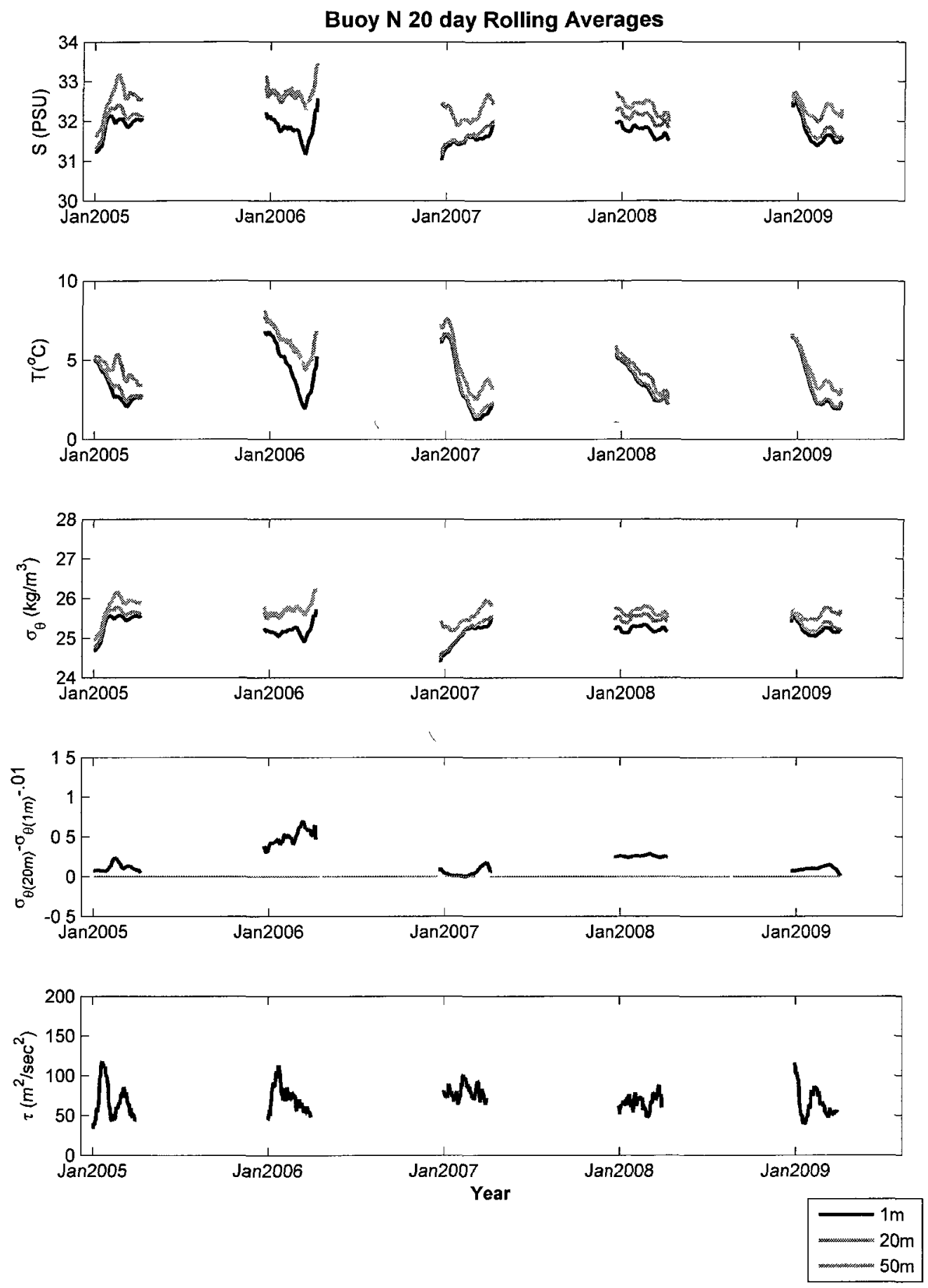

Figure 3-10: 20 day rolling averages of salinity, temperature, potential density, and pseudo wind stress are plotted at 1,20 , and $50 \mathrm{~m}$ for 2005-2009. The plot of $\left(\sigma_{\theta}(20 \mathrm{~m})\right.$ $\left.\sigma_{\theta}(1 m)-.01\right)$ (solid black line) above the horizontal red line at zero shows times when a shallow mixed layer was present. 


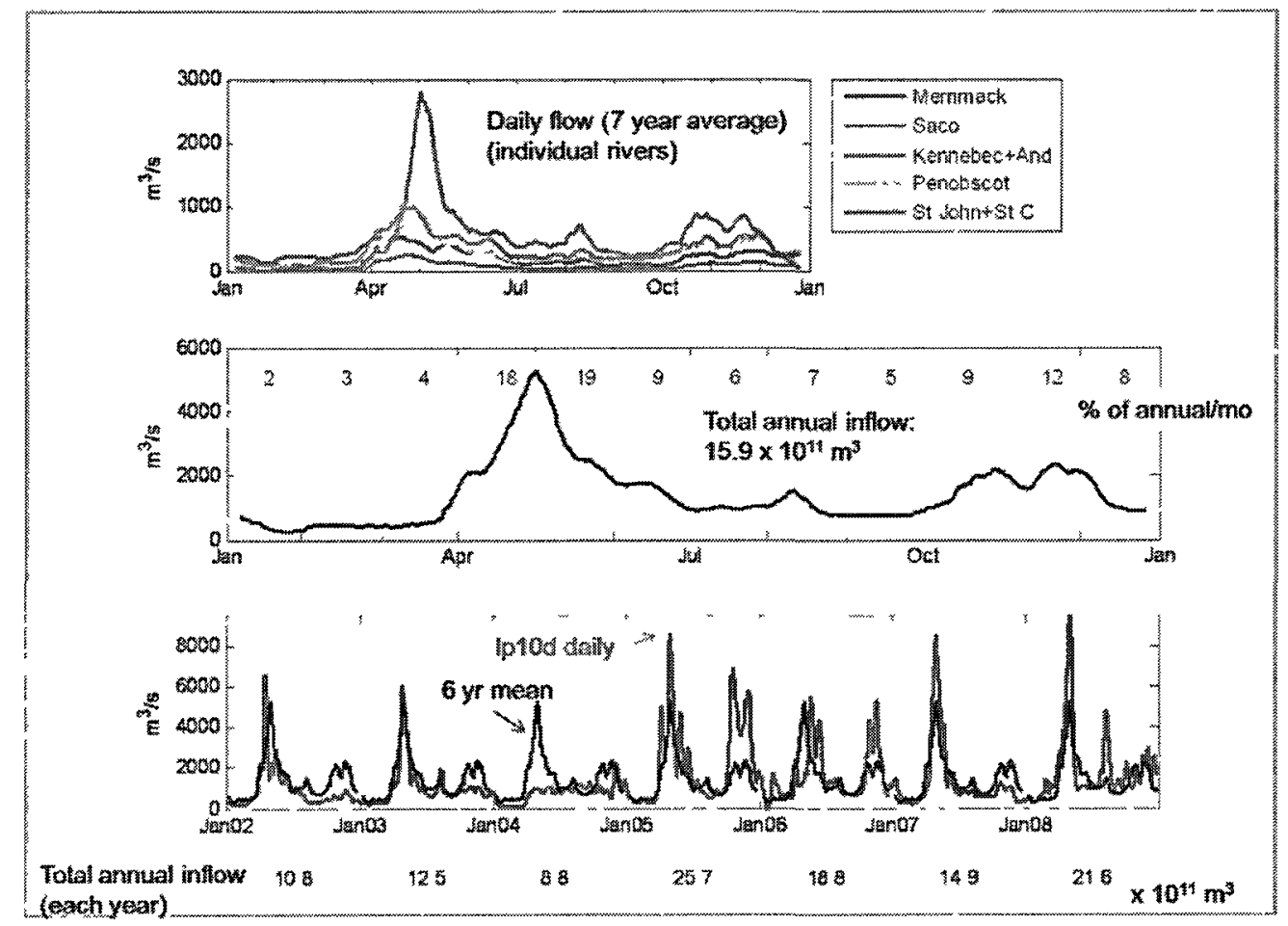

Figure 3-11: Gulf of Maine river discharge from (Deese-Riordan, 2009). Top panel: Flow rates from USGS gauges are averaged over seven years (2001-2008) for each day. Daily dishcarge values are smoothed with a 10 day rolling average. Dishcarge values from the St. John and St. Croix Rivers and the Kennebec and Androscoggin Rivers are combined. Average discharge is the greatest in the spring. Middle Panel: Total discharge of all rivers combined. Bottom Panel: total river inflow smoothed using a 10 day rolling average (lp10day) compared to 6 year average daily values (black line). Total inflow for each year in $10^{11} \mathrm{~m}^{3} / y r$ is shown below the bottom panel. 


\section{CHAPTER 4}

\section{DISCUSSION AND CONCLUSIONS}

\subsection{Major Findings}

\subsubsection{Regional Differences in Stratification}

Shallow mixed layers are frequently found in the Coastal and Eastern Zones of the GOM during the winter. Time-series records from the GOMOOS moorings show that shallow mixed layers persist throughout the winter at many coastal locations and in the far-eastern GOM. In contrast, cast data from 1970-2009 show that deeper mixing occurs in the interior GOM. Tidally-forced, full water-column mixing occurs in the Northern Zone and over Georges Bank. Quantifying the contributions of salinity and temperature to density increase in the upper water-column shows that salinity increase with depth is more important in the Coastal, Northern, and Eastern Zones, while temperature decrease with depth is more important in the Western Zone and over Georges Bank.

\subsubsection{Patterns in the Coastal and Eastern Zones}

Stratification during the winter is most pronounced in the Coastal and Eastern Zones of the GOM. These areas have the highest average stabilities and shallowest mixed layer depths (Table 2.13 and Fig. 3-1). A variety of factors impact stratification in the upper water-column (0-20m) in the Coastal Zone. These include fresh river discharge, circulated SSW, tidal/wind mixing, and ocean-air heat flux (Townsend, 
1991). Tidal/wind mixing reduces stratification by physically stirring the watercolumn. Cooling the surface waters initiates vertical mixing by creating dense water that sinks. Conversely, river discharge and SSW increase stratification by creating a salinity gradient in the upper-water column. In this situation, the water-column will resist overturning since less-dense, fresher water is above more-dense, saltier water. In the Coastal Zone, both the cast data and GOMOOS mooring data agree that salinity increase with depth is the primary cause of winter strattication. In fact, $81 \%$ of casts with a shallow mixed layer $(<20 \mathrm{~m})$ owe their density increase to salinity (Fig. 4-1). At Buoys A, B, and E, in the Coastal Zone, average salinity contributions are positive and signficant $(\mathrm{P}<.05)$, while temperature contributions are not statistically different from zero $(\mathrm{P}>.10)$. Average wintertime salinity contribution and stability values at Buoys $\mathrm{A}$ and $\mathrm{B}$, in the southern Coastal Zone, are typically higher than other coastal GOMOOS moorings because fresh river discharge accumulates in the Northern and Coastal Zones and flows southward in the WMCC (Fong et al., 1997). Since it takes a few months for SSW to impact Buoys A and B, freshening will mainly be caused by river discharge or runoff in these areas (Deese-Riordan, 2009). Further north along the Maine Shelf, at Buoys E and I, however, it is expected that both river discharge and SSW will influence the density structure of the water-column (Bisagni et al., 1996). The degree to which SSW influences areas along the Northern Maine Shelf will depend on the total inflow volume during the winter as well as the extent of mixing with deeper, more saline waters (Brown and Beardsley, 1978; Smith et al., 2001).

The Eastern Zone is strongly impacted by the inflow of cool, fresh SSW at the surface, and by deep, saline slope water that enters the GOM through the Northeast Channel (Ramp et al., 1985). Maximum inflow of SSW occurs during the winter (Smith, 1983). Fresh SSW overrides dense, more saline water and creates a pronounced salinity gradient. This salinity gradient is responsible for the relatively 
stratified water-column seen throughout the winter in the Eastern Zone (Mountain and Manning, 1994). The presence of SSW in this region is clear from the spatial distribution of shallow mixed layers $(<20 \mathrm{~m})$ seen in the Eastern Zone (Fig. 3-1). In the Eastern Zone, $92 \%$ of casts with a shallow mixed layer owe their density increase to increased salinity with depth. This finding is supported by the positive average salinity contribution value seen over the Northeast Channnel (Buoy N) during the

winter. According to averaged cast data, temperature does not contribute to the stratification seen in this area since the average temperature change with depth is small and statistically insignificant $(\mathrm{P}>.10)$.

Salinity driven stratification events in the Coastal and Eastern Zones are accompanied by temperature inversions in the upper water-column. During these events, salinity increase in the upper $20 \mathrm{~m}$ is great enough to counter temperature inversions. Temperature inversions during stratification events may be the result of increased cooling of the surface layer, or the advection of a cold, fresh water past the mooring (Deese-Riordan, 2009). Stratification intensifies temperature change of the surface ocean since only a relatively thin layer is interacting with the cold, winter atmosphere. Deep mixing, on the other hand, homogenizes a greater volume of water and makes changes from atmospheric forcing more gradual.

\subsubsection{Patterns in the Western Zone}

The Western Zone is characterized by greater mixing and low average stability in the upper $20 \mathrm{~m}$. In contrast to the Coastal and Eastern Zones, where temperature contributions are larger than salinity contributions in only $25 \%$ of casts, in the Western Zone, temperature contributions are greater than salinity contributions in $56 \%$ of casts. In other words, in more than half of the casts taken during the winter in the Western Zone, temperature had a greater impact on upper water-column density increase than salinity. In this region, surface water cooled by the atmosphere is able 
to penetrate to deeper depths because typically the water-column is weakly-stratified (Pringle, 2006). Fresh river discharge in the Coastal Zone does not have a significant impact on the density structure of the upper water-colum $(0-20 \mathrm{~m})$ in Western Zone because it is confined by the WMCC. Furthermore, even under conditions of upwelling favorable, southwest winds, fresh plumes thin and mix with increasing distance offshore (Fong et al., 1997). It is interesting that $73 \%$ of casts with a shallow mixed layer in the Western Zone have a salinity contribution greater than temperature contribution. This indicates that although deep mixing is the norm in the Western Zone, when shallow mixed layers do occur, fresh surface water is often responsible. This fresh surface water may result from advection of SSW or offshore extension of the EMCC (Brooks, 1985). For the shallow mixed layers whose density increase is primarily from temperature decrease, however, warming of surface waters on relatively warm, sunny winter days may be important.

\subsubsection{Patterns in the Northern Zone and over Georges Bank}

The Northern Zone and Georges Bank are heavily influenced by tidal mixing (Townsend, 1991). On average, stratification in these areas is very low due to the physical mixing of the water column. The Northern Zone is influenced by fresh river discharge from the St. John and St. Croix rivers. SSW also contributes to the freshening of this region (Bisagni et al., 1996). In the Northern Zone, $71 \%$ of casts have salinity contributions greater than temperature contributions. More importantly, salinity increase with depth is responsible for $96 \%$ casts with a shallow mixed layer in this region. Data from Buoy I, on the Eastern Maine Shelf, supports this finding, showing that on average the salinity contribution is positive and significant $(\mathrm{P}<.05)$, while temperature contribution not significantly different from zero $(\mathrm{P}>.10)$.

On average, salinity and temperature change in the upper $20 \mathrm{~m}$ are not significantly different from zero over Georges Bank $(\mathrm{P}>.10)$. However, comparing salinity and 
temperature contributions for each cast, reveals that the majority of casts (63\%) over Georges Bank owe density increase in the upper water-column to temperature decrease. Like the other regions, however, it is salinity increase in the upper $20 \mathrm{~m}$ that sets up the majority (87\%) of shallow mixed layers in this region. The likely cause of the observed salinity driven stratification during these events is the presence of SSW (Smith et al., 2001). Shallow mixed layers caused by temperature decrease with depth may be caused by atmospheric heating of the surface layer or the presence of warm-core Gulf Stream rings (Brooks, 1985).

\subsubsection{Interannual Variability of Salinity and Temperature in the Upper $50 \mathrm{~m}$}

As discussed in section 3.4.1, the $\sim 3$ year variability of salinity and temperature change is apparent at all GOMOOS buoys. Salinity and temperature increase/decrease are in sync at all moorings and depths considered (1,20, and 50m). Salinities and temperatures fell from 2004-2005, increased from 2005-2007, and then fell again from 2007-2009. Although it is accepted that the origin of salinity and temperature differences in the grcater GOM can be traced back to the hydrographic properties of SSW and slope water (Smith et al., 2001; Petrie and Drinkwater, 1993), more research is necessary to explain the short-term variability seen at the GOMOOS moorings. To date, sub-decadal to decadal variations in salinity and temperature have been observed in the GOM and attributed to fluctuations in the western transport of Labrador Slope Water (Petrie and Drinkwater, 1993). Smith et al. (2001) postulated that variability in salinity and temperature anomalies noticed by Petrie and Drinkwater (1993) may be linked with the North Atlantic Oscillation (NAO). The NAO index describes the pressure difference at sea-level between the Azores/Bermuda "High" and the Icelandic "Low". When the NAO index is high and positive, "the Icelandic Low deepens and intensifies, producing excessively strong, cold winter winds off the 
North American continent and over the Labrador Sea/Baffin Bay" (Smith et al., 2001). These periods of intense cold weather, in combination with freshwater from Arctic origins, may be the source of cold, fresh water that is eventually advected to the Scotian Shelf and GOM (Smith et al., 2001). According to Petrie (2007), however, changes in the western transport of Labrador Slope Water, linked with changes in the NAO, have a bigger impact on salinity and temperature in the GOM. Petrie (2007) found that warmer, saltier conditions prevail in the GOM during sustained periods (at least 2 years) with positive NAO index. During these periods, cold, relatively fresher Labrador Slope Water is not transported as far westward and "allows positive bottom temperature anomalies to develop more readily on the western Scotian Shelf and in the Gulf of Maine". These differences are seen in the deep waters of the GOM, and are subsequently reflected in surface waters by deep mixing of the water-column. Improved understanding of the conditions that create the surface and deep waters which move into the GOM, and the factors that control the volume of their respective inflow, will help in forecasting the density structure of the GOM. The ways in which the density structure of the water-column impact biological and physical systems will be explored in section 4.3 .

\subsubsection{Wind Stress and Stratification}

The relationship between wind stress and stratification is often difficult to measure accurately. Intuitively one would expect stratification to decrease following periods of high wind stress. For example, in the GOM region, it is well-accepted that destratification during the fall coincides with cooling and sinking of surface waters in conjunction with increasing frequency of strong wind events (Lentz et al., 2003). Based on findings in this study, however, increased wind stress during the winter does not necessarily mean decreased stratification. A visual inspection of trends of stratification compared with a time-series of pseudo-stress illustrates this nicely. In 
some cases, as at Buoy B in 2006, maximum wind stress values in combination with downwelling-favorable (northerly) winds, coincided with the period of highest stratification in the upper $20 \mathrm{~m}$ (Fig. 4-2).

Differences in the pattern of pre- and post-wind event stratifications in the fall and winter, might be explained by seasonal differences in hydrographic and meteorological conditions in the GOM. For example, mixing linked with a wind event during the late summer or early fall may result in temporary destratification followed by the redevelopment of stratification from thermal heating of the surface layer. In the winter, however, re-stratification may not occur following the conclusion of a major wind event since temperatures are much colder and average wind stress values are higher. In this situation, it is not useful to compare before and after wind event stratification values since the water may be unstratified to begin with. Instead, regional changes in stratification during the winter are better accounted for by changes in the volume inflows of river and SSW.

A potential issue in attempting to correlate stratification and wind stress at a fixed point, like a mooring, is that water-mass advection is ignored. In this case, although increased wind stress magnitude is expected to cause increased mixing and the breakdown of stratification, it may instead be responsible for the advection of a different water mass which shows a high degree of stratification. Further complications also arise when considering non-linearities associated with wind-speed and surface cooling (Pringle, 2006). Increased wind speeds act to both mechanically mix the water-column, and cool the surface through increased evaporative heat flux. It is difficult to separate the mixing due to vertical sinking of surface cooled waters from that linked with physical stirring of the water-column by the wind. 


\subsection{Contributions of Cast Data to Understanding Region-Wide Patterns in Stratification}

A shortcoming of the GOMOOS data are their limited spatial coverage. With the exception of Buoy M, in Jordan Basin, the GOMOOS buoys don't provide information on the interior GOM. It is important to investigate if stratification found in coastal areas is representative of other regions in the GOM. This study goes beyond the work of Deese-Riordan (2009) by providing insight on the geographic extent of stratification events and the relative roles of salinity and temperature in affecting the density of the upper water-column.

Maps of mixed layer depth for the BIO and COOA cast data show that patterns in stratification are not the same throughout the GOM (Fig. 3-1). For example, in the Western Zone casts indicate greater winter mixing than in the Coastal or Eastern Zones. Greater mixing in the Western Zone is accompanied by near-zero average upper water-column stabilities. A comparison of stability values in the upper $20 \mathrm{~m}$ between the Coastal/Eastern and Western Zone shows that the difference is significant at the $15 \%$ level. Based on regionally averaged mixed layer depths, it is clear that the persistent winter stratification recorded by the GOMOOS moorings in the Coastal Zone are not necessarily representative of mixed layer depth trends in the interior GOM. Buoy $M$, in Jordan Basin, hints at this difference as it shows typically low stratification values, and winters that only have a few days with a shallow mixed layer. Differences in mixed layer depth are driven by the physical processes affecting the various regions. Depending on the location, coastal areas may be influenced by both SSW and fresh river water. Local mixing due to tides may also be important. In the interior GOM, river discharge does not have the same impact as it does near the coast because thinning and mixing occur with increasing distance offshore. The fact that the coastal and interior GOM are affected by different physical processes 
is reflected by regional differences in the contributions of salinity and temperature to density increase in the upper water-column. In the Coastal Zone, both cast and GOMOOS mooring data indicate that salinity increase with depth during the winter is almost always responsible for density increase in the upper $20 \mathrm{~m}$. In the Western Zone, however, temperature decrease with depth is responsible for density increase in the upper water-column for the majority of casts.

Inter-zonal differences in stratification for specific years are investigated using cast data from the winters of 1991, 1998, and 2006. The winters of 1991 and 1998 are useful because more casts, over a wider-area, are available these years. The winter of 2006 is chosen to take a close look at the spatial extent of the "coastally trapped fresh plume" that impacted stratification in the Coastal Zone (Shcherbina and Gawarkiewicz, 2008).

In 1991 and 1998, mixed layer depths were typically shallowest in the Coastal and Eastern Zones, and greatest in the Western Zone (Fig. 4-3 and Fig. 4-4). In the Coastal Zone, during the winter of 1991, a mix of salinity and temperature dominated casts were found. In other words, at certain times a positive salinity gradient in the upper $20 \mathrm{~m}$ was responsible for density increase, while at other times temperature decrease with depth had a larger impact on density change. This result is not surprising since in this region, upper water-column density is governed by both fresh river discharge and temperature. Salinity change with depth was responsible for $83 \%$ of shallow mixed layers seen in the Coastal Zone this winter. This finding is consistent with GOMOOS mooring data of the same area, which shows that periods of stratification are caused by positive salinity gradients in the upper water-column. In 1991, only $33 \%$ of casts in the Western Zone were salinity dominated. Weak stratification in this region is shown by the deep mixed layers (>75m) in Fig. 4-3. In 1998, again, the deepest mixed layers were seen in the Western Zone (Fig. 4-4). Similar to 1991, in the Western Zone, the presence of shallow mixed layers $(<20 \mathrm{~m})$ was almost 
exclusively the result of postive salinity gradients in the upper water-column. In fact, salinity contribution to density increase was greater than temperature contribution in $72 \%$ of casts with a shallow mixed layer. In the Western Zone, the presence of shallow mixed layers with salinity-driven stratification, may reflect the offshore advection of relatively fresh coastal waters.

Stratification in January of 2006 resulted from higher-than-average autumn river discharge (Deese-Riordan, 2009). High discharge resulted in a "coastally trapped fresh plume" (Shcherbina and Gawarkiewicz, 2008) (Fig. 3-11). Eleven casts are available during the winter of 2006, ten in the Coastal Zone, and one in the Western Zone. The cast data provide decent temporal coverage of the 2006 winter, but unfortunately no data are available during January at the peak of the first stratification event observed at Buoys A, B, and E, in the Coastal Zone. Data are available, however, for early February at the end of the January stratification event, as well as in March for a separate event. Time-series of salinity and temperature at Buoy B, on the Western Maine Shelf, indicate that the March stratification event was caused by increased river discharge (likely from snowmelt), as well as from solar heating of the surface layer. At the end of the first stratification event, a $(\sim 74 \mathrm{~m})$ mixed layer was recorded in the Western Zone on February $9^{\text {th }}, 2006$ (Fig. 4-5). On the same date a cast in the Coastal Zone, $36 \mathrm{~km}$ shoreward, recorded a mixed layer depth of $(\sim 27 \mathrm{~m})$ (Table 4.1). This observation shows that at the end of the January stratification event, the fresh plume of river water was restricted to a narrow area near the coast. Not enough cast data are available to look at the maximum seaward extent of stratification since no data were collected in mid-January when GOMOOS buoys in the Coastal Zone show peak stratification. A look at the salinity and temperature profiles for the two casts taken on February $9^{\text {th }}, 2006$ indicate different mechanisms controlled the density structure of the upper water-column. In the Coastal Zone salinity and temperature both increased with depth, while on the same date in the Western Zone, 
salinity remained constant in the upper $20 \mathrm{~m}$ and temperature decreased. From these observations, it is clear that either the surface plume of river water did not extend far from the coast, hence "coastally trapped", or it thinned and eventually mixed away before impacting the density structure at offshore locations. Given the 20 day rolling average wind-direction values from the NCEP Reanalysis II, it is possible to rule out the spreading and thinning of the river plume as southwesterly (upwelling favorable) winds were not persistent during this time (Fig 4-2) (Fong et al., 1997).

Casts from 1991, 1998, and 2006 show that stratification trends in the Coastal Zone do not necessarily translate to the Western Zone. That is not to say that shallow mixed layers were not seen in the Western Zone of the GOM, but rather that both shallow and deep mixed layers were found depending on when the cast was taken. The variability in mixed layer depths seen in the Western Zone during 1991 and 1998 indicate that shallow stratification occurs in this region, but does not persist through the winter as found at the coastal GOMOOS buoys or at Buoy N, over the Northeast Channel.

Based on patterns in mixed layer depth, it appears that significant physical changes occur over short distances when moving offshore. As was seen on February $9^{t h}$, there was a significant difference over $36 \mathrm{~km}$ in the mixed layer depth between the Coastal and Western Zone. Similarly, on March $7^{t h}, 2006$ a notable difference in mixed layer depth was observed between two casts separated by only $12 \mathrm{~km}$ in the Coastal Zone. This case also shows that the factor causing density increase (salinity or temperature) in the upper water-column $(0-20 \mathrm{~m})$ is variable over short-distances (Fig 4-6). The two casts taken on March $7^{\text {th }}, 2006$ illustrate this point nicely. The cast further offshore had a mixed layer depth of $44 \mathrm{~m}$, and density increase in the upper $20 \mathrm{~m}$ was attributable to temperature decrease with depth, while the shoreward cast had a shallow mixed layer $(18 \mathrm{~m})$ caused by a positive salinity gradient. 


\subsection{Biological and Physical Implications}

Although winter phytoplankton blooms are far less documented than the annual spring phytoplankton bloom, their impact on the marine ecosystem may be significant. One such bloom occurred in late February of 1999, when cool, fresh SSW spread into the eastern GOM and established stratified conditions conducive to rapid phytoplankton growth. Importantly, increased phytoplankton stocks in 1999 coincided with a 10 fold increase in zooplankton abundance compared to 2000 (Durbin et al., 2003). In addition, Townsend et al. (1994) argued that heterotrophic activity may be slowed by colder water temperatures present during wintertime phytoplankton blooms. Colder temperatures act to "decouple" the interaction between phytoplankton and zooplankton, allowing phytoplankton stocks to grow. Greater phytoplankton stocks contribute to better year-classes of many fish populations (Durbin et al., 2003). Using remotely sensed data, Platt et al. (2003) found that two especially good year-classes of Haddock in 1981 and 1999 were correlated with an early spring phytoplankton bloom. Platt et al. (2003) hypothesized that survival success rates of fish with longer spawning periods are higher during earlier blooms since larvae are not limited by food resources. In opposition, Ji et al. (2008) argue that early spring phytoplankton blooms, or intermittent winter blooms, can deplete surface waters of essential nutrients, thus limiting the magnitude of the spring bloom. Using a dataset spanning from 1998-2006, Ji et al. (2008) found that negative sea-surface salinities in the eastern GOM, attributable to increased inflow of SSW, were correlated with earlier spring blooms. Therefore, understanding the physical forcing factors, such as the variability in total volume and timing of SSW, is critical in predicting future changes in the onset and magnitude of phytoplankton blooms.

From the arguments of Platt et al. (2003) and Ji et al. (2008), it is clear that both the timing, duration, and strength of stratification events are important factors when considering phytoplankton blooms and food web dynamics. On one hand, 
stratification can induce a bloom and increase larval fish survival rates, while on the other hand, persistent stratification may allow phytoplankton to deplete nutrients before the onset of the primary spring bloom. Nutrient deplete conditions place tremendous strain on fish populations which rely on phytoplankton and zooplankton as their food source. It is unclear at this point how the duration and strength of stratification events during the winter affect the magnitude of the spring bloom. However, it is understood that nutrients need to be replenished in the euphotic zone if biological productivity is to be sustained. Currently, there is no consensus on the exact stability required for a phytoplankton bloom to develop. Future research in this area will be helpful in studying how the persistent upper water-column stratification observed in the Coastal and Eastern Zones of the GOM during the winter, or future changes in patterns of stratification, could impact biological systems. Specifically, the marine food web may be negatively affected if upwelling of nutrient-rich, deep waters is prevented by stratification.

Winter-time stratification may also have important physical implications for average annual carbon export and air-sea $\mathrm{CO}_{2}$ flux. For example, in early March of 2005, shallow stratification in the Coastal Zone established by high river discharge, led to significant biological uptake of dissolved inorganic carbon (DIC) (Salisbury et al., 2009). Colder than average air temperatures in combination with uptake of DIC in the surface layer was likely responsible for the increased atmosphere-to-ocean $\mathrm{CO}_{2}$ gradient observed by Vandemark et al. (2010). This air-sea gradient caused a positive flux of $\mathrm{CO}_{2}$ into the waters of the western coastal GOM this winter. This case illustrates that when physical conditions are suitable for a winter phytoplankton bloom (i.e. a shallow mixed layer is present), increased productivity by autotrophs may lead to greater export of carbon to the benthos (Townsend et al., 1994). Conversion of inorganic carbon to organic carbon, and its export to the sediment via the sinking of particulate organic carbon (POC), draws down atmospheric $\mathrm{CO}_{2}$. If export 
of carbon to the seabed is greater than remineralization in the water-column by heterotrophs, then carbon will accumulate and be buried. Winter phytoplankton blooms linked to shallow stratification events often seen in the Coastal and Eastern Zones of the GOM, could be an important sink for atmospheric $\mathrm{CO}_{2}$. Further research is required to determine the magnitude and frequency of winter phytoplankton blooms in the GOM, as well as the mass of biogenic carbon transported to the seafloor. A better understanding of wintertime carbon drawdown and export will also help in resolving the ongoing debate of whether the GOM is a source or sink of atmospheric $\mathrm{CO}_{2}$ (Vandemark et al., 2010).

In the GOM, seasonal cycles in air-sea gas flux are governed by temperature, water-column mixing, biological activity, and wind speed (Vandemark et al., 2010). Temperature is one factor driving the partial pressure of $\mathrm{CO}_{2}\left(\mathrm{pCO}_{2}\right)$ at the surface. $\mathrm{pCO}_{2}$ follows the seasonal sea surface temperature cycle, with highest and lowest values in the summer and winter, respectively. During the winter, however, periods of deeper winter mixing introduce $\mathrm{CO}_{2}$ rich waters to the surface, increasing their $\mathrm{pCO}_{2}$. When surface water becomes supersaturated in $\mathrm{CO}_{2}$, with respect to the atmosphere, an ocean-to-atmosphere efflux of gas occurs. Wind speed also affects gas flux, with higher wind speeds resulting in greater gas transfer velocities (Wanninkhof, 1992). A study from 2004-2008 in the western coastal GOM, using shipborne and high-temporal resolution mooring data, found that the largest seasonal anomalies in air-sea $\mathrm{CO}_{2}$ flux occur during the winter (Vandemark et al., 2010). For example, using a $\mathrm{CO}_{2}$ recording mooring roughly $10 \mathrm{~km}$ east of the Piscataqua River, Vandemark et al. (2010) found an average negative (air-to-ocean) $\mathrm{CO}_{2}$ flux in 2005, and a positive (ocean-to-air) flux in 2007 .

Winter-to-winter variability in $\mathrm{CO}_{2}$ gas flux may be attributable to stratification or biological forcing. A study on the Scotian Shelf, adjacent to the GOM, showed that gas transfer velocity is significantly correlated with mixed layer depth $\left(\mathrm{r}^{2}=.79, \mathrm{~N}=12\right.$, 
$\mathrm{p}<0.001$ ) (Shadwick et al., 2010). According to Shadwick et al. (2010), as mixed layer depth decreases so does the gas transfer velocity. Physically, this may be in part due to reduced vertical mixing during conditions of shallow stratification which allow near-surface waters to equilibrate more quickly with the atmosphere (Takahashi et al., 2002). Since patterns in winter stratification and mixed layer depth are variable across the GOM, it is not appropriate to assume uniform gas transfer velocities across the region. Although recent work by Vandemark et al. (2010) provides some information on wintertime air-sea $\mathrm{CO}_{2}$ flux in the Coastal Zone, more data, over a longer period of time, is needed to accurately describe air-sea gas exchange over the entire GOM. Furthermore, since biological uptake of $\mathrm{CO}_{2}$ also affects air-sea flux, the average atmospheric drawdown from phytoplankton blooms must be considered to close the GOM's carbon budget.

\subsection{Final Thoughts and Future Research Needs}

GOMOOS and cast data reveal that salinity-driven, shallow stratification is common during the winter in the Coastal and Eastern Zones of the GOM. Conversely, casts taken in the Western Zone often show little stratification and greater vertical mixing. An area for future study is investigating the relationship between stratification and winter phytoplankton blooms. It is assumed that shallow stratification is a necessary physical requirement for a bloom, but it is not known how often shallow mixed layers are actually accompanied by increased biological productivity. Winter blooms are an important area of focus because increased phytoplankton stocks often lead to better-year classes of fish populations in the GOM (Platt et al., 2003). However, it is not understood how the strength and duration of winter phytoplankton blooms affect the magnitude of the spring bloom. For example, do winter phytoplankton blooms leave the upper-water column deplete of nutrients? If stratification 
persists throughout the winter, can nutrients be upwelled and recharge the euphotic zone? More research is required to answer these questions, and more broadly, to describe how winter blooms affect carbon cycle dynamics in the GOM. At this point, it is undecided whether the the GOM is a source or sink of $\mathrm{CO}_{2}$. In fact, $\mathrm{CO}_{2}$ gas flux is variable from year-to-year depending on physical and biological forcings (Vandemark et al., 2010; Salisbury et al., 2009). In order to answer this question and improve ocean-atmosphere circulation models, long-term time-series from autonomous moorings covering both the coastal and interior GOM, need to be acquired.

Lastly, future work should focus on improving air-sea gas flux estimates to account for regional differences in stratification observed in the GOM. As seen by Salisbury et al. (2009), shallow stratification accompanied by a phytoplankton bloom creates a $\mathrm{CO}_{2}$ gradient that drives air-to-sea $\mathrm{CO}_{2}$ exchange. Shallow stratification unaccompanied by biological productivity, however, may slow down air-sea flux since the $\mathrm{pCO}_{2}$ in surface layer quickly equilibrates with the overlying atmosphere (Takahashi et al., 2002). Currently, it is unclear which situation typically dominates in the GOM. In the Western Zone, deep winter mixing of $\mathrm{CO}_{2}$-rich waters appears to be more common, and thus this area may act as a source of $\mathrm{CO}_{2}$ to the atmosphere. To definitively answer this question, however, time-series data from moorings are necessary to characterize seasonal and annual patterns in $\mathrm{CO}_{2}$ flux. 


\begin{tabular}{|c|c|c|c|c|c|}
\hline \multicolumn{6}{|c|}{$\begin{array}{c}2006 \text { Winter Stratification } \\
\text { Case Study }\end{array}$} \\
\hline Date & $\begin{array}{l}\text { Mixed Layer } \\
\text { Depth }(\mathbf{m})\end{array}$ & Zone & $\begin{array}{l}\text { Salinity } \\
(20 \mathrm{~m}-1 \mathrm{~m})\end{array}$ & $\begin{array}{l}\text { Temperature } \\
(20 \mathrm{~m}-1 \mathrm{~m})^{\circ} \mathrm{C}\end{array}$ & $\begin{array}{c}\text { Relative } \\
\text { Contribution }\end{array}$ \\
\hline $2006-2-9$ & 27.25 & Coast & .0034 & .0346 & .0051 \\
\hline $2006-2-9$ & 74.38 & West & 0 & -.0156 & -.0034 \\
\hline $2006-2-21$ & 21.63 & Coast & .0166 & .0842 & .0206 \\
\hline $2006-2-21$ & 25.0 & Coast & .0136 & .0281 & .0126 \\
\hline $2006-2-22$ & 7.38 & Coast & .2568 & .1714 & 2196 \\
\hline $2006-3-7$ & 18.0 & Coast & .0224 & .0584 & .0226 \\
\hline $2006-3-7$ & 44.25 & Coast & -.0020 & -.0533 & -.0081 \\
\hline $2006-3-22$ & 28.25 & Coast & .0020 & -.0180 & -.0011 \\
\hline $2006-3-22$ & 31.89 & Coast & -.0016 & -.0569 & -.0081 \\
\hline $2006-3-23$ & 15.38 & Coast & .0203 & -.0024 & .0149 \\
\hline $2006-3-23$ & .13 & Coast & .3846 & -.1380 & .2922 \\
\hline
\end{tabular}

Table 4.1: Dates, zone, mixed layer depth, salinity/temperature difference between $(1-20 \mathrm{~m})$, and relative contribution of salinity or temperature to the density increase in the upper $20 \mathrm{~m}$ for 11 casts are shown for the 2006 stratification event along the Western Maine Shelf. 


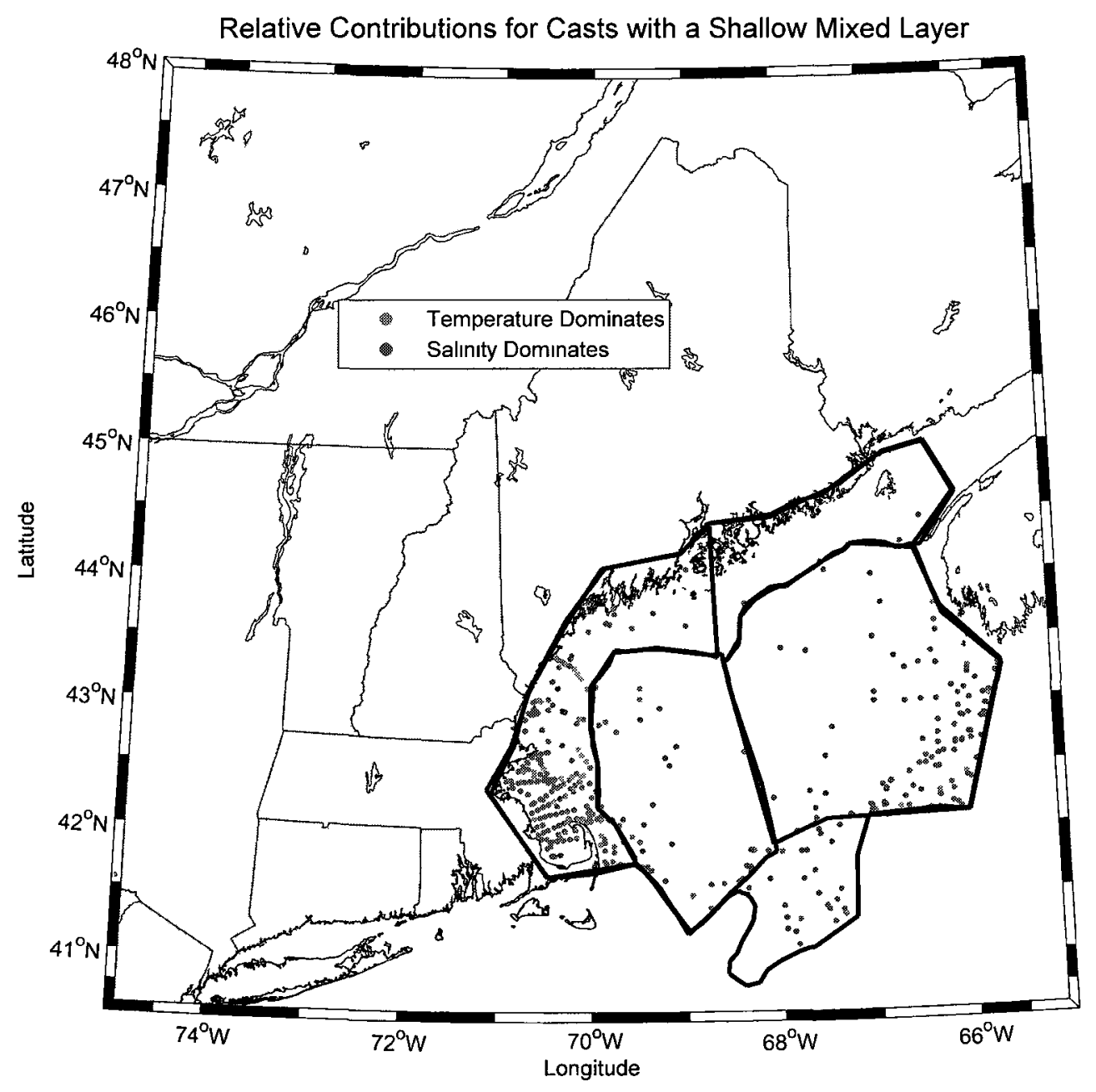

Figure 4-1: A map of the Gulf of Maine showing relative contributions for casts with a mixed layer less than or equal to $20 \mathrm{~m}$. Relative contributions are calculated between the surface depth and the mixed layer depth using the same form as (Equation 3.3). 

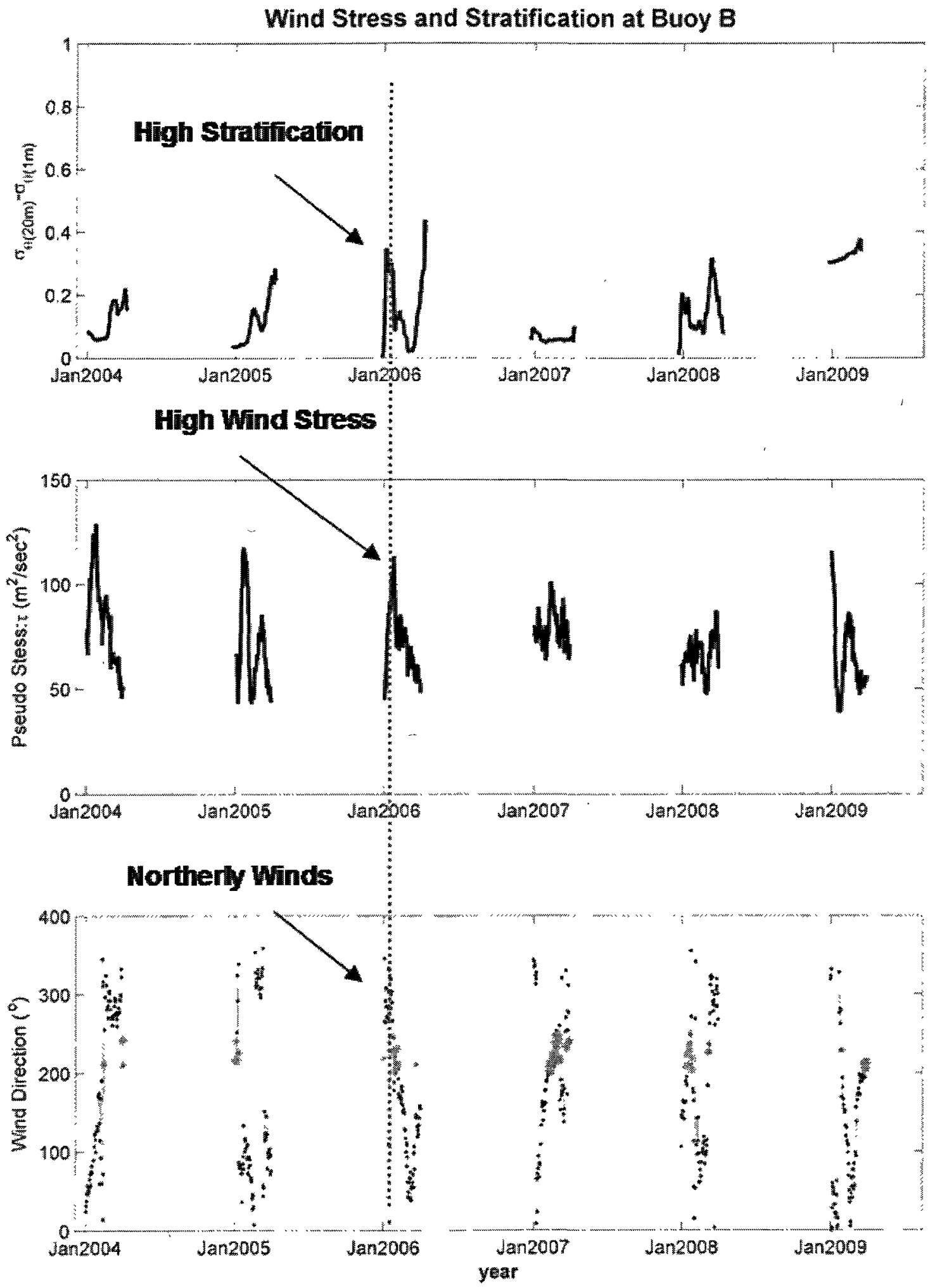

Figure 4-2: Wind stress and direction $\left(0-360^{\circ}\right)$, during the 2006 stratification event on the Western Maine Shelf. Black points in the last graph represent 20 day rolling averages of wind direction while red stars indicate upwelling-favorable winds $\left(200^{\circ}\right.$ $\left.250^{\circ}\right)$. 

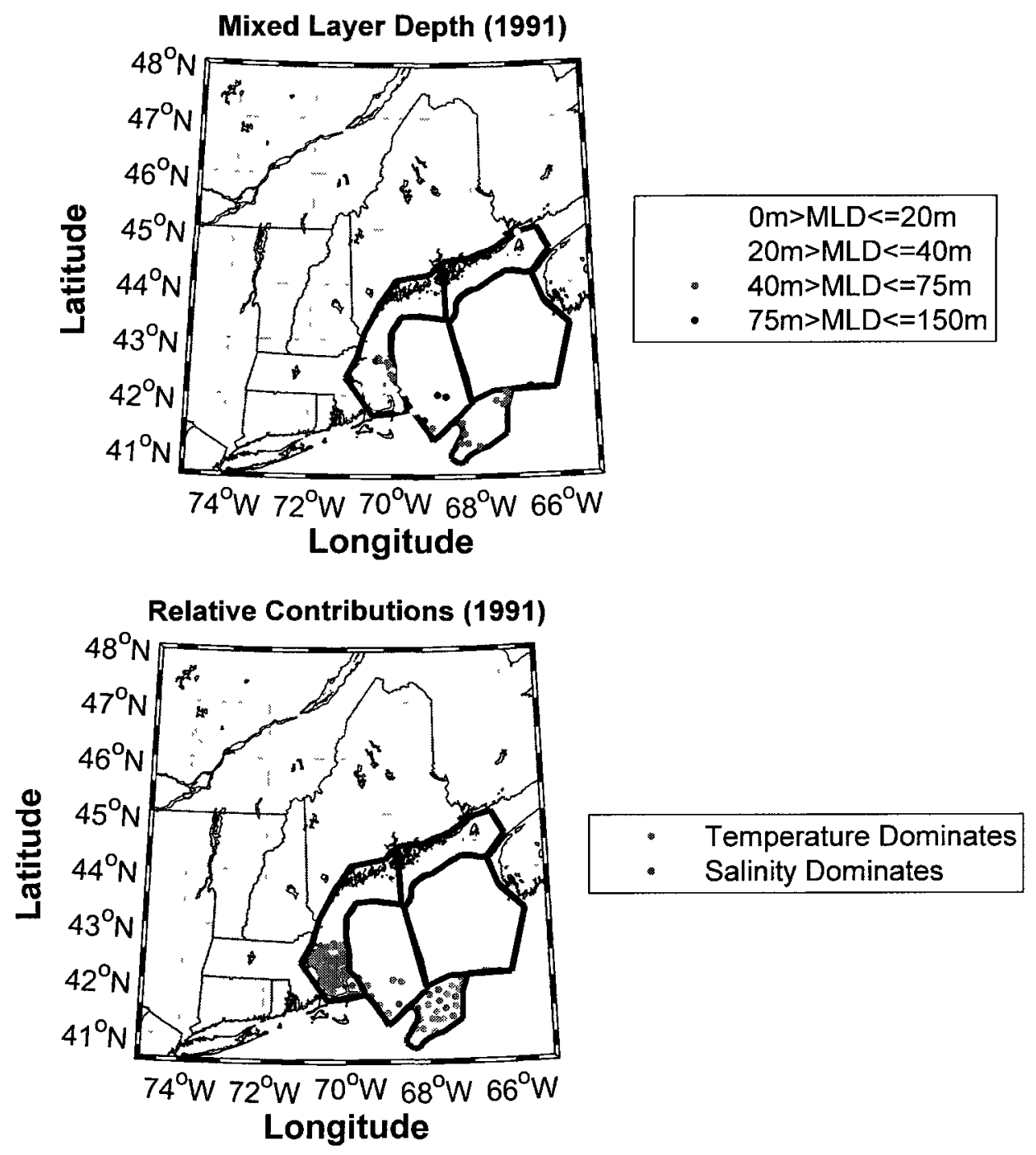

Figure 4-3: Maps of all casts taken during the winter of 1991. Top: Mixed layer depths. Bottom: Relative contributions of salinity and temperature to density increase in the upper $20 \mathrm{~m}$. 

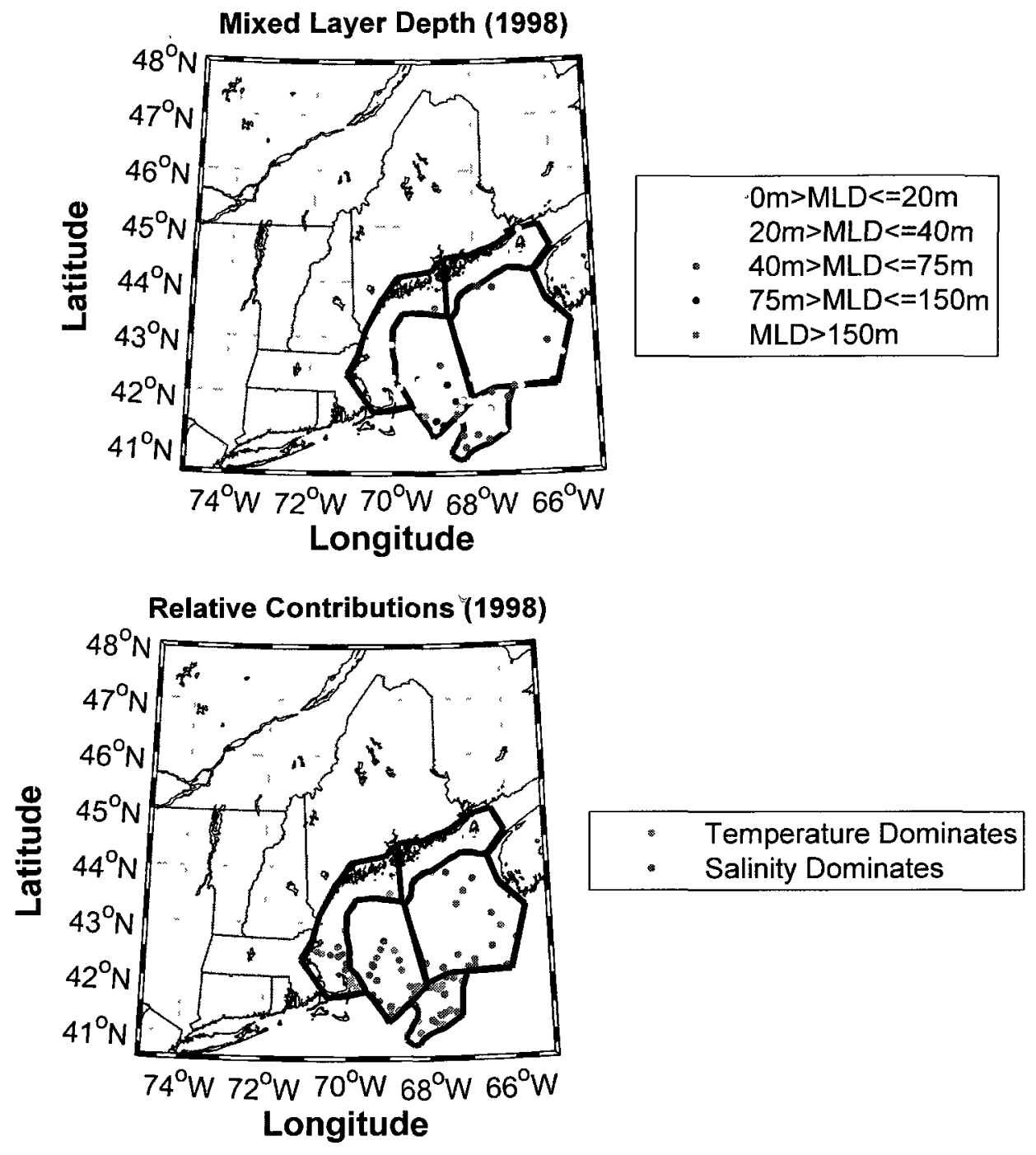

Figure 4-4: Maps of all casts taken during the winter of 1998. Top: Mixed layer depths. Bottom: Relative contributions of salinity and temperature to density increase in the upper $20 \mathrm{~m}$. 

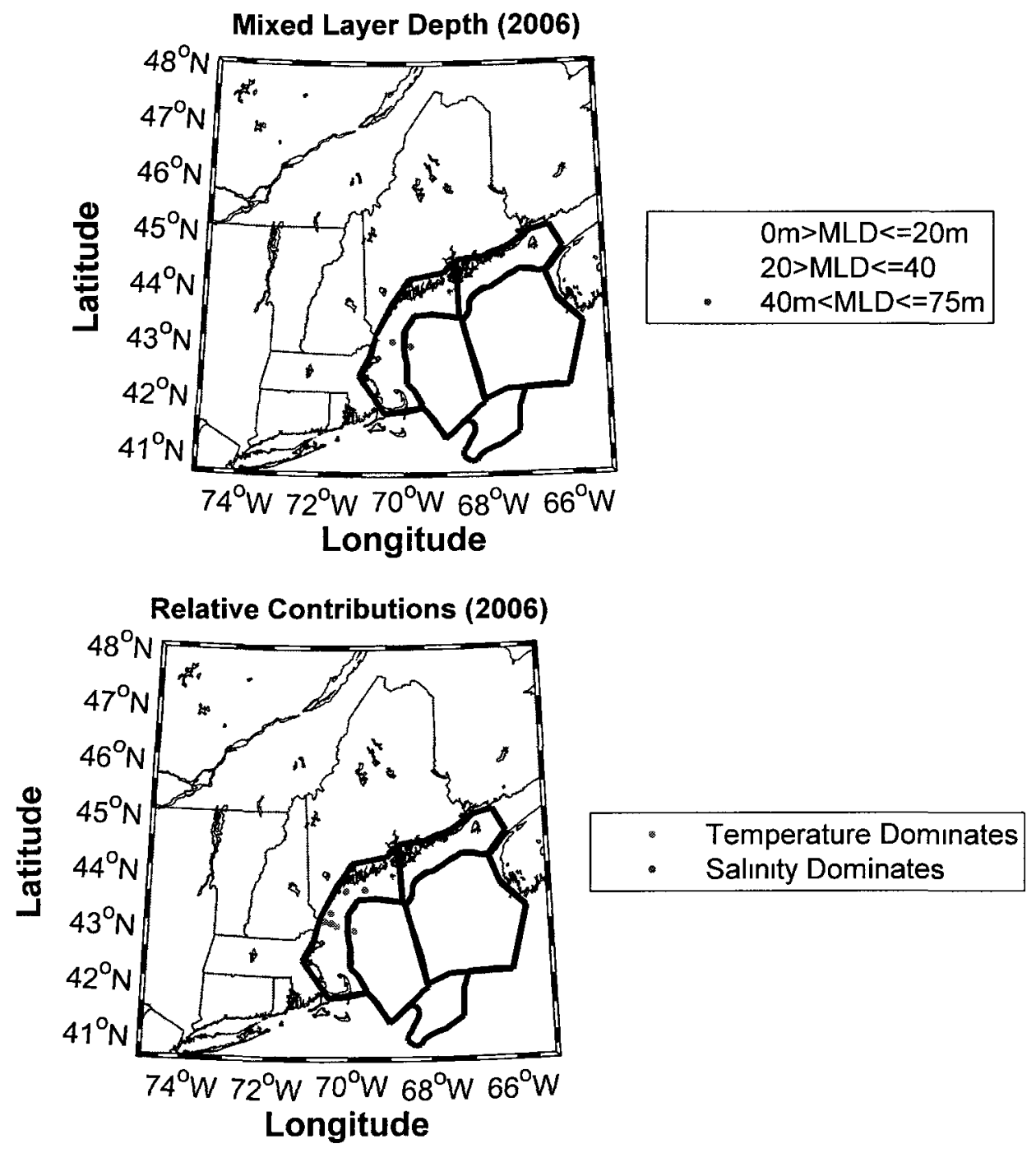

Figure 4-5: Top: A map of mixed layer depths for casts taken during the winter of 2006. Bottom: A map showing the relative contribution of salinity and temperature in increasing the density in the upper $20 \mathrm{~m}$. 

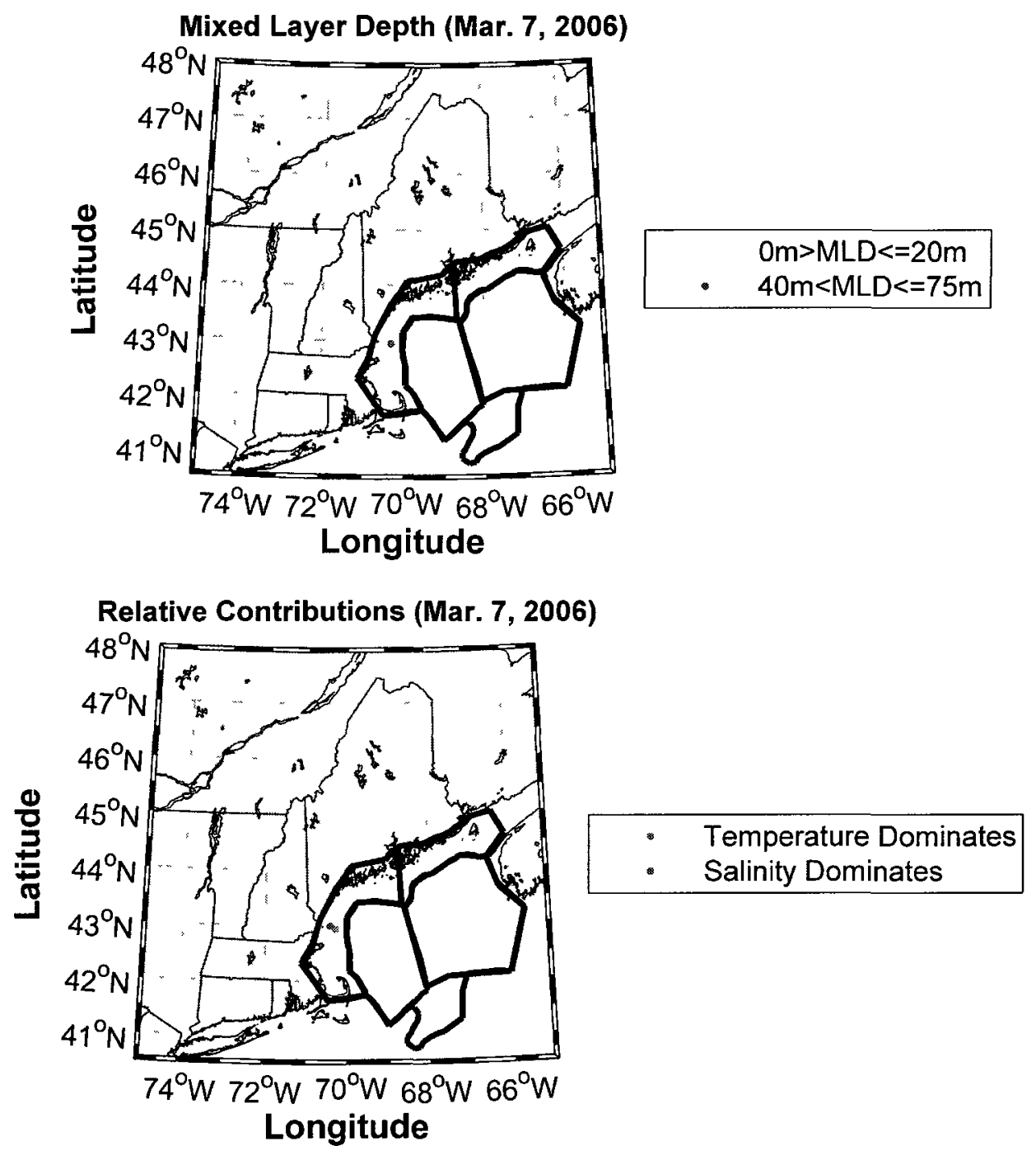

Figure 4-6: A comparison of mixed layer depth and relative contribution of salinity and temperature for two casts on March $7^{\text {th }} 2006$. This comparison shows that significant changes in mixed layer depth and the factors driving the density gradient in the upper water column can occur over short-distances $(12 \mathrm{~km}$ in this case) when moving away from the coast. 


\section{REFERENCES}

Backhaus, J. O., Hegseth, E. N., Wehde, H., Irigoien, X., Hatten, K., Logemann, K., 2003. Convection and primary production in winter. Marine Ecology Progress Series 251, 1-14.

Bathen, K. H., 1972. On the seasonal changes in the depth of the mixed layer in the North Pacific Ocean. Journal of Geophysical Research 77 (36), 7138-7150.

Behrenfeld, M. J., 2010. Abandoning Sverdrup's Critical Depth Hypothesis on phytoplankton blooms. Ecology 91 (4), 977-989.

Benway, R. L., Jossi, J. W., Thomas, K. P., Goulet, J. R., 1993. Variability of Temperature and Salinity in the Middle Atlantic Bight and Gulf of Maine. NOAA Technical Report NMFS 112.

Bisagni, J. J., Gifford. D. J., Ruhsam, C. M., 1996. The spatial and temporal distribution of the Maine Coastal Current during 1982. Continental Shelf Research 16, $1-24$.

Brainerd, K. E., Gregg, M. C., 1995. Surface mixed and mixing layer depths. Deep Sea Research Part I: Oceanographic Research Papers 42 (9), 1521-1543.

Brooks, D. A., 1985. Vernal Circulation in the Gulf of Maine. Journal of Geophysical Research 90, 4687-4706.

Brown, W. S., Beardsley, R. C., 1978. Winter Circulation in the Western Gulf of Maine: Part 1. Cooling and Water Mass Formation. Journal of Physical Oceanography $8,265-277$.

Brown, W. S., Irish, J. D., 1993. The annual variation of water mass structure in the Gulf of Maine: 1986-1987. Journal of Marine Research 51 (1), 53-107.

Bunker, A. F., 1956. Measurements of Counter-Gradient Heat Flows in the Atmosphere. Australian Journal of Physics 9, 133.

Dale, T., Rey, F., Heimdal, B. R., 1999. Seasonal development of phytoplankton at a high latitude oceanic site. Sarsia 84, 419-435.

Deese-Riordan, H. E., 2009. Salinity and Stratification in the Gulf of Maine: 20012008. Ph.D Disseration. 
Durbin, E. G., Campbell, R. G., Ohman, M. D., Wagner, M., Casas, M. C., Niehoff, B., Runge, J., 2003. Interannual variation in phytoplankton blooms and zooplankton productivity and abundance in the Gulf of Maine during winter. Marine Ecology Progress Series 254, 81-100.

Ellertsen, H. C., 1993. Spring blooms and stratification. Nature 363, 24.

Evans, G. T., Parslow, J. S., 1985. A model of annual plankton cycle. Biological Oceanography $3,327-347$.

Fogarty, M. J., Murawski, S. A., 1998. Large-Scale Disturbance and the Structure of Marine Systems: Fishery Impacts on Georges Bank. Ecological Applications 8, S6-S22.

Fong, D. A., Geyer, W. R., Signell, R. P., 1997. The wind-forced response on a buoyant coastal current: Observations of the western Gulf of Maine plume. Journal of Marine Systems 12 (1), 69-81.

Gatien, M. G., 1976. A study in the slope water region south of Halifax. Journal of the Fisheries Research Board of Canada 33 (10), 2213-2217.

Geyer, W. R., Signell, R. P., Fong, D. A., Wang, J., Anderson, D. M., Keafer, B. A., 2004. The freshwater transport and dynamics of the western Maine coastal current. Continental shelf research 24 (12), 1339-1357.

Gill, A. E., 1982. Atmosphere-Ocean dynamics. Academic Press 265.

Gran, H. H., Braarud, T., 1935. A quantitative study of the phytoplankton in the Bay of Fundy and the Gulf of Maine (including observations on hydrography, chemistry and turbidity). Journal of the Biological Board of Canada 1, 279-467.

Heimdal, B. R., 1974. Composition and abundance of phytoplankton in the Ullsfjord area, North Norway. Astarte 7, 17-42.

Hitchcock, G. L., Smayda, T. J., 1977. The Importance of Light in the Initiation of the 1972-1973 Winter-Spring Diatom Bloom in Narragansett Bay. Limnology and Oceanography 22 (1), 126-131.

Hopkins, T. S., Garfield, N., 1977. The Existence of the Marine Intermediate Water. In: A Summary of an Informal Workshop of the Physical Oceanography of the Gulf of Maine and Adjacent Seas Woods Hole, MA: WHOI.

Hopkins, T. S., III, N. G., 1979. Gulf of Maine Intermediate Water. Journal of Marine Research 37, 103-139.

Ji, R., Davis, C. S., Chen, C., Townsend, D. W., Mountain, D. G., Beardsley, R. C., 2007. Influence of ocean freshening on shelf phytoplankton dynamics. Geophysical Research Letters 34, L24607. 
Ji, R., Davis, C. S., Chen, C., Townsend, D. W., Mountain, D. G., Beardsley, R. C., 2008. Modeling the influence of low-salinity water inflow on winter-spring phytoplankton dynamics in the Nova Scotian Shelf-Gulf of Maine region. Journal of Plankton Research 30 (12), 1399-1416.

Kanamitsu, M., Ebisuzaki, W., Woollen, J., Yang, S. K., Hnilo, J. J., Fiorino, M., Potter, G. L., 2002. NCEP-DOE AMIP-II REANALYSIS (R-2). Bulletin of the American Meteorological Society 83 (11), 1631-1643.

Kara, A. B., Rochford, P. A., Hurlburt, H. E., 2000. An optimal definition for ocean mixed layer depth. Journal of Geophysical Reasearch 105 (C7), 16803-16821.

Knauss, J. A., 1996. Introduction to Physical oceanography.

Körtzinger, A., Send, U., Lampitt, R. S., Hartman, S., Wallace, D. W. R., Karstensen, J., Villagarcia, M. G., Llinas, O., DeGrandpre, M. D., 2008. The seasonal pCO ${ }^{2}$ cycle at $49^{\circ} \mathrm{N} / 16.5^{\circ} \mathrm{W}$ in the northeastern Atlantic Ocean and what it tells us about biological productivity. Journal of Geophysical Research 113, C04020.

Lentz, S., Shearman, K., Anderson, S., Plueddemann, A., Edson, J., 2003. Evolution of stratification over the New England shelf during the Coastal Mixing and Optics study, August 1996-June 1997. Journal of Geophysical Research 108 (C1), 3008.

Lukas, R., Lindstrom, E., 1991. The mixed layer of the western equatorial Pacific Ocean. Journal of Geophysical Research 96, 3343-3358.

Meade, R. H., Emery, K. O., 1971. Sea level as Affected by River Runoff, Eastern United States. Science 173 (3995), 425-428.

Miller, C. B., Lynch, D. R., Carlotti, F., Gentleman, W., Lewis, C. W., 1998. Coupling of an individual-based population dynamic model of Calanus finmarchicus to a circulation model for the Georges Bank region. Fisheries Oceanography 7 (3-4), 219-234.

Mountain, D. G., Manning, J. P., 1994. Seasonal and interannual variability in the properties of the surface waters of the Gulf of Maine. Continental Shelf Research 14 (13-14), 1555-1581.

Peters, H., Gregg, M. C., Toole, J. M., 1988. On the Parameterization of Equatorial Turbulence. Journal of Geophysical Research 93 (C2), 1199-1218.

Petrie, B., 2007. Does the North Atlantic Oscillation affect hydrographic properties on the Canadian Atlantic continental shelf? Atmosphere-Ocean 45 (3), 141-151.

Petrie, B., Drinkwater, K., 1993. Temperature and Salinity Variability on the Scotian Shelf and in the Gulf of Maine 1945-1990. Journal of Geophysical Research 98 (C11), 20079-20089. 
Pettigrew, N. R., Townsend, D. W., Xue, H., Wallinga, J. P., Brickley, P. J., Hetland, R. D., 1998. Observations of the Eastern Maine Coastal Current and its offshore extensions in 1994. Journal of Geophysical Research 103 (C13), 30623-30639.

Pingree, R. D., Holligan, P. M., Mardell, G. T., Head, R. N., 1976. The influence of physical.stability on spring, summer and autumn phytoplankton blooms in the Celtic Sea. Journal of the Marine Biological Association of the UK 56, 845-873.

Platt, T., Bird, D. F., Sathyendranath, S., 1991. Critical Depth and Marine Primary Production. Proceedings: Biological Sciences 246 (1317), 205-217.

Platt, T., Fuentes-Yaco, C., Frank, K. T., 2003. Marine ecology: Spring algal bloom and larval fish survival. Nature 423 (6938), 398-399.

Price, J. F., Weller, R. A., Pinkel, R., 1986. Diurnal Cycling: Observations and Models of the Upper Ocean Response to Diurnal Heating, Cooling, and Wind Mixing. Journal of Geophysical Research 91 (C7), 8411-8427.

Pringle, J. M., 2006. Sources of Variability in Gulf of Maine Circulation, and the Observations Needed to Model it. Deep Sea Research Part II: Topical Studies in Oceanography 53 (23-24), 2457-2476.

Ramp. S. R., Schlitz, R. J., Wright, W. R., 1985. The deep flow through the Northeast Channel, Gulf of Maine. Journal of Physical Oceanography 15 (12), 1790-1808.

Richards, K. J., Inall, M. E., Wells, N. C., 1995. The diurnal mixed layer and upper ocean heat budget in the western equatorial Pacific. Journal of Geophysical Research 100 (C4), 6865-6879.

Riley, G. A., 1957. Phytoplankton of the North Central Sargasso Sea, 1950-52. Limnology and Oceanography $2(3), 252-270$.

Salisbury, J., Vandemark, D., Hunt, C., Campbell, J., Jonsson, B., Mahadevan, A., McGillis, W., Xue, H., 2009. Episodic riverine influence on surface DIC in the coastal Gulf of Maine. Estuarine, Coastal and Shelf Science 82 (1), 108-118.

Schei, B., 1974. Phytoplankton investigations in Skjomen, a fjord in North Norway, 1970-1971. Astarte 7, 43-59.

Schneider, N., Muller, P., 1990. The meridional and seasonal structures of the mixedlayer depth and its diurnal amplitude observed during the Hawaii-to-Tahiti Shuttle experiment. Journal of Physical Oceanography 20 (9), 1395-1404.

Shadwick, E. H., Thomas, H., Comeau, A., Craig, S. E., Hunt, C. W., Salisbury, J. E., 2010. Air-Sea $\mathrm{CO}_{2}$ fluxes on the Scotian Shelf: seasonal to multi-annual variability. Biogeosciences 7, 3851-3867.

Shcherbina, A. Y., Gawarkiewicz, G. G., 2008. A coastal current in winter: Autonomous underwater vehicle observations of the coastal current east of Cape Cod. Journal of Geophysical Research 113, C07030. 
Skyllingstad, E. D., Smyth, W. D., Moum, J. N., Wijesekera, H., 1999. Upper-ocean turbulence during a westerly wind burst: A comparison of large-eddy simulation results and microstructure measurements. Journal of Physical Oceanography 29, $5-28$.

Smetacek, V., Passow, U., 1990. Spring bloom Initiation and Sverdrup's CriticalDepth Model. Limnology and Oceanography 35 (1), 228-234.

Smith, P. C., 1983. The mean and seasonal circulation off southwest Nova Scotia. Journal of Physical Oceanography 13 (6), 1034-1054.

Smith, P. C., Houghton, R. W., Fairbanks, R. G., Mountain, D. G., 2001. Interannual variability of boundary fluxes and water mass properties in the Gulf of Maine and on Georges Bank: 1993-1997. Deep-Sea Research. Part 2. Topical Studies in Oceanography 48 (1-3), 37-70.

Stewart, R., 2007. Our Ocean Planet: Oceanography in the 21st Century. On-line textbook in html format.

Sverdrup, H. U., 1953. On Conditions for the Vernal Blooming of Phytoplankton. Journal du Conseil 18, 287-295.

Takahashi, T., Sutherland, S. C., Sweeney, C., Poisson, A., Metzl, N., Tilbrook, B., Bates, N., Wanninkhof, R., Feely, R. A., Sabine, C., Olafsson, J., Norjiri, Y., 2002. Global sea-air $\mathrm{CO}_{2}$ flux based on climatological surface ocean $\mathrm{pCO}_{2}$, and seasonal biological and temperature effects. Deep Sea Research Part II: Topical Studies in Oceanography 49 (9-10), 1601-1622.

Taylor, M. H., Mountain, D. G., 2009. The influence of surface layer salinity on wintertime convection in Wilkinson Basin, Gulf of Maine. Continental Shelf Research 29 (2), 433-444.

Thomas, A. C., Townsend, D. W., Weatherbee, R., 2003. Satellite-measured phytoplankton variability in the Gulf of Maine. Continental Shelf Research 23 (10), 971-989.

Thomson, R. E., Fine, I. V., 2003. Estimating Mixed Layer Depth from Oceanic Profile Data. Journal of Atmospheric and Oceanic Technology 20, 319-329.

Townsend, D. W., 1991. Influences of Oceanographic Processes on the Biological Productivity of the Gulf of Maine. Reviews in Aquatic Sciences 5 (3-4), 211-230.

Townsend, D. W., Cammen, L. M., Holligan, P. M., Campbell, D. E., Pettigrew, N. R., 1994. Causes and consequences of variability in the timing of spring phytoplankton blooms. Deep Sea Research Part I: Oceanographic Research Papers $41(5-6), 747-765$. 
Townsend, D. W., Keller, M. D., Sieracki, M. E., Ackleson, S. G., 1992. Spring phytoplankton blooms in the absence of vertical water column stratification. Nature 360 (6399), 59-62.

Townsend, D. W., Spinrad, R. W., 1986. Early spring phytoplankton blooms in the Gulf of Maine. Continental Shelf Research 6 (4), 515-529.

van Oostveen, P., Weissing, F. J., Huisman, J., 1999. Critical depth and critical turbulence: Two different mechanisms for the development of phytoplankton blooms. Limnology and Oceanography 44 (7), 1781-1787.

Vandemark, D., Salisbury, J. E., Hunt, C. W., Shellito, S. M., Irish, J. D., McGillis, W. R., Sabine, C. L., Maenner, S. M., 2010. Temporal and spatial dynamics of $\mathrm{CO}_{2}$ air-sea flux in the Gulf of Maine. Journal of Geophysical Research 116.

Wanninkhof, R., 1992. Relationship Between Gas Exchange and Wind Speed Over the Ocean. Journal of Geophysical Research 97 (C5), 7373-7381.

Wijffels, S., Firing, E., Bryden, H., 1994. Direct observations of the Ekman balance at $10^{\circ} \mathrm{N}$ in the Pacific. Journal of Physical Oceanography 24 (7), 1666-1679. 